\title{
Role of 5-FU in DNA double strand break repair for improved targets in colorectal cancer therapy
}

\author{
Dissertation \\ for the award of the degree \\ "Doctor of Philosophy (PhD)" \\ in the "Molecular Biology" Program \\ at the Georg-August-Universität Göttingen,
}

submitted by

Upadhyayula Sai Srinivas

born in

Hyderabad, India 


\section{Thesis Committee}

Prof. Dr. Matthias Dobbelstein, Institute of Molecular Oncology, University of Göttingen.

PD Dr. Wilfried Kramer, Institute for Microbiology and Genetics, University of Göttingen.

Prof. Dr. Holger Reichardt, Department of Cellular and Molecular Immunology, University of Göttingen. 


\section{Affidavit}

Herewith, I declare that I prepared the PhD Thesis "Role of 5-FU in DNA double strand break repair for improved targets in colorectal cancer therapy" on my own and with no other sources and aids than quoted.

28.09.2014

Göttingen 


\section{Acknowledgements}

Firstly, I would like to express my deepest gratitude to my parents and brother for their continuous support, guidance and wishes all through my life.

Secondly, I would like to extend my sincere gratitude to Prof. Dr. Matthias Dobbelstein for his continuous and rigorous support over the years that has contributed immensely to my understanding and development as a scientist.

I also thank PD.Dr. Wilfried Kramer and Prof. Dr. Holger Reichardt for their support and insightful scientific discussions during the thesis committee meetings.

I thank Prof. Dr. Heidi Hahn, Prof. Dr. Kai Tittman and Dr. Roland Dosch for being in my extended thesis committee.

I sincerely thank the IMPRS Molecular Biology program for all the support from the time of Masters' enrollment to submission of thesis and for also funding my studies

during the first year of my Master's studies. I also thank Göttingen Graduate School for Neurosciences, Biophysics and Molecular Biosciences (GGNB) for their continuous support, exciting courses and industrial excursions.

This work was partly supported by the Göttingen Graduate School for Neurosciences, Biophysics, and Molecular Biosciences (GGNB) (DFG grant GSC 226).

I sincerely thank GRK 1034 for funding me during the first 3 years of my PhD and also for organizing retreats at some really nice places.

I extend my thanks to Patricia and Karola for helping me with the contracts and foreign office dealings.

I extend special thanks to my close friends Manu, Prateek and Karthik for continuous help and encouragement.

I would like to thank everyone, past and present, associated with the Institute of Molecular Oncology for stimulating scientific environment and motivation. 
Personally, I would like to thank, Cathrin, Antje, Kamilla for support with orderings of consumables and other lab stuff.

I also thank Konstantina, Franziska, Uli, Vijaya, Fred, Xin, and Lena for guiding me and introducing me to techniques in the lab.

I thank Priyanka, Veena, Sonja, Magdalena, Hannes, Daniela, and Ramona for a wonderful time in the lab.

I thank Robyn, Cris, Henrik, Fabian and Muriel for funny and insightful conversations in the office. 
Table of Contents

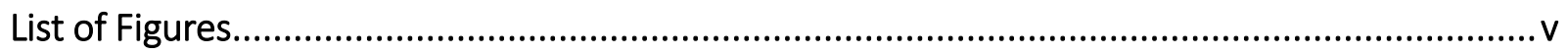

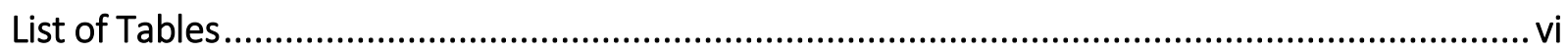

Abbreviations ..................................................................................................................... vii

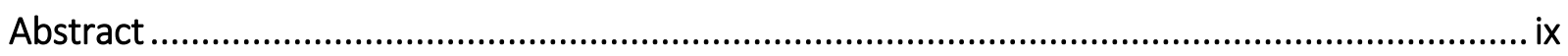

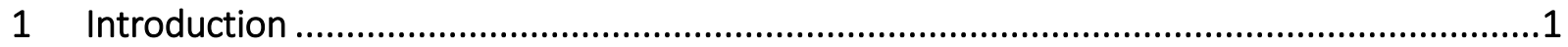

1.1 Colorectal cancer and its therapy ................................................... 1

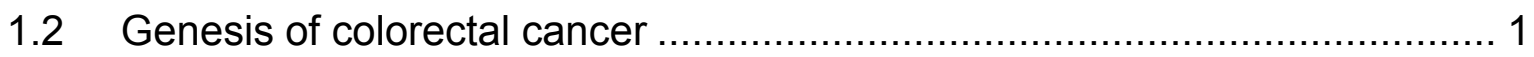

1.3 Neoadjuvant and adjuvant therapy .................................................. 2

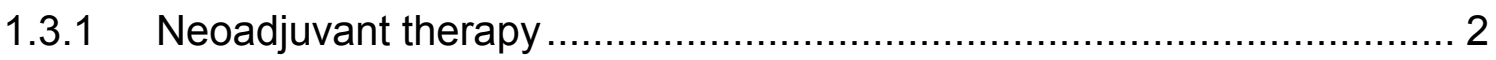

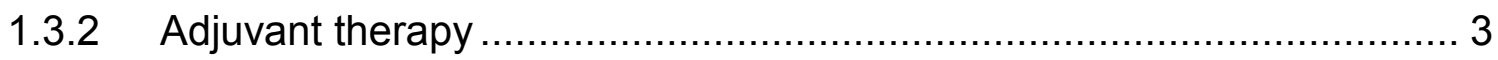

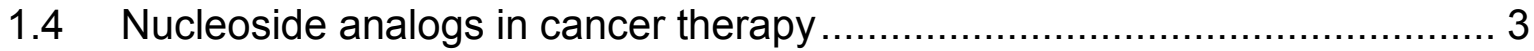

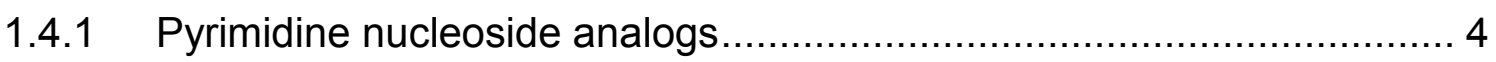

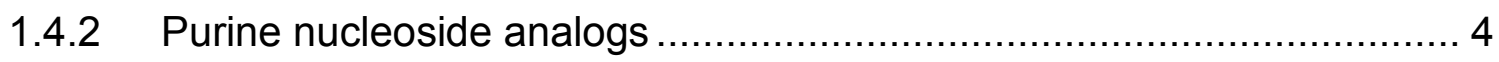

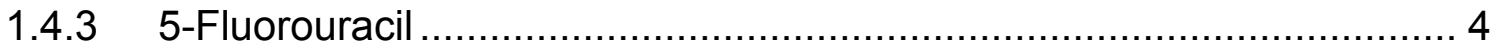

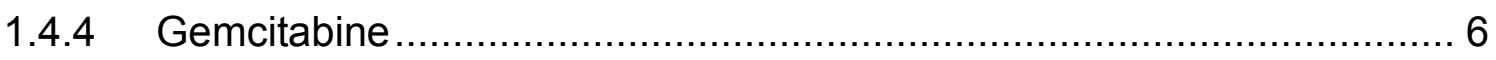

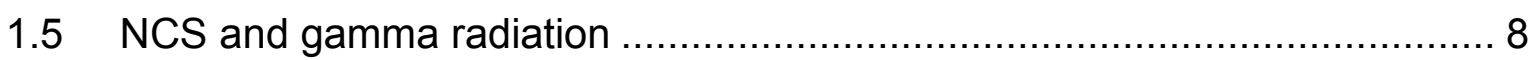

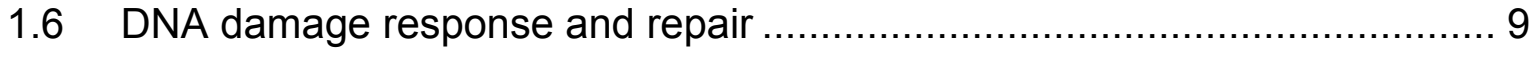

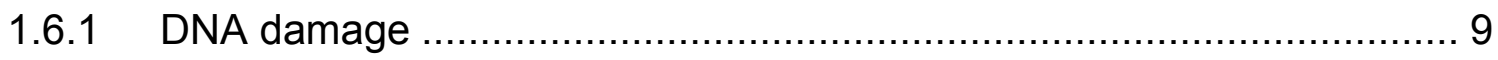

1.6.2 Mechanism and signaling in response double strand breaks ............. 10

1.6.3 Signaling for double strand break repair ......................................... 10

1.7 DNA damage response and apoptosis ................................................ 12

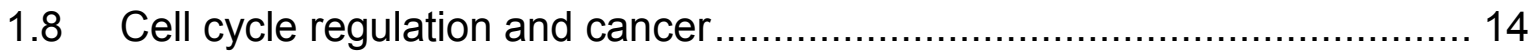

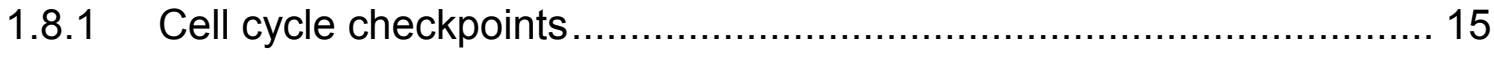

1.9 DNA double strand break repair processes ........................................... 16

1.9.1 H2AX and Homologous Recombination Repair ............................... 16

1.9.2 Homologous recombination repair .............................................. 18

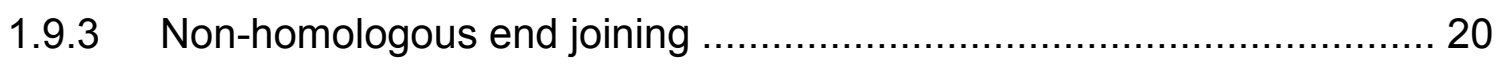


1.9.4 Interplay and regulation of repair pathways …............................... 21

1.9.5 DNA double strand break repair and cancer development.................. 23

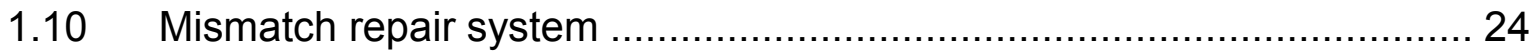

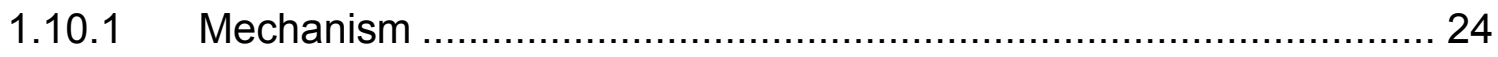

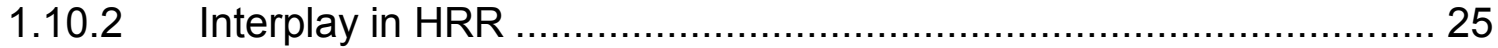

1.10.3 MMR and Colorectal cancers..................................................... 25

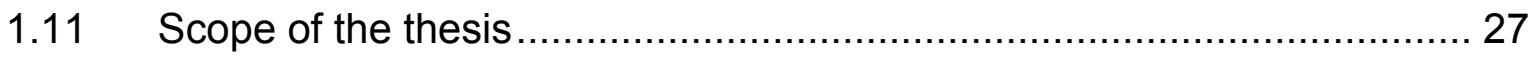

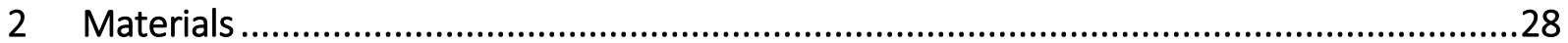

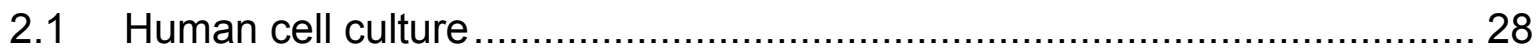

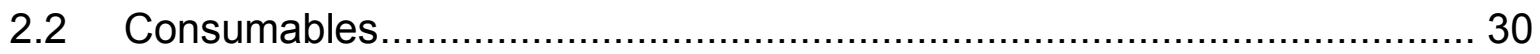

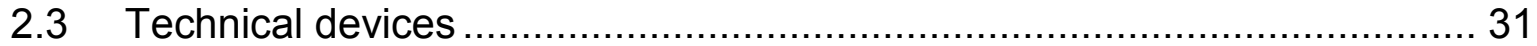

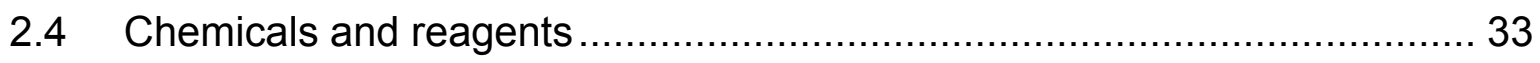

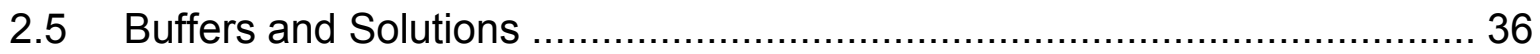

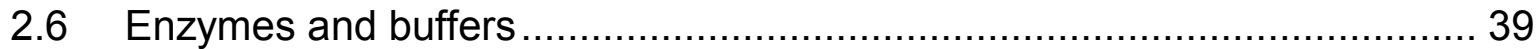

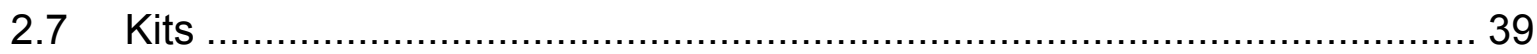

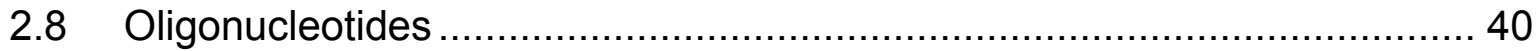

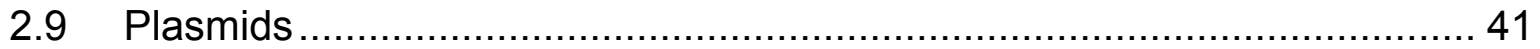

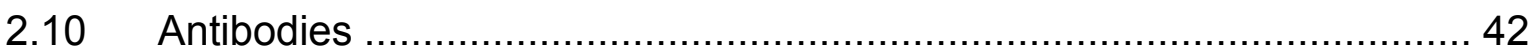

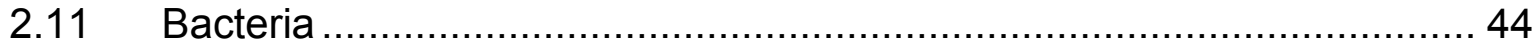

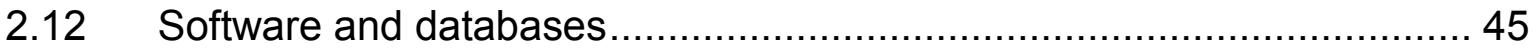

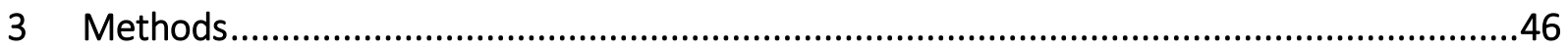

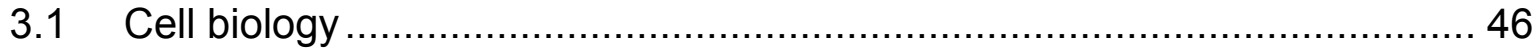

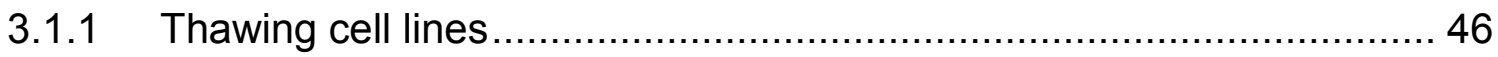

3.1.2 Passaging human tumor cell lines ............................................ 46

3.1.3 Counting and seeding cells for experiments ................................ 47

3.1.4 Treatment of cells with chemotherapeutics ................................... 47

3.1.5 Reporter assay for assessing homologous recombination repair........ 48

3.1.6 Reporter assay for assessing Non-homologous end joining ............... 48

3.1.7 GFP measurements for HRR and NHEJ assays............................ 49

3.1.8 Transient siRNA transfections.................................................... 49

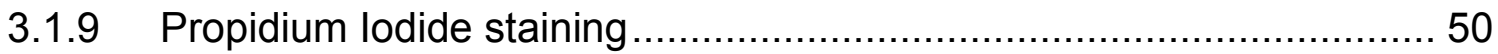

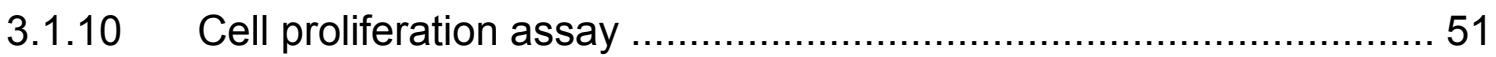




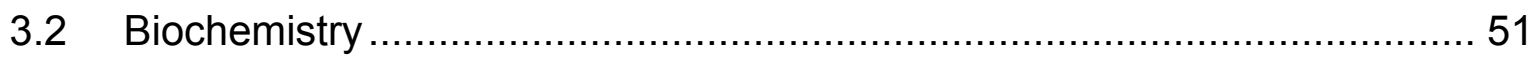

3.2.1 SDS PAGE and Immunoblotting ................................................. 51

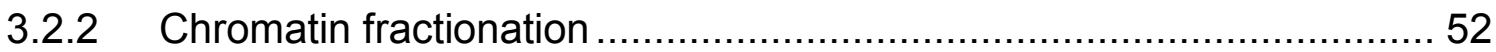

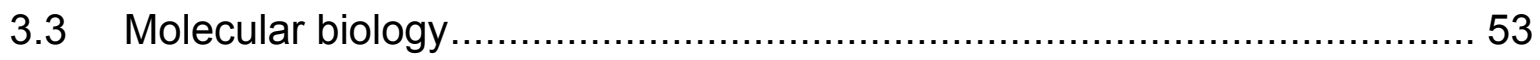

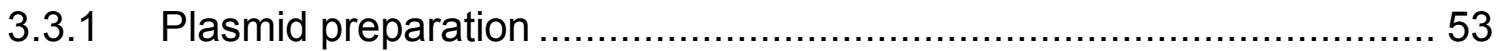

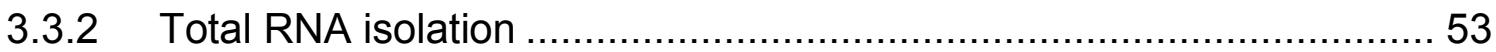

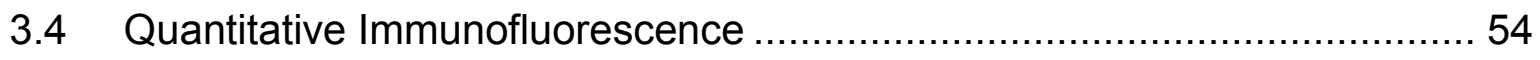

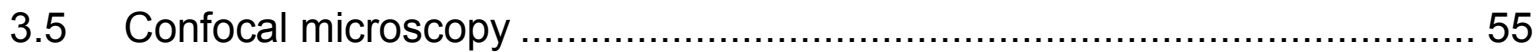

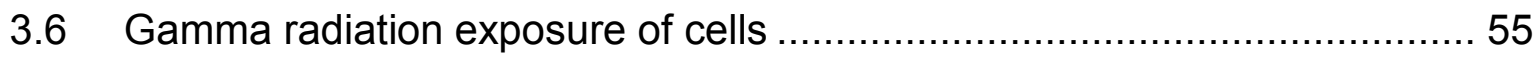

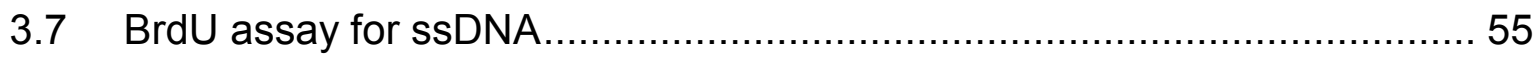

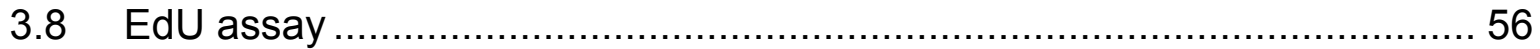

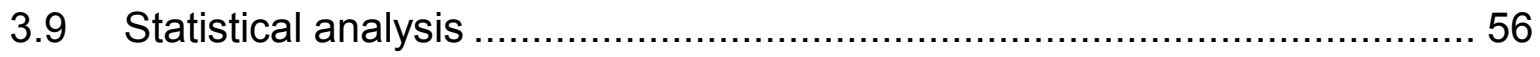

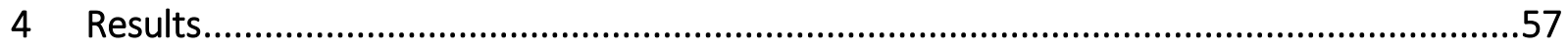

4.1 5-FU and NCS combination results in persistent $\mathrm{y}-\mathrm{H} 2 \mathrm{AX} \ldots \ldots \ldots \ldots \ldots \ldots \ldots \ldots . . . . . . . . . . . . .57$

4.2 NCS and y-radiation produce similar cellular effects on the kinetics of $y$ -

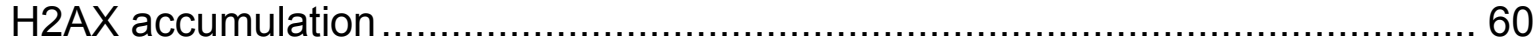

4.3 5-FU and NCS combination reduces cell proliferation and survival ........... 61

4.45 -FU reduces the ability to perform HRR but does not affect NHEJ .......... 63

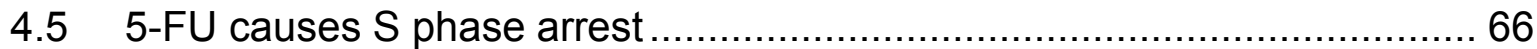

4.6 Existence of DSB repair proteins on chromatin indicates ongoing repair in

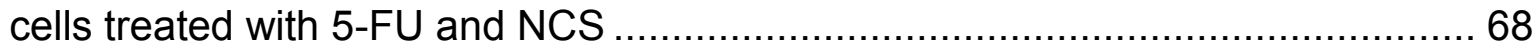

4.7 Ribonucleotide supplementation rescues cells from the persistent $\mathrm{Y}-\mathrm{H} 2 \mathrm{AX} 71$

4.8 Comparison of RNA expression of repair proteins in tumor and mucosa ... 73

4.9 TS inhibition does not synergize with NCS to induce DNA damage ........... 76

4.10 MK2 knock down and gamma H2AX ........................................... 79

4.11 Gemcitabine also leads to accumulation of $\mathrm{y}-\mathrm{H} 2 \mathrm{AX}$ but is accompanied

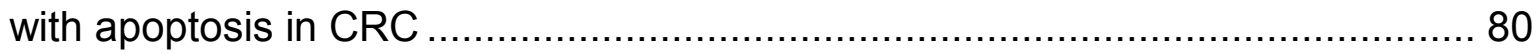

4.12 Ribonucleotide supplementation does not rescue gemcitabine treated cells 83

4.13 HU induced ribonucleotide reductase inhibition and depletion of RRM2

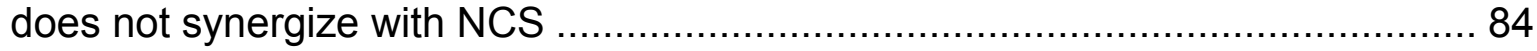

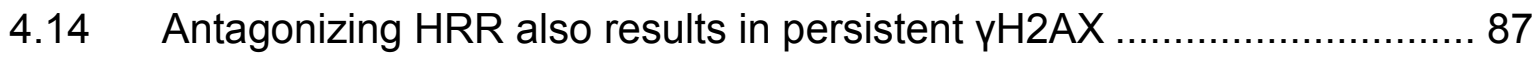

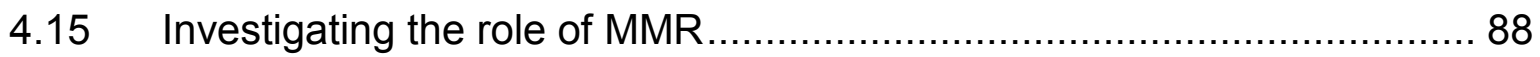




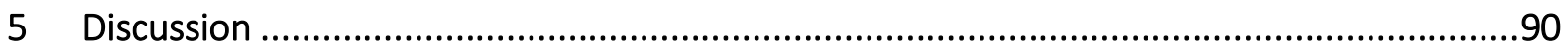

5.1 Do nucleoside analogs induce $\mathrm{Y}-\mathrm{H} 2 \mathrm{AX}$ accumulation? ............................ 90

5.2 Does 5-FU treatment activate DNA damage response? .......................... 91

5.3 Is persistent $\mathrm{Y}-\mathrm{H} 2 \mathrm{AX}$ a mark for irreparable DNA damage? ..................... 92

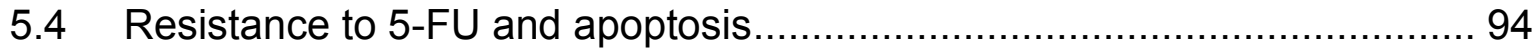

5.5 Does inhibition of double strand break repair sensitize cells to

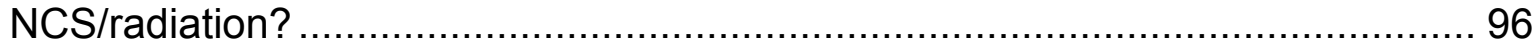

5.6 Why TS inhibition does not sensitize cells to NCS and why do 5-FU and

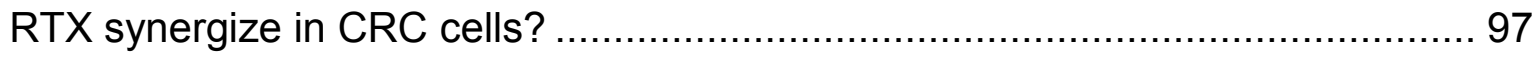

5.7 Can gemcitabine be used as an alternative to 5-FU in CRC patients? ....... 99

5.8 Why MK2 does not rescue 5-FU treated cells? .................................... 100

5.9 Summary and future perspectives .................................................... 102

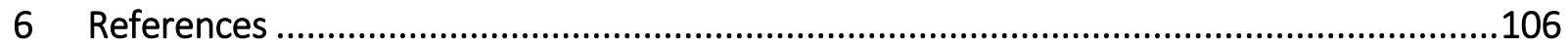

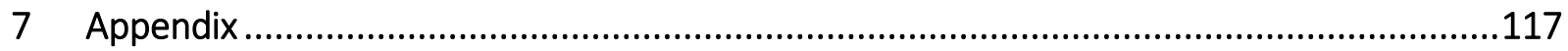

7.1 Plasmid maps of DRGFP, pCBASCE I ........................................... 117

7.2 Compounds screened for synergistic activity with 5-FU ....................... 118

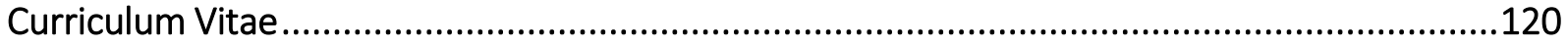




\section{List of Figures}

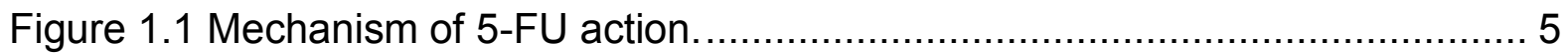

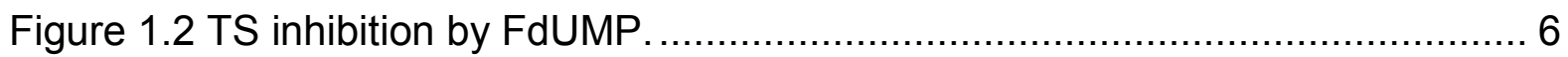

Figure 1.3 Mechanism of gemcitabine activation and misincorporation into DNA. .... 8

Figure 1.4 Mechanism of neocarzinostatin action............................................. 9

Figure 1.5 DNA double strand breaks induced response. .................................. 11

Figure 1.6 p53 dependent and independent apoptosis...................................... 13

Figure 1.7 Control of cell cycle by cyclin-Cyclin dependent kinase complexes........ 15

Figure 1.8 Phosphorylation sites in Rad51 and RPA2 .................................... 18

Figure 1.9 Mechanism of homologous recombination repair. ............................. 19

Figure 1.10 Mechanism of non-homologous end joining. .................................... 21

Figure 1.11 Cell cycle dependence of HRR and NHEJ.................................... 23

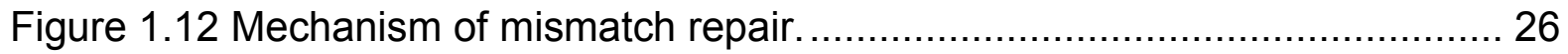

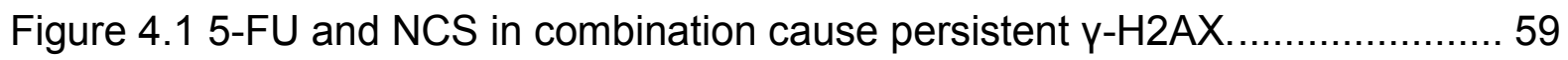

Figure 4.2 Kinetics of $\mathrm{y}-\mathrm{H} 2 \mathrm{AX}$ accumulation is similar between NCS and $\mathrm{y}-\mathrm{H} 2 \mathrm{AX} .60$ Figure 4.3 5-FU and NCS in combination severely impairs cell proliferation in

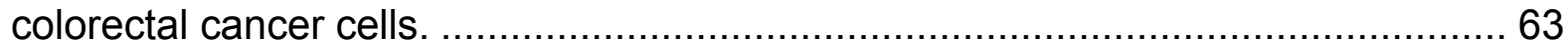

Figure 4.4 5-FU reduces the homologous recombination repair but does not affect

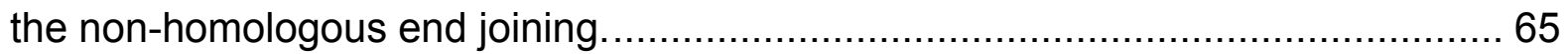

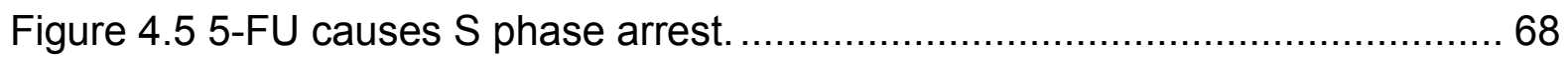

Figure 4.6 Recruitment of repair proteins in response to 5-FU and NCS............... 71

Figure 4.7 Ribonucleotide supplementation reduces the DNA damage and apoptosis

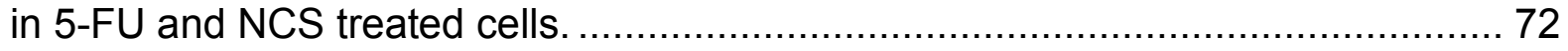

Figure 4.8 Tumors overexpress components of HRR and NHEJ. ........................ 76

Figure 4.9 Depletion of TS using siRNA or pharmacological inhibition does not

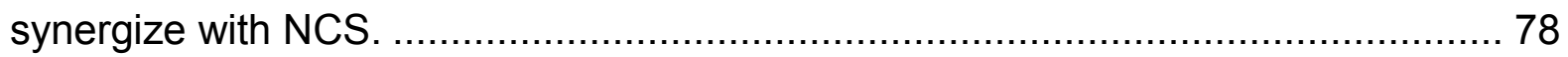

Figure 4.10 5-FU induced DNA damage is not rescued by MK2 inhibition. ............. 80

Figure 4.11 Gemcitabine exhibits concentration dependent cytotoxicity but does not

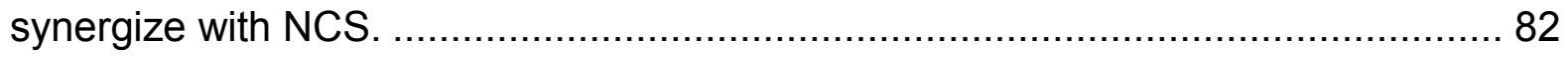

Figure 4.12 Ribonucleotide supplementation does not rescue gemcitabine treated

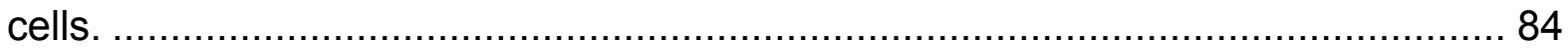

Figure 4.13 Ribonuleotide reductase inhibition or depletion of RRM2 causes DNA damage but does not synergize with NCS.................................................... 86 Figure 4.14 Inhibition of HRR by Rad51 inhibitor also causes persistent $\gamma-\mathrm{H} 2 \mathrm{AX}$.. 87 Figure 4.15 Inhibition of MMR does not synergize with NCS or 5-FU.................... 89 Figure 5.1 A model for 5-FU induced HRR inhibition...................................... 104 


\section{List of Tables}

Table 1.1 5-FU based chemotherapy regimens ................................................. 3

Table 1.2 CRC cell lines used in the study and their p53 and MSI/CIN status MMR and DDR

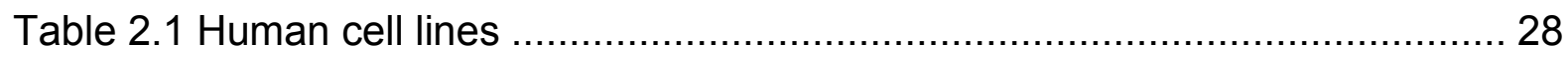

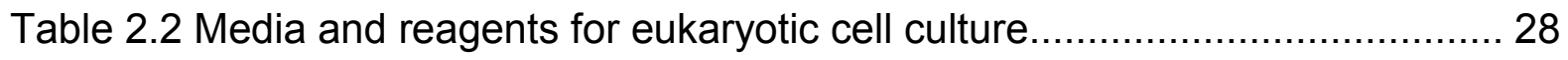

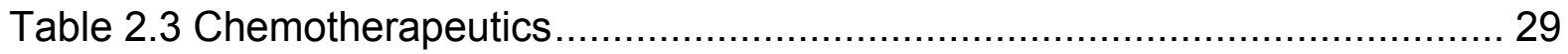

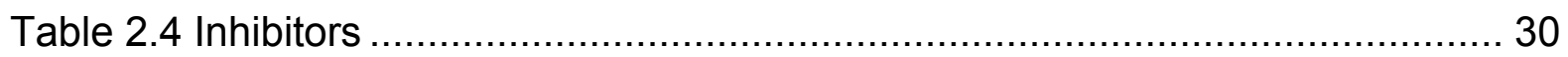

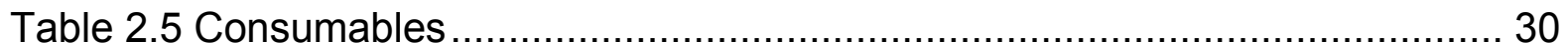

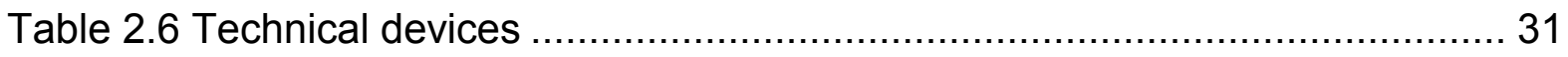

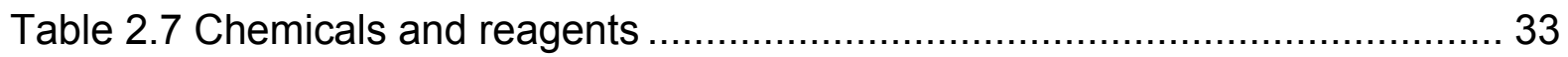

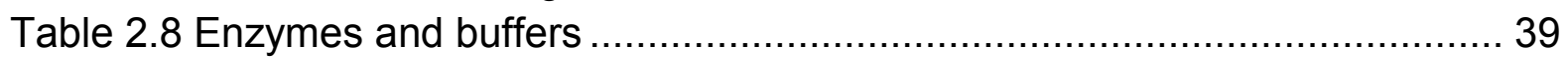

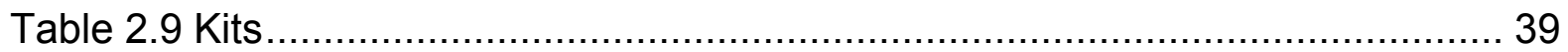

Table 2.10 Small interfering RNAs from Ambion/Life Technologies ..................... 40

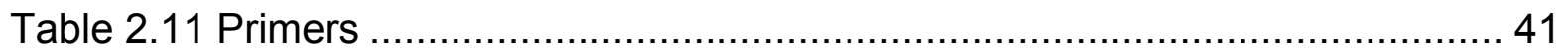

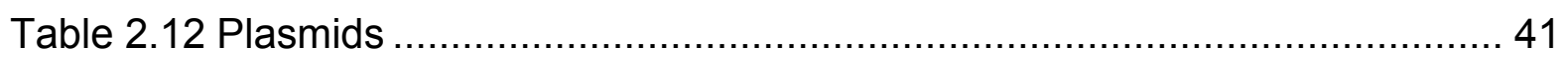

Table 2.13 Primary antibodies for Western blot ............................................... 42

Table 2.14 Primary antibodies for immunofluorescence ...................................... 43

Table 2.15 Secondary antibodies for Western blot ............................................. 43

Table 2.16 Secondary antibodies for immunofluorescence ................................... 44

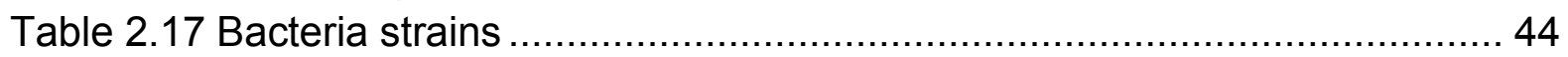

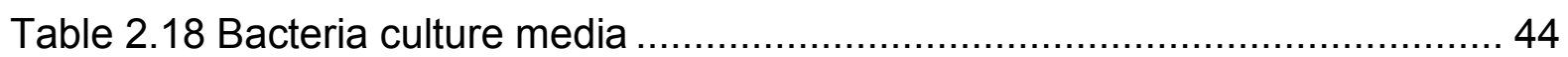

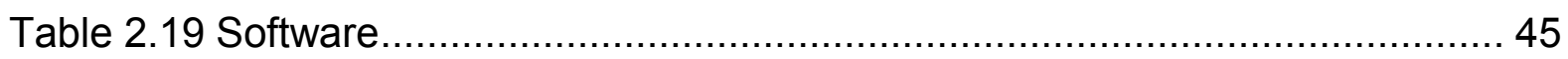




\section{Abbreviations}

\begin{tabular}{|c|c|}
\hline $5-\mathrm{FU}$ & 5-Fluorouracil \\
\hline AML & Acute myeloid leukemia \\
\hline APC & Adenomatous polyposis coli \\
\hline Ara-C & Cytosine arabinoside \\
\hline ATM & Ataxia telangiectasia mutated \\
\hline ATP & Adenosine triphosphate \\
\hline ATR & Ataxia telangiectasia and Rad3 related \\
\hline $\mathrm{Bcl}$ & B-cell lymphoma \\
\hline BLM & Bloom syndrome protein \\
\hline BRCA 1 & Breast cancer type 1 susceptibilty protein \\
\hline BSA & Bovine serum albumin \\
\hline Cdk & Cyclin- dependent kinase \\
\hline Chk1/2 & Checkpoint kinase $1 / 2$ \\
\hline $\mathrm{CIN}$ & Chromosomal instablity \\
\hline CLL & Chronic lymphocytic leukemia \\
\hline CRC & Colorectal cancer \\
\hline CtIP & CtBP interating protein \\
\hline Cyс & Cyclins \\
\hline dCTP & Deoxycytidine triphosphate \\
\hline DDR & DNA damage response \\
\hline DISC & Death-inducing signaling complex \\
\hline DMEM & Dulbecco's Modified Eagle Medium \\
\hline DMSO & Dimethylsulfoxide \\
\hline DNA & Deoxy nucleic acid \\
\hline DNA & Deoxyribonucleic acid \\
\hline DNA-PKCS & DNA dependent protein kinase catalytic subunit \\
\hline dNTP & Deoxynucleoside triphosphate \\
\hline dsDNA & Double stranded DNA \\
\hline DTT & Dithiothreitol \\
\hline dUTP & Deoxyuridine triphosphate \\
\hline E.coli & Escherichia coli \\
\hline EDTA & Ethylene diamine tetraacetic acid \\
\hline EGTA & Ethylene glycol tetraacetic acid \\
\hline Exo1 & Exonuclease1 \\
\hline FADD & Fas associated protein with death domain \\
\hline FCS & Fetal calf serum \\
\hline FdUMP & Fluorodeoxyuridine monophosphate \\
\hline FdUTP & Fluorodeoxyuridine triphosphate \\
\hline $\mathrm{FHA}$ & Fork head associated \\
\hline FUTP & Fluorouridine triphosphate \\
\hline GFP & Green fluorescent protein \\
\hline GSK3 $\beta$ & Glycogen synthase 3 beta \\
\hline
\end{tabular}




\begin{tabular}{ll}
\hline HNPCC & Hereditary nonpolyposis colorectal cancer \\
HRR & Homologous recombination repair \\
HU & Hydroxyurea \\
KRAS & Kirsten rat sarcoma \\
MDC1 & Mediator of DNA damage checkpoint 1 \\
Mdm2 & Mouse double minute 2 \\
MK2 & Mitogen activated protein kinase- activated protein kinase 2 \\
MLH1 & MutL homolog 1 \\
MRN & Mre11-Rad50-Nbs1 \\
MSH2 & MutS homolog2 \\
MSI & Microsatellite instability \\
NAD & Nicotinamide adenine dinucleotide \\
NBS1 & Nimegen breakage syndrome 1 \\
NCS & Neocarzinostatin \\
NHEJ & Non-homologous end joining \\
PBS & Phosphate buffered saline \\
PI & Propidium lodide \\
Polס & DNA polymerase delta \\
PTEN & Phosphatase and tensin homolog \\
RNA & Ribonucleic acid \\
RNF8 & Ring finger protein8 \\
ROS & Reactive oxygen species \\
RPA & Replication protein A \\
rRNA & Ribosomal ribonucleic acid \\
RTX & Raltitrexed \\
SDS & Sodium dodecyl sulphate \\
SDS PAGE & SDS Polyacrylamide gel electrphoresis \\
SSDNA & Single stranded DNA \\
TBST & Tris buffered saline + Tween 20 \\
TEMED & Tetramethylethylenediamine \\
TGF- 3 & Transforming growth factor beta \\
Thr & Threonine \\
TP53 & Tumor protein 53 \\
tRNA & Transfer ribonucleic acid \\
TS & Thymidylate synthetase \\
Tyr & Tyrosine \\
WRN & Werner syndrome, RecQ helicase like \\
XRCC & X-ray repair cross-complementing \\
& \\
\hline & \\
\hline
\end{tabular}




\section{Abstract}

Colorectal cancer ( $\mathrm{CRC})$ is the second leading cause of cancer related deaths in the world, and 5-Fluorouracil (5-FU) based regimens are chiefly employed for its therapy. Modern regimens, based on 5-FU in combination with other drugs have improved the response rates in the terminal CRCs to $\sim 50 \%$. However, a lack of molecular understanding of the cellular response process upon 5-FU treatment has stalled development of more improved therapies. Here, it behooves to study the mechanistic aspects of the complex, but coordinated signaling pathway that gets activated upon DNA damage, the DNA damage response (DDR). Current focus is on understanding the action of chemotherapeutic drugs, especially nucleoside analogs like 5-FU, in the context of DDR to find molecular targets to enhance their efficacies.

In the present study, we focus on understanding the molecular basis of 5-FU based neoadjuvant therapy and finding novel targets for improving the response rates in CRC patients. We find that 5-FU pretreatment radiosensitizes CRC cell lines to neocarzinostatin (NCS) and leads to persistent $\mathrm{y}-\mathrm{H} 2 \mathrm{AX}$, a marker for DNA double strand breaks. We further show that 5-FU reduces the ability of cells to perform homologous recombination repair (HRR) but not non-homologous end joining (NHEJ), which points towards HRR being the underlying molecular mechanism of radiosensitizaztion by 5 -FU. The use of $\mathrm{B} 02$, an inhibitor of HRR also shows persistent $\mathrm{y}-\mathrm{H} 2 \mathrm{AX}$, further strengthening our hypothesis.

Our subsequent investigations rule out impaired recruitment of repair proteins as the possible cause of 5-FU induced HRR reduction. On the other hand, ribonucleotide supplementation reduces 5-FU and NCS induced DNA damage suggesting that nucleotide pool disruption is a possible cause of 5-FU induced HRR reduction. Also the Thymidylate synthetase (TS) inhibitor raltitrexed does not synergize with NCS. Interestingly, we find complementary lethality between TS depletion and 5-FU; however, TS depletion using siRNA also does not synergize with NCS. We, therefore, postulate that 5-FU induced TS inhibition and DNA damage both are essential for reducing the HRR. 
We also find that Gemcitabine, another nucleoside analog, does not show any synergism with NCS, which render it unsuitable for studying DDR in SW480 cells. Interestingly, Ribonucleotide Reductase M2 (RRM2) depletion and hydroxyurea treatment also does not lead to synergism with NCS. Therefore, we conclude that Ribonucleotide reductase inhibition cannot synergize or affect the HRR in SW480 cells. Further, MK2 depletion, which rescues cells from gemcitabine-induced DNA damage does not exert such an effect in 5-FU treated cells, indicating that MK2 does not play any significant part in 5-FU induced DNA damage.

In conclusion, our results strongly suggest that the molecular reason for 5-FU induced radiosensitization is a reduction in the cellular ability to carry out HRR. This leads us to postulate that HRR inhibitors like B02 can be used in future regimens to overcome 5-FU resistant colorectal cancers. 


\section{Introduction}

\subsection{Colorectal cancer and its therapy}

Cancer is classified as a disease characterized by uncontrolled cell growth. It has been attributed to 8.2 million deaths in 2012 by WHO and occurs in almost all the tissues in the body. The most common cancer staging system is known as TNM (Tumors/Nodes/Metastasis), which classifies cancers from stage 0 to stage IV with stage 0 confined to mucosa while stage IV represents distant metastasis.

Colorectal cancer ( $\mathrm{CRC}$ ) is the second most common cancer in the world and accounts for around 600,000 deaths every year (Jemal et al., 2011) As with other cancers, early diagnosis of the cancer is key to a better overall survival; response rates in stage I are more than $90 \%$ as compared to a dismal $10 \%$ in stage IV (Longley et al., 2003).

\subsection{Genesis of colorectal cancer}

It is difficult to predict the exact reason for tumor development but there are certain genetic and physiological changes that can forecast the onset and progression of tumor. Firstly, certain germline mutations are known to increase the risk of acquiring $\mathrm{CRC}$, chief among these is germline mutation in mismatch repair genes, MLH1 and $\mathrm{MLH} 2$; persons with these mutations have an $80 \%$ chance of developing hereditary nonpolyposis colon cancer (HNPCC). Similarly, germline inactivation of both the alleles of a base excision repair gene mutY homologue (MUTYH) is associated with definite probability of developing CRC (Rustgi, 2007).

Not all the mutations described in CRC are hereditary or germline. Instead most of the mutations are acquired progressively and correspond to the growth of tumor from a small adenoma to metastatic adenocarcinoma. One of the first genes that gets affected is adenomatous polyposis coli (APC) (Fodde, 2002). APC normally forms a complex with glycogen synthase kinase 3-beta (GSK3- $\beta$ ) and axin to form a $\beta$ catenin degradation complex. In the absence of APC, this complex is inactive and 
therefore $\beta$-catenin is not degraded. $\beta$-catenin is the major canonical effector of Wnt signaling and the lack of APC constitutively activates the Wnt signaling (Najdi et al., 2011).

The second major mutation in the progression of CRC occurs in TP53 (Valentini et al., 2003). The p53 is a tumor suppressor that performs many functions including cell cycle arrest and/or apoptosis in response to DNA damage. Mutation in this gene is pivotal in the transition of adenomas to invasive carcinomas.

A third major mutation happens in TGF- $\beta$, whose inactivation uncouples the growth inhibitory signals and the tumor growth (Derynck et al., 2001). This further aids in the transition from adenoma to carcinoma. Apart from these there are several other mutations like KRAS, PTEN, BRAF which contribute to the growth and progression of the CRC from a benign adenoma to malignant adenocarcinoma (Markman et al., 2010) (Molinari and Frattini, 2013).

\subsection{Neoadjuvant and adjuvant therapy}

The therapeutic regimen for CRC is largely guided by the stage at which it is diagnosed. Wherever feasible the cornerstone of treatment is surgical removal of the tumor. This is followed by chemoradiotherapy to prevent any relapse of the tumor. Recently, a chemoradiotherapy regimen has also been added and is known as Neoadjuvant therapy (Fleming et al., 2011).

\subsubsection{Neoadjuvant therapy}

Neoadjuvant therapy constitutes the pre-operative regimen and is mainly administered to sensitize tumor cells towards chemotherapy. In general, the patients are given 5-Fluorouracil (5-FU) alone or in combination with other chemotherapeutics and radiation. This regimen was introduced in early 2000's after studies showed an increased 5 year survival rates in patients (Sauer et al., 2004). However, similar studies conducted independently elsewhere did not give such promising results (Park et al., 2011). Of late however, neoadjuvant therapy has come to be associated with several advantages: 
(i) Size of the tumors can be reduced which may help the surgical procedure,

(ii) Response of individual patients towards the chemotherapeutics can be gauged and tailored regimens can be created with improved response rates.

\subsubsection{Adjuvant therapy}

Adjuvant therapy is the chemoradiotherapy regimen administered post-surgery. Here, insights gained during neoadjuvant therapy are used to devise the regimen. The goal of the adjuvant therapy is to prevent the tumor relapse. 5-FU is the drug of choice for the treatment of CRC and is combined with other drugs in the adjuvant therapy. Popular regimens include combination of folinic acid, 5-FU and oxaliplatin (FOLFOX); folinic acid, 5-FU and irinotecan (FOLFIRI), combination choices also vary with the location. These and several other combinations are listed in the Table 1.1 along with typical doses.

Table 1.1 5-FU based chemotherapy regimens

\begin{tabular}{lll}
\hline Chemotherapeutics & Dose $\left(\mathbf{m g} / \mathbf{m}^{2}\right)$ & Acronym \\
\hline $\begin{array}{l}\text { 5-FU+Folinic } \\
\text { acid+Irinotecan }\end{array}$ & $2000+500+100$ & FOLFIRI \\
5-FU+Folinic \\
$\begin{array}{l}\text { acid+Oxaliplatin } \\
\text { 5-FU+Folinic } \\
\begin{array}{l}\text { acid+Oxaliplatin } \\
\text { 5-FU+Folinic } \\
\text { acid+Oxaliplatin }\end{array}\end{array}$ & FOLFOX4 \\
5-FU+Oxaliplatin & $400+400+85-100$ & FOLFOX6 \\
Capecitabine +Oxaliplatin & $1000+130$ & FUFOX \\
\hline \multicolumn{2}{c}{ http://emedicine.medscape.com/article/2005487 }
\end{tabular}

\subsection{Nucleoside analogs in cancer therapy}

Nucleoside analogs have been used in cancer treatment for over five decades. They are classified as purine and pyrimidine nucleoside analogs and each one has its own unique way of inducing DNA damage and apoptosis. 


\subsubsection{Pyrimidine nucleoside analogs}

Cytarabine (ara-C) was the first nucleoside analog developed and is still used for treating acute myelogenous leukemia (AML) (Johnson et al., 2001). Following phosphorylation, it competes with dCTP for incorporation into DNA, once incorporated it causes chain termination and replication fork stalls (Townsend and Cheng, 1987). A closely related analog called gemcitabine is also used in clinics for treating a variety of solid tumors (see ahead). Interestingly, even nucleoside analogs having a $\beta$-L-configuration are damaging to DNA. For instance, troxacitabine has been reported to passively diffuse into cells and get phosphorylated resulting in replication fork stalls (Grove and Cheng, 1996). Another pyrimidine analog, CNDAC produces DNA double strand breaks but unlike others leads to G2 arrest in cells. The oral form of this drug, sapacitabine is currently in phase 3 trials for AML therapy (Kantarjian et al., 2012).

\subsubsection{Purine nucleoside analogs}

The purine nucleoside analogs were also developed around the same time as the pyrimdine analogs. Fludarabine functions by affecting the dNTP pools and inhibiting the DNA polymerase (Randerath et al., 1983). It is used for treating chronic lymphocytic leukemia (CLL) and non-Hodgkin's lymphoma. Another purine analog, Cladribine functions by depleting ATP and NAD in cells (Carson et al., 1986) leading to apoptosis. Further, clofarabine also gets incorporated into DNA and causes disruption of the nucleotide pools, however it is more stable than others causing greater damage (Carson et al., 1992).

\subsubsection{5-Fluorouracil}

As already mentioned, 5-FU is a nucleoside analogue that is most commonly used to treat CRC. It was discovered in 1957 and has been in use for almost five decades now as an anti-cancer drug (Heidelberger et al., 1957). In 1989, continuous venous infusions were accepted as a standard therapy for colorectal cancer (Lokich et al., 1989). Through this mode of administration the response rates are around $10-15 \%$ but generally it is given in combination with other drugs that increase response rates to $40-50 \%$ (Longley et al., 2003). 
Mechanism of action

5-FU enters the cells by facilitated diffusion and is then progressively metabolized into FUTP, FdUTP and FdUMP (Figure 1-1). FUTP gets incorporated into RNA causing RNA damage and FdUTP in DNA causing DNA damage, while FdUMP forms a covalent bond with thymidylate synthetase (TS) and inhibits its action (Longley et al., 2003). TS inhibition causes disruption of nucleotide pools affecting the DNA synthesis. FUTP inhibits processing of the pre-rRNA and also prevents post translational modifications of tRNA (Ghoshal and Jacob, 1994). Misincorporation of 5-FU in the DNA leads to lesions that are recognized by the mismatch repair system (MMR) system or the base excision repair (BER) system (Wyatt and Wilson, 2009)

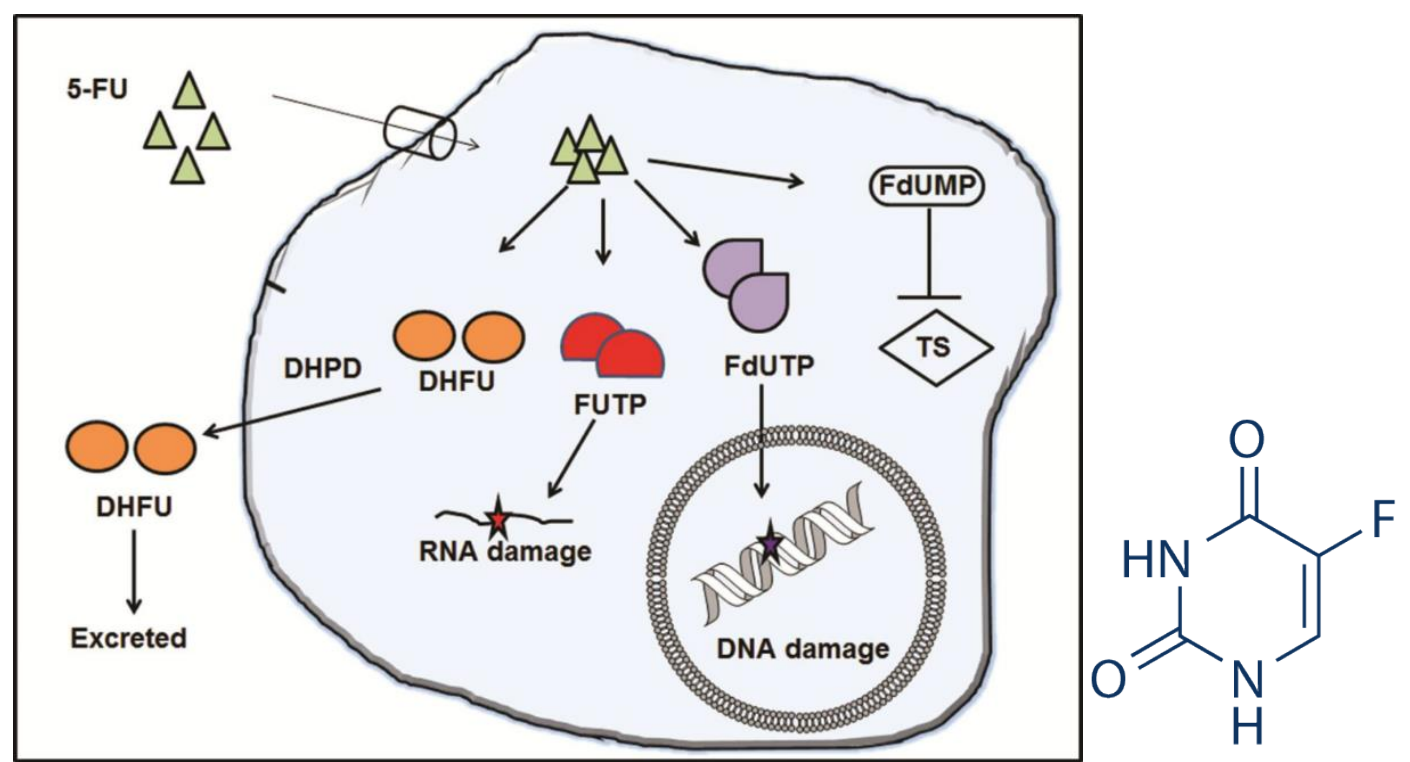

Figure 1.1 Mechanism of 5-FU action.

5-FU enters the cell using facilitated diffusion and is metabolized into, FdUMP that inhibits TS; FdUTP that gets misicorporated in DNA causing DNA damage; FUTP, that gets misicorporated in RNA casuing RNA damage and; DHFU that does not have any anti-cancer effect. Figure modified from (Longley et al., 2003). Chemical structure of 5-FU obtained from Sellechkem.com.

\section{Inhibition of Thymidylate synthetase}

TS catalyzes the conversion of dUMP to dTMP and is the only source of de novo synthesis of thymidylate in the cell (Touroutoglou and Pazdur, 1996). TS functions as a dimer and binds to dUMP and 5, 10 methylene tetrahydrofolate, which acts as the methyl group donor (Figure 1-2). FdUMP competes with dUMP for the active site 
on TS and forms a covalent ternary complex with 5, 10 methylene tetrahydrofolate, which is very stable (Carreras and Santi, 1995; Longley et al., 2003). The ternary complex with FdUMP was shown to have $13 \mathrm{Kcal} / \mathrm{mol}$ less binding energy than dUMP indicating the stability of the complex over dUMP containing complex (Kaiyawet et al., 2013). The end result of this stable complex formation is the sequestration of TS and hence the disruption of the nucleotide pools.
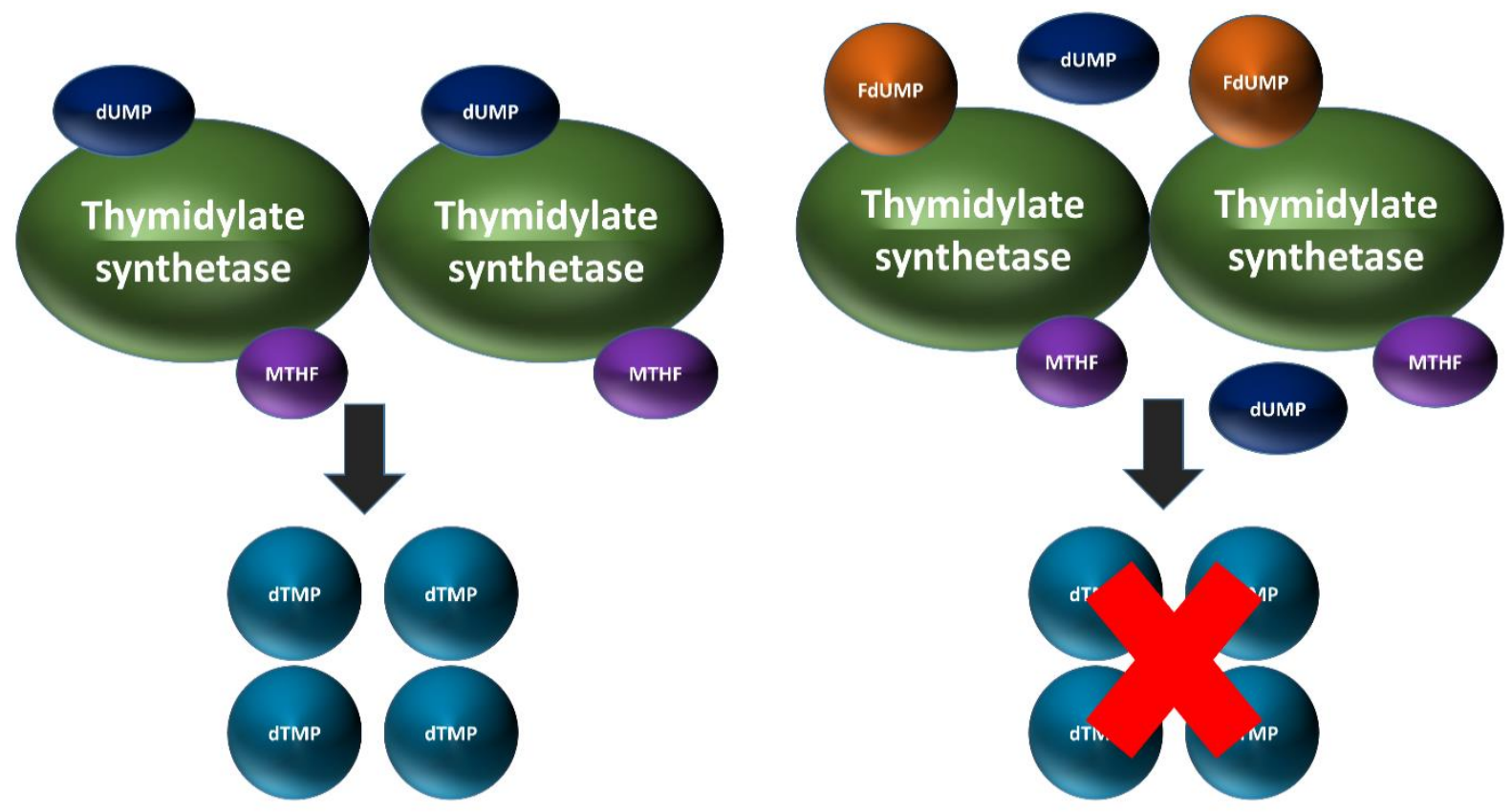

Figure 1.2 TS inhibition by FdUMP.

TS dimer binds to dUMP and 5, 10 methylene tetrahyrofolate (MTHF) to catalyze conversion to dTMP. 5-FU metabolite. FdUMP competes with dUMP and inhibits the catalytic conversion to dTMP. Figure modified from (Longley et al., 2003).

\section{Clinical use and toxicity}

It has been reported that 1 in 3 patients receiving 5 -FU encounters serious life threatening side effects. These include decrease in white blood cells, infections, nausea, vomiting etc. About 1-7\% patients, receiving 5-FU also exhibit cardiac symptoms like myocardial infarctions (Alter et al., 2006).

\subsubsection{Gemcitabine}

Gemcitabine (2', 2'-difluoro-2'-deoxycytidine; dFdC) was synthesized in 1980, as an anti-viral drug (Hertel et al., 1990) but was later shown to have anti-tumor activity. It 
is used in therapy of breast cancer, pancreatic cancer, and bladder cancer either as a single agent or in combination with other drugs. It is a radiosensitizer and induces an S phase arrest (Shewach and Lawrence, 1996b)

Mechanism of action

Upon activation by deoxycytidine kinase, gemcitabine is incorporated into DNA, causing DNA damage (Figure 1-3). When two dFdC molecules are added next to each other in the newly synthesized DNA strands, the DNA polymerase cannot elongate the DNA strand any further and therefore the replication stalls (Sampath et al., 2002; Shi et al., 2001). The stalled replication is irreversible, and is one of the reasons for its anti-cancer activity. Apart from replication fork stall, gemcitabine also inhibits the enzyme ribonucleotide reductase (Pereira et al., 2004). This inhibition causes a disruption in nucleotide pools which affects the new DNA synthesis. It is administered intravenously in combination with carboliplatin or other drugs, but there are a myriad of side effects of gemcitabine like pulmonary toxicity, diarrhea, myelosuppression and proteinuria.

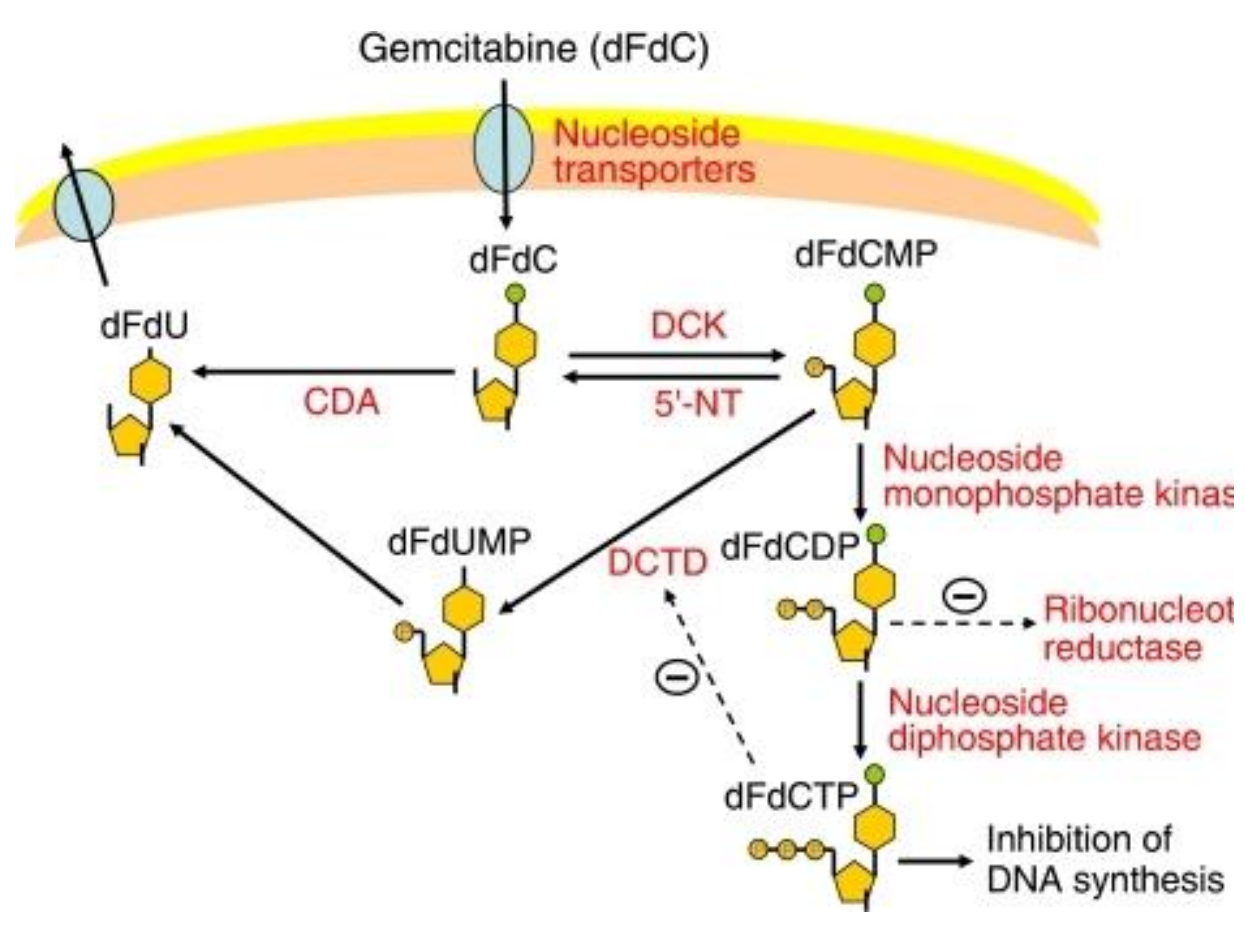

\section{Gemcitabine}

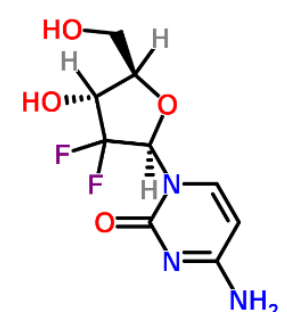


Figure 1.3 Mechanism of gemcitabine activation and misincorporation into DNA. Gemcitabine (dFdC) enters the cell and is activated by deoxycytidine kinase (DCK) followed by further phosphorylations to form dFdCDP, which inhibits ribonucleotide reductase, and dFdCTP which gets incorporated in DNA causing chain termination. Figure modified from (Resende et al., 2007). Gemcitabine structure was obtained from http://www.chemspider.com/lmageView.aspx?id=54753.

\subsection{NCS and gamma radiation}

Neocarzinostatin is a radiomimetic secreted by Streptomyces neocarzinostaticus. It is composed of a protein and an enediyne component (Figure 1-4). The protein component is proposed to stabilize the enediyene component, and improve the halflife of the molecule (Goldberg, 1991). However, another view is that the protein component guides the enediyene component in to the cell (Kappen et al., 1980). This view is based on high concentration of the protein component around the cell membrane. Nevertheless, the function of the enediyene component is well established. Upon cellular entry, it encounters a reducing environment in the cytoplasm causing its cyclic aromatization leading to biradical formation, which causes double strand breaks in the DNA. Like NCS, y-radiation also produces double strand breaks (DSB) but the mechanisms are different. $\mathrm{y}$-radiation on account of high energy causes the molecules inside cells to break up and produce ions. The most abundant cellular molecule, water splits up producing hydroxyl radicals that cause DNA breaks (Gross, 2007). 


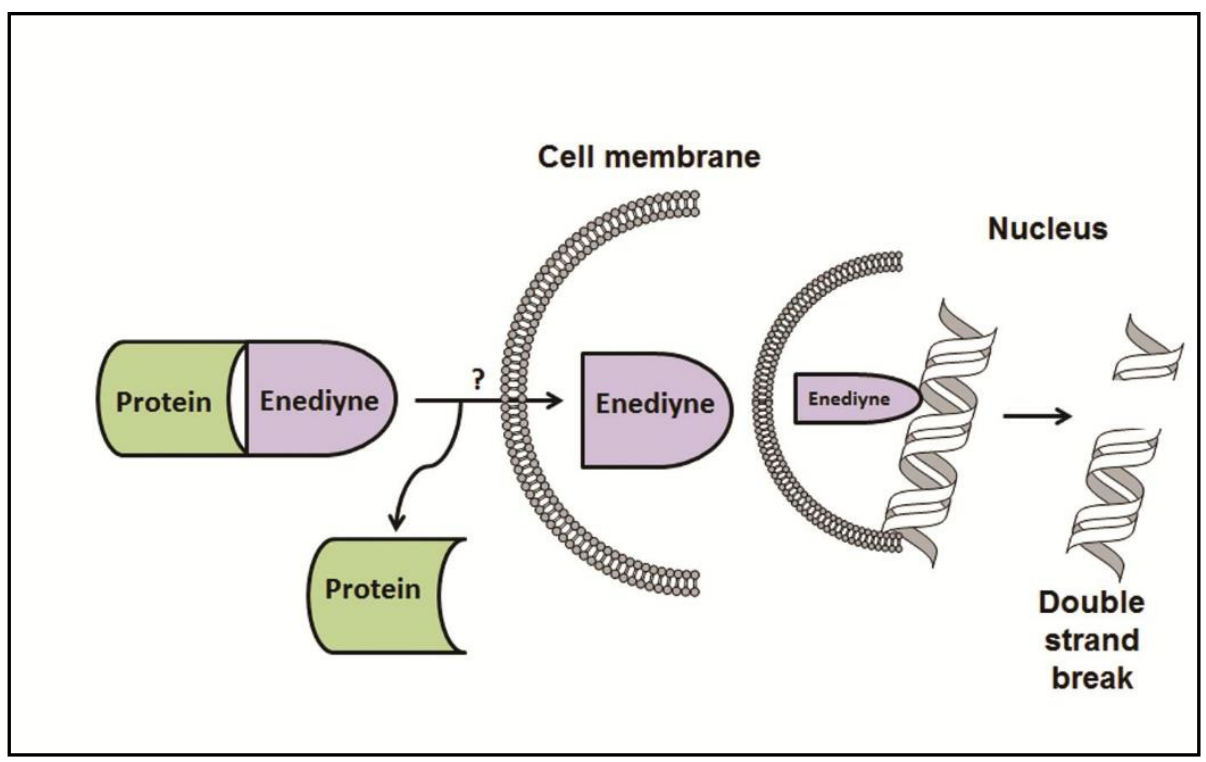

Figure 1.4 Mechanism of neocarzinostatin action.

Neocarzinostatin (NCS) is a radiomimetic consisting of two components, a protein part and an enediyene part. Upon entry into cell, Enediyene undergoes cyclic aromatization producing biradical. The cyclic biradical is considered to induce double strand DNA breaks. Figure modified from (Goldberg, 1991).

\subsection{DNA damage response and repair}

\subsubsection{DNA damage}

DNA is the information storehouse and any damage to it is detrimental to cells. Damage to DNA can be physical (e.g. chromosomal breakage), base alterations (e.g. deamination), or strand breaks (e.g. single or double). Any physical, chemical or biological agent that compromises the integrity of DNA can be classified as a DNA damaging agent. Intuitively, the cell has put in a number of stringent measures to protect the integrity of DNA; these include recognition of DNA damage, cell cycle checkpoints to prevent chromosomal imbalances, mitotic catastrophe, and efficient DNA repair machinery. Also, the type of DNA damage induced depends on the causative agent for example, radiomimetic like NCS lead to double strand breaks, cis-platin causes inter strand cross links, and nucleoside analogs like 5-FU and gemcitabine induce replication fork stalls. Apart from these exogenous agents, the normal metabolism of a cell produces reactive oxygen species (ROS) which are equally potent in damaging the DNA. 
If the DNA damage is undetected or not repaired, it could lead to cell death or tumor formation. Tumor genesis begins with mutations in tumor suppressors like p53 or oncogenes like c-myc. Nucleoside analogs as described earlier, target the cancer cells by misincorporation into DNA leading to either replication fork stalling or mutations. Therefore, understanding DNA damage is crucial for devising cancer therapy.

\subsubsection{Mechanism and signaling in response double strand breaks}

Once the DNA has been damaged, the damage must be recognized and depending on the type of DNA damage, appropriate repair machineries must be employed. The signaling cascade in response to the DNA damage, starting from recognition till repair of the DNA is called DNA damage response (DDR). The proteins carrying out the DDR can be classified as,

(i) Sensors (e.g. MRN complex)

(ii) Transducers (e.g. ATM and ATR)

(iii) Mediators (e.g. MDC1, 53BP1)and,

(iv) Effectors (e.g. Chk1 and Chk2)

The sensors recognize the damage and facilitate the recruitment of other proteins while activating the downstream signals. A common protein complex involved in DDR is explained in Figure 1.5. The protein complex, MRN is composed of Mre11, Rad50 and NBS1 (Nijmegen breakage syndrome) that detects the DNA double strand breaks. The MRN complex then recruits Ataxia telangiectasia mutated (ATM) while the RPA recruits Ataxia telangiectasia mutated and Rad 3 related (ATR) kinase; ATM and ATR are master regulatory kinases that phosphorylate close to 600 substrates in the cell (Chapman et al., 2012). In the context of DDR, ATM is involved in the DNA double strand break repair while ATR is involved in single strand break repair (Figure 1.5).

\subsubsection{Signaling for double strand break repair}

In normal cells, ATM is present as an inactive dimer but upon DNA damage it forms active monomers (Bakkenist and Kastan, 2003). Once activated it phosphorylates $\mathrm{H} 2 \mathrm{AX}$, a histone $\mathrm{H} 2 \mathrm{~A}$ variant which constitutes about $10 \%$ of the total $\mathrm{H} 2 \mathrm{~A}$, however 
this proportion varies depending on the species and the cell type (Rogakou et al., 1998). Phosphorylated H2AX (Ser139) is commonly referred to as $\mathrm{Y}-\mathrm{H} 2 \mathrm{AX}$ and is a marker for DNA double strand breaks (Kuo and Yang, 2008).

The $\mathrm{y}-\mathrm{H} 2 \mathrm{AX}$ signal spreads for several thousand bases from the site of the DNA damage and facilitates the recruitment of downstream repair proteins. It is recognized by proteins with tandem BRCT domains or fork head domains (FHA), like MDC1, 53 BP1 and NBS1(Kinner et al., 2008). Mediator of Damage Checkpoint protein1 (MDC1) is considered to be among the first proteins to recognize $\mathrm{Y}-\mathrm{H} 2 \mathrm{AX}$ and further recruits MRN complex (Stucki et al., 2005).

Activation of ATM in response to DNA double strand breaks is explained by a twostep model, in which the MRN complex tethers the DNA ends to promote ATM monomerization followed by activation and autophosphorylation of ATM at Ser1981(Dupre et al., 2006). NBS1 has an ATM binding domain and it is speculated that interaction with NBS1 may prevent the re-association of ATM monomers to inactive dimers and that NBS1 functions as an activating cofactor.

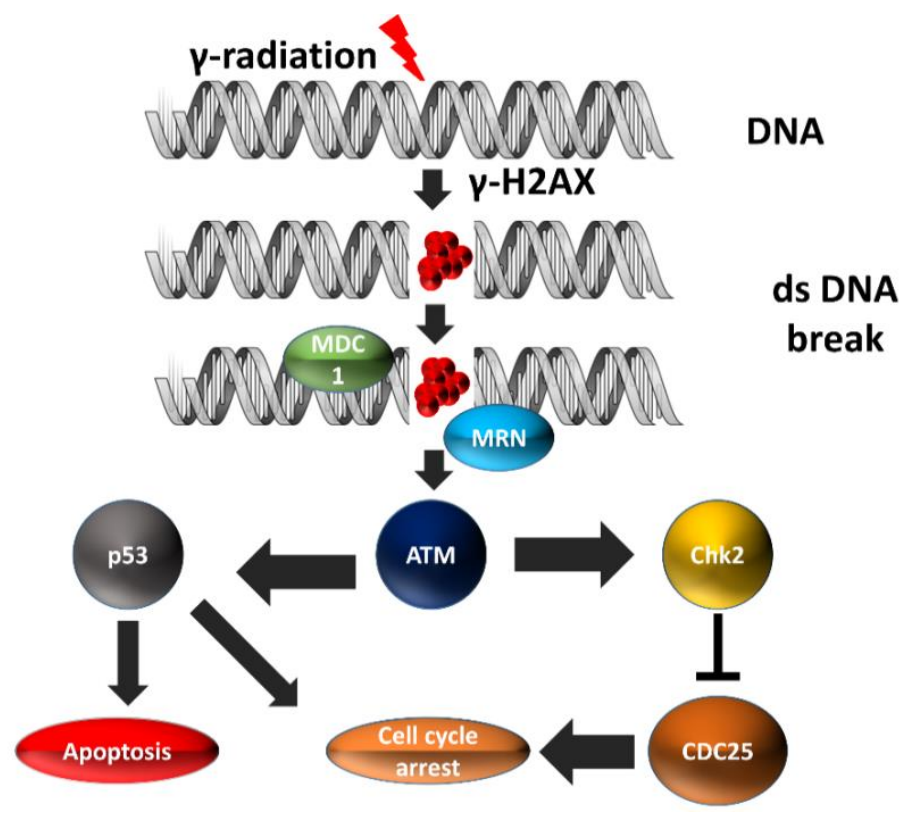

Figure 1.5 DNA double strand breaks induced response.

DNA double strand breaks are recognized by MDC1 which recruits the Mre11-Rad50-Nbs1 complex. MRN complex activates ATM kinase which in return activates p53 leading to cell cycle arrest and apoptosis, Chk2 leading to cell cycle arrest. Figure modified from (Lukas et al., 2011) 


\subsection{DNA damage response and apoptosis}

There are many modes of cell death like apoptosis, necrosis, autophagy and cornification (Kroemer et al., 2009). Among these apoptosis is the most studied cell death type in cancer biology. Apoptosis is defined as a programmed cell death, and can be broadly classified as extrinsic and intrinsic apoptosis. In the extrinsic pathway, apoptosis is triggered by external stimuli like a ligand that binds to a special kind of receptors, called as death receptors. The death receptors belong to the tumor necrosis factor superfamily and include cd95 and TRAIL receptor that bind to cd95L and TRAIL to induce apoptosis. Binding of ligand to the receptor causes trimerization and clustering of the death domain, followed by recruitment of Fas Associated protein with Death Domain (FADD). FADD recruits caspase 8 and the formation of Death-inducing signaling complex (DISC) leads to self-cleavage of caspase 8 and its activation which further activates downstream caspases culminating in apoptosis.

CRC cell lines with both p53 mutant and wild type genotypes exist, for example, SW480 harbor a mutant p53 whereas RKO has a functional wild type p53. Therefore, it is imperative to understand both p53 dependent and independent apoptosis to elucidate the molecular mechanisms behind 5-FU induced apoptosis in p53 mutant and wild type CRC cell lines.

The intrinsic pathway on the other hand does not involve any external stimuli, and is activated in response to cells internal signaling processes which get activated especially in cases of irreversible DNA damage. Intrinsic apoptosis can be further divided into p53 dependent or independent. This is an important distinction as p53 mutations have been described in more than $50 \%$ of the tumors (Vogelstein et al., 2000).

DNA damage leads to the activation of the DDR and as described earlier, ATM and ATR are the key protein kinases activated in this process. ATM and ATR phosphorylate p53 at multiple sites which prevent the interaction of p53 with Mdm2, the negative regulator of p53 (Saito et al., 2002), phosphorylation by Chk2 at Ser20 is also responsible to reduce the interaction with Mdm2 (Ou et al., 2004). The p53 
protein activates transcription of Bcl2 family of proteins including Bax, Noxa and PUMA. Apart from increasing the transcription of pro-apoptotic genes p53 binds to the anti-apoptotic genes $\mathrm{Bcl}-2$ and $\mathrm{Bcl}-\mathrm{X}_{\mathrm{L}}$ and prevents their action (Nakanoko et al., 2013).

The kinase Chk2 plays a major role in the p53 independent apoptosis. It phosphorylates and activates the transcription factor E2F-1 (Stevens et al., 2003). E2F-1 has been shown to promote the expression of a variety of apoptotic factors and also p53 related protein p73, which can activate pro-apoptotic genes. Apart from Chk2, Nur 77 a gene that codes for an orphan receptor is translocated to cytosol in response to 5-FU treatment where it is shown to facilitate the release of mitochondrial cytochrome c (Calnan et al., 1995). Caspase-2 then promotes apoptosis by causing mitochondrial dysfunction and later in the apoptosis relocalizes from the nucleus and aids in the translocation of Bax and release of cytochrome $\mathrm{c}$ and Smac leading to apoptosis (Guo et al., 2007).

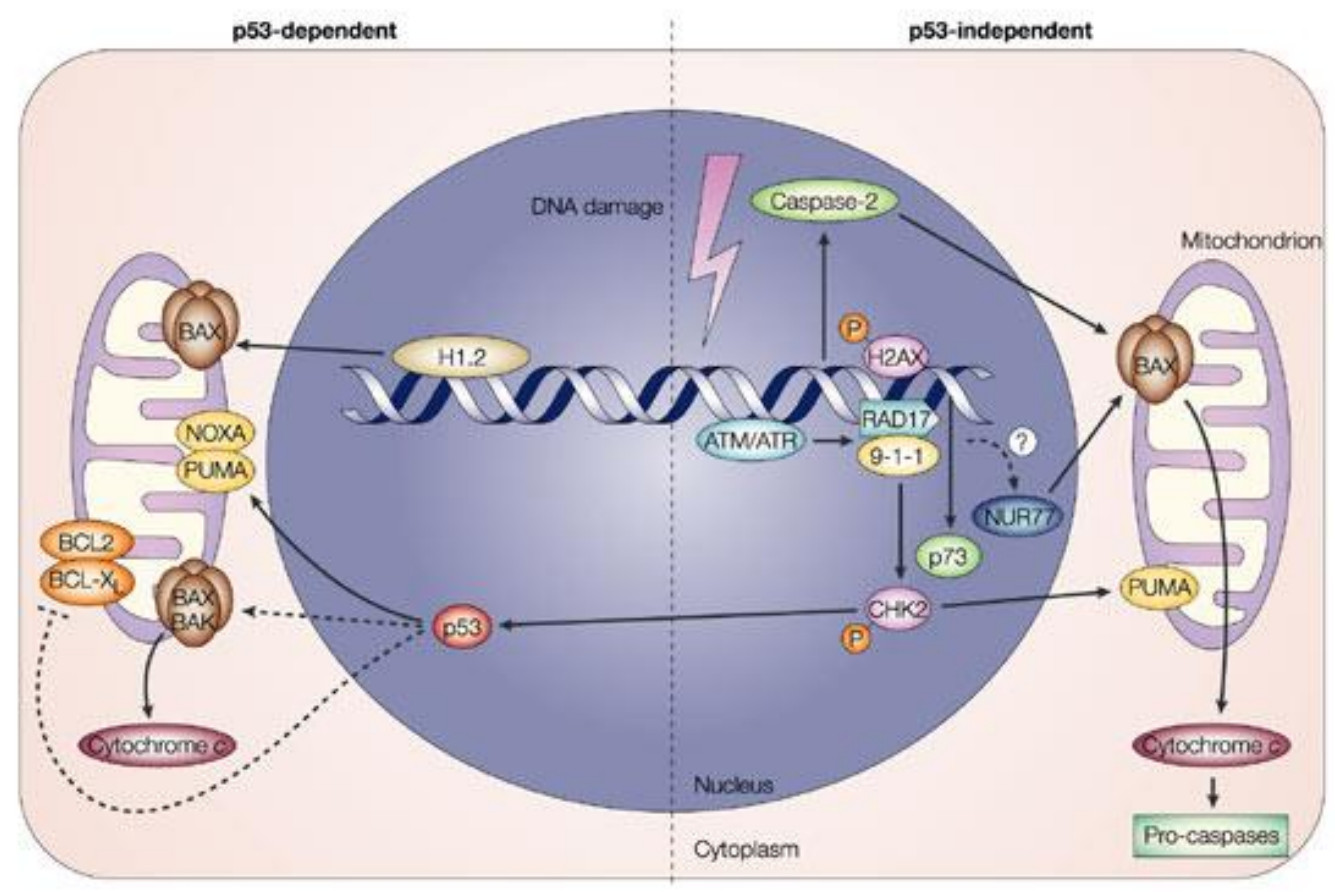

Figure 1.6 p53 dependent and independent apoptosis.

Apoptosis induced in response to DNA damage can be executed in both p53 dependent and independent manner. Both the pathways converge on mitochondrial release of cytochrome c. Figure modified from (Norbury and Zhivotovsky, 2004). 


\subsection{Cell cycle regulation and cancer}

Cyclins (cyc) and cyclin dependent kinases (Cdk) control the transition from one cell cycle phase to next. In humans, Cdk are encoded by 13 loci and cyclins by 25 though not all of the cyclin-Cdk complexes are involved in cell cycle (Malumbres and Barbacid, 2005). There are 10 cyclins belonging to four different families: A, B, D and $\mathrm{E}$. In the $\mathrm{G} 1$ phase, cycD forms complex and activates Cdk4 and Cdk6 which leads to expression of cycE, cycE-Cdk2 complex is crucial for $\mathrm{G} 1 / \mathrm{S}$ transition. In the $S$ phase, the cycE-Cdk2 complex is active, but during the late $S$ phase the expression of cycA2 increases thus, cycE-Cdk2 complex is replaced by cycA2-Cdk2 complex which facilitate transition into G2. In interphase, cycA activates Cdk1 but the nuclear envelope breakdown increases the cycB-Cdk1 complex and this drives the cell through mitosis (Figure 1.7).

Cdk4 overexpression has been reported in melanomas and Cdk6 overexpression in breast tumors. cycD2 and D3 are also found to be overexpressed in tumors; cycA and $E$ are overexpressed in lung carcinoma while Cdc25B is overexpressed in breast tumors. Numerous reports have shown a causal link between cyc and/or Cdk overexpression and tumor formation (Guha, 2012). Given this, it is conceivable that cyc and Cdk are expected to have anti-tumor activity. Olomuoucine inhibits cycBCdk1, cycA-Cdk2, and cycE-Cdk2 leading to reduced cell proliferation and increased apoptosis (Vesely et al., 1994). Recently, Cdk4/6 inhibitor Palbociclib was shown to improve the median progression free survival from 7.5 months to 26 months, but this drug is still in phase II clinical trials (Kelly et al., 2013). 


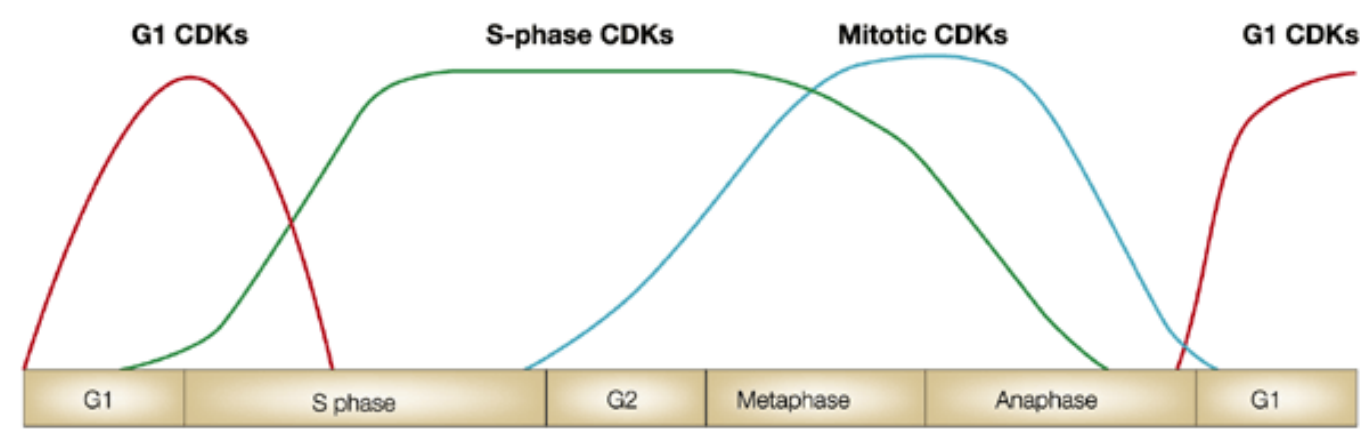

Figure 1.7 Control of cell cycle by cyclin-Cyclin dependent kinase complexes. Periodic changes of cyclins regulate activity of Cdk and transition through cell cycle phases. Figure modified from (Bardin and Amon, 2001).

\subsubsection{Cell cycle checkpoints}

The cyclical passage of cells from a metabolically active state to duplication and production of two daughter cells constitutes the cell cycle. During this complex process the cell has to take some very critical decisions such as-

(i) Is there enough energy available to complete the entire process,

(ii) Is the DNA damaged?

(iii) Have the chromosomes properly segregated?

Intuitively, the cell has a complicated but elegant machinery to guard against any untoward incident that will have serious effects on either of the daughter cells. This machinery operates during cell cycle checkpoints and can be rightly called as guardians of the cell. The checkpoints needed to understand the current study include -

\section{G1/S checkpoint}

The G1/S checkpoint is activated in response to DNA damage and prevents the cell from entering the $S$ phase. The key protein involved in the $\mathrm{G} 1 / \mathrm{S}$ arrest is p53. Phosphorylation by ATM/Chk2 increases its stability, which leads to the transcription of genes like p21 that effectuate G1 arrest by inhibiting the cycE-Cdk2 (Coqueret, 2003). Activation of the DDR leads to increased activity of the kinases Chk1 (only in late G1) and Chk2, that phosphorylate Cdc25A (phosphatase required for progression into $S$ phase) increasing its degradation by the proteasome (Falck et al., 
2001). Reduced levels of Cdc25 A inactivate the cycE-cdk2 thereby causing a G1 arrest.

Intra S phase checkpoint

The $S$ phase checkpoint is activated in response to damaged DNA. The cell must first repair the DNA and complete synthesis before moving into $\mathrm{G} 2$ and $\mathrm{M}$ phases, as once it leaves the $S$ phase, DNA replication and synthesis are not possible. Here, Cdk2 inhibition by Chk1- and Chk2- mediated phosphorylation of Cdc25, prevents the DNA polymerase from assembling on to replication sites and thus prevents the firing of new origins of replication leading to $S$ phase arrest.

\section{G2/M checkpoint}

The G2/M checkpoint depends on the ATM/ATR mediated phosphorylation and inhibition of cycB-Cdk1, that is required for the mitosis. Activation of Cdk1 requires Cdc25, however ATM/ATR mediated phosphorylation of Cdc25 prevent the activation of Cdk1, thereby preventing entry into M phase.

\subsection{DNA double strand break repair processes}

\subsubsection{H2AX and Homologous Recombination Repair}

$\mathrm{Y}-\mathrm{H} 2 \mathrm{AX}$ has been shown to have only modulating effect in homologous recombination repair (HRR). H2AX deletion mice show increased genomic instability but are not embryonic lethal, however mice lacking components of HRR are embryonic lethal indicating that $\mathrm{y}-\mathrm{H} 2 \mathrm{AX}$ is not necessary for $\mathrm{HRR}$ but can function to improve the efficiency of the HRR (Yin et al., 2012). It is known that MRN complex can recognize the DNA double strand breaks and perform limited end resection needed for HRR (Dong et al., 2012). However, normally Exo1 performs the end resection and is recruited to the sites of DNA damage by MRN complex. Once end resection is completed the SSDNA is covered by RPA that protects the SSDNA from degradation and prevents secondary structure formation.

The recruitment of Rad51 a key regulator of HRR depends on many factors like BRCA1, Ring finger protein 8 (RNF8), and p400 (Nakada et al., 2012). It is not yet clear which factor contributes to the recruitment and to what extent although RNF8 
may be a good guess as it is also involved in the DDR. Another important aspect is the replacement of RPA by Rad51 to facilitate HRR which is aided by Rad52 and Rad55-57 complex (Liu et al., 2002). Rad52 binds to Rad51 and is primarily required for the formation of Rad51 filaments on the DNA and its interaction with RPA allows it to detect the ssDNA. Rad52 is phosphorylated at Tyr104 by c-Abl kinase increasing its affinity to ssDNA. C-Abl is activated by ATM or DNA-PK thus linking the activation of Rad52 to DDR (Honda et al., 2014). The Rad55-57 heterodimer also interacts with Rad51 and facilitates its loading onto RPA coated ssDNA. Rad51 filament is shown to be more resistant to Srs2 anti-recombinase in the presence of Rad55-57 heterodimer. It has been shown that Rad55 is phosphorylated at Ser2, 8 and 14 by Rad53 kinase in S.cerevisiae and that these phosphorylation events are necessary for efficient HRR. The human homolog of the Rad53 is Chk2, which is phosphorylated by ATM in response to DSB therefore these observations can be extrapolated to mammalian cells albeit with caution.

RPA is a heterotrimeric protein composed of 3 subunits, RPA1 (70 kDa), RPA2 (34 $\mathrm{kDa}$ ) and RPA3 (14 kDa). RPA is phosphorylated at multiple sites and subunits in response to DNA damage. Cdc2 cyclin dependent kinase phosphorylates RPA2 at Ser23 and Ser29 facilitating the recruitment and binding to ssDNA, while PIKK phosphorylates RPA2 at Ser4, 8, 11, 12, 13, 33 and Thr21 (Figure 1-8). This hyperphosphorylation is speculated to regulate the functioning of the RPA molecule but the exact role of each phosphorylation event is not entirely known (Summers et al., 2011). 


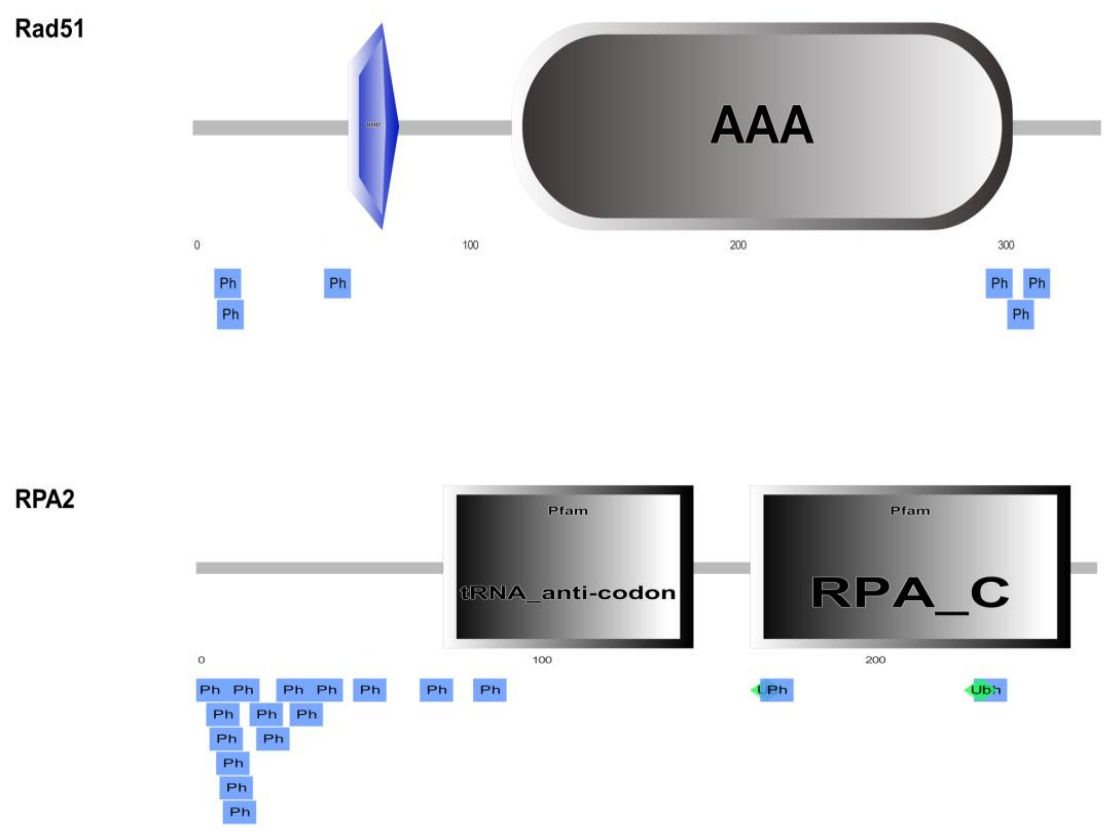

Figure 1.8 Phosphorylation sites in Rad51 and RPA2.

Rad51 and RPA2 are phosphorylated at multiple sites which regulate their function, localization and activation. All known phosphorylation sites are indicated in blue and the domain structures are indicated in gradient of black. Images were obtained using PTMcode 2. AAA- ATPases Associated with diverse cellular Activities; RPA_C - oligonucleotide binding fold.

\subsubsection{Homologous recombination repair}

Homologous recombination repair (HRR) is considered to be an error free DNA repair process that repairs the DNA double strand breaks using a sister chromatid or homologous stretch of DNA. The use of homologous DNA strand makes this process error free though loss of heterozygosity may occur due to the same reason.

For description, HRR is usually divided into 3 phases; (a) Presynaptic; (b) Synaptic; (c) Post synaptic. The presynaptic phase involves, (a) end resection, (b) binding of RPA and (c) loading of Rad51 filaments on to the DNA. End resection is a complex process that involves Exo1 (protein with exonuclease activity), Dna2, CtIP and BLM helicase. As described above the mediators facilitate the loading of Rad51 while removing the RPA from the sites of DNA damage. Rad51 has five paralogs in mammals Rad51B, Rad51C, Rad51D, XRCC2 and XRCC3 (Masson et al., 2001). All the paralogs of Rad51 have the ability to form filaments on the DNA but they do 
not have the recombinase activity possessed by Rad51. The presynaptic phase ends with the loading of Rad51 on to the DNA (Figure 1-9).

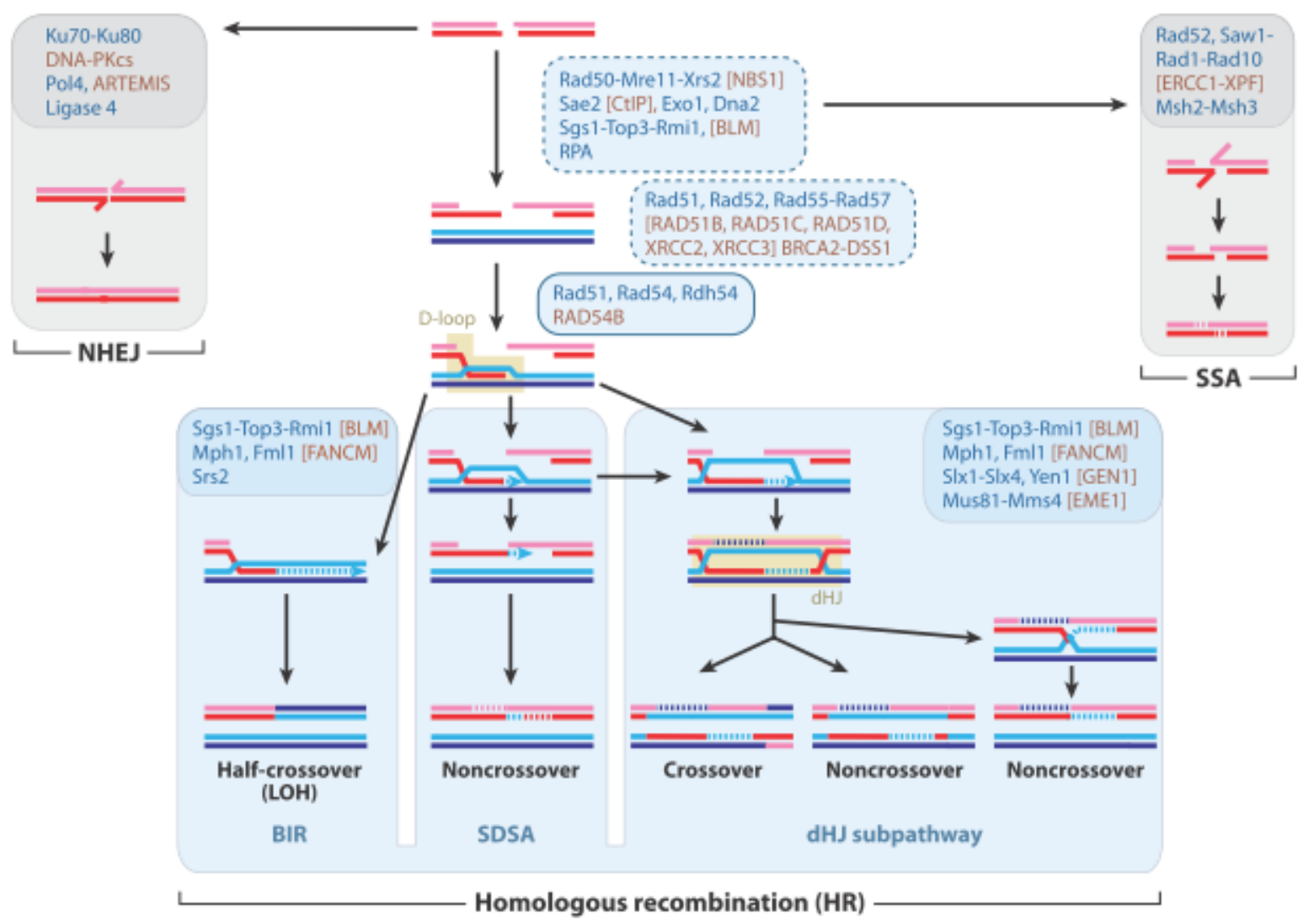

Figure 1.9 Mechanism of homologous recombination repair.

MRN complex recognizes DNA double strand breaks followed by end resection producing ssDNA bound by RPA. Rad51 is recruited at the sites of bound RPA followed by strand invasion and DNA synthesis. Figure modified from (Heyer et al., 2010)

During synapsis Rad51 starts the homology search; this process is aided by the mediator protein Rad54 (Mazin et al., 2010). Once the homologous region is found the 3' overhang is used to initiate DNA synthesis. The DNA synthesis in the D-loop (Figure 1.9) is completed by DNA polymerase $\eta$, but in its absence other polymerases have been speculated to take over this function (Sebesta et al., 2013). After the completion of synthesis, newly synthesized DNA strand is released by the sliding of the Holliday Junction (HJ) whose migration is aided by Rad54, BLM and other proteins, but the extent of their role is still unclear (Bugreev et al., 2006). 
Finally the 3' end of the released strand is ligated to give a repaired DNA. The processing of the released DNA depends on the extent of DNA synthesis, for example if the newly synthesized makes flap, i.e. an overhang, then specific endonucleases are employed to remove the excess nucleotides before filling the gaps and ligation (Kikuchi et al., 2005). Final DNA synthesis is performed by DNA polymerase $\delta$ or $\varepsilon$ (Maloisel et al., 2008). The end products obtained after homologous recombination depend on the resolution of the $\mathrm{HJ}$ giving either a crossover or a non-crossover product. As detailed in Figure 1.9, there are many more proteins and sub pathways that ultimately decide the fate of the products. Discussing all the sub pathways and the functions of proteins in details is beyond the scope of the present text.

\subsubsection{Non-homologous end joining}

Non-homologous end joining (NHEJ) is a DNA double strand break repair process that does not use a homologous template for the repair and consequently, it is more prone to errors. NHEJ bluntly joins the two ends and ligates them without the concern for the loss of information on the DNA during the process. Though, in most cases the information may not be lost but because of the nature of repair the chances are high. NHEJ is the preferred pathway for repairing the DNA double strand breaks in the G1 phase when the sister chromatids are not present (Sebesta et al., 2013). The advantage of this process is that it is quick and requires very little energy to complete the repair.

In its simplest form, NHEJ involves the binding of Ku70/80 heterodimer to the double strand breaks, followed by recruitment and activation of DNA-PKcs (Figure 1.10). This complex brings the two ends close together and the DNA ligase IV ligates the broken ends to complete the repair (Lieber, 2010). In more complex cases where the 3 ' end may contain a phosphate group or the sugar backbones may be damaged a more elaborate system is employed. For example, WRN protein using its exonuclease activity can remove damaged nucleotides; Artemis nuclease can cleave hairpin structures (Davis and Chen, 2013). 


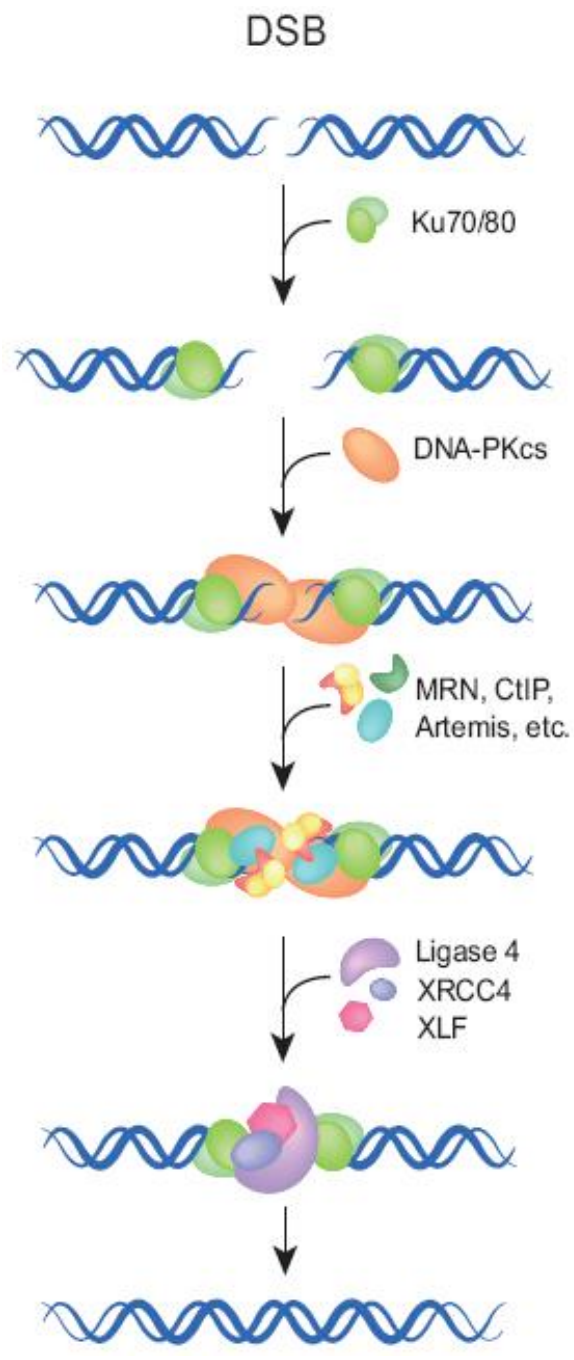

Figure 1.10 Mechanism of non-homologous end joining.

Ku70/80 heterodimer recognizes the DNA double strand breaks followed by recruitment of DNA-PKCS and this complex holds the DNA ends together DNA ligase IV ligates the DNA with help from XRCC4 and XLF. Figure modified from (Osolodkin et al., 2013).

\subsubsection{Interplay and regulation of repair pathways}

Both HRR and NHEJ perform the double strand break repair in mammalian cells and this adds an additional layer of complexity in cells to regulate the two pathways. Ideally, a cell would like to employ the error free HRR to maintain the integrity of the genome but, as described earlier this is not feasible in all cases.

One of the key regulators in this balancing act is CtIP, the human homolog of yeast Sae2 (Penkner et al., 2007). CtIP is phosphorylated at Ser327 and Thr847 in the S phase by Cdk2, the latter phosphorylation is required for ssDNA generation and RPA 
phosphorylation both of which are needed for HRR. Phosphorylation at Ser327 is required for the interaction with BRCA1 and this phosphorylation of CtIP is restricted to the S/G2 phase promoting the HRR (Yu and Chen, 2004). Furthermore, BRCA2 a protein that plays a critical role in the Rad51 filament formation is dephosphorylated in the S phase paving way for its interaction with Rad51, which also promotes HRR (Esashi et al., 2005). BRCA2 is phosphorylated at Ser3291 by cycA-Cdk2 in the M phase thus preventing its interaction with Rad51 and hence HRR.

Apart from the cell cycle regulators of HRR, BLM sumoylation on Lys317 and Lys331 increases the end resection thus favoring the HRR. Apart from the cell cycle regulations, checkpoint kinases Chk1 and Chk2 also influence the fate of HRR. Chk1 is majorly expressed in $S$ and $G 2$ phases of a cell cycle and is known to phosphorylate Rad51 at Thr309 facilitating latter's recruitment on to the chromatin, and as described earlier, Chk2 kinase phosphorylates the mediator Rad55 that facilitates loading of the Rad51 on the RPA coated DNA (Feijoo et al., 2001).

NHEJ is regulated by the DNA-PKcs autophosphorylation and ATM. DNA-PKcs is phosphorylated at a cluster of six residues that includes Thr2609, Ser2056 and Thr3950. It has been reported that in S phase, phosphorylation of the clusters Thr2609 and Ser2056 is reduced, down regulating NHEJ (Summers et al., 2011). The cell may use all of the above mentioned mechanisms to ensure that HRR stays active in S and $\mathrm{G} 2$ phases of the cell cycle while the NHEJ remains active in $\mathrm{G} 1$ phase (Figure 1-11). 


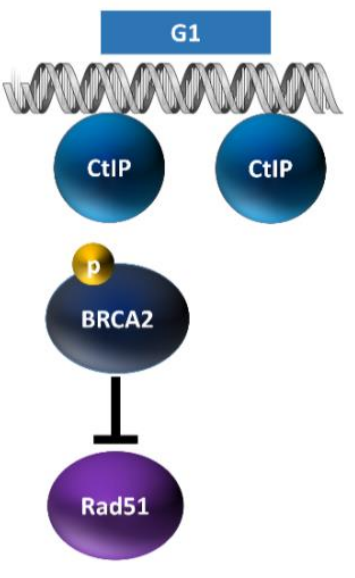

NHEJ>HR

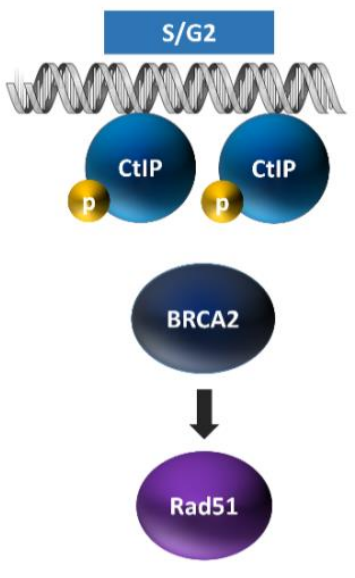

NHEJ<HR
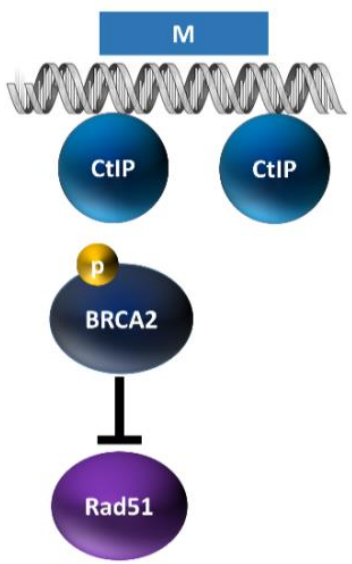

NHEJ>HR

Figure 1.11 Cell cycle dependence of HRR and NHEJ.

In the G1 phase, CtIP is present in its inactive dephosphorylated form while BRCA2 is phosphorylated preventing its interaction with Rad51 and this setup favors the NHEJ. In the $S$ phase, CtIP is phosphorylated by CDK2 making it active and BRCA2 is dephosphorylated allowing it to interact with Rad51, this setup favors the HRR. In the M phase the CtIP is dephosphorylated and BRCA2 is phosphorylated favoring NHE over HRR. Figure modified from (Ciccia and Elledge, 2010).

\subsubsection{DNA double strand break repair and cancer development}

Homologous recombination because of its function, as described earlier, is integral to guard the genome against DNA double strand breaks. Mutations in HRR lead to gene rearrangements that can pave way for cancer development and are described in many cancers. Mutations in BRCA1 and BRCA 2 are associated with breast cancer predisposition, while mutations in Rad54 and CtIP are observed in nonHodgkin's lymphoma. Rad51 B has been reported to be mutated in uterine leiomyoma (Jasin, 2002; Schoenmakers et al., 1999; Wong et al., 1998). Rad51 protein expression is reduced in breast cancer but so far it has not been directly implicated in the development of breast cancers.

There are contrasting reports on the involvement of NHEJ in cancer development, with some groups claiming Ku70 mutation increases the incidence of lymphomas while some argue otherwise (Burma et al., 2006). Till date no particular mutation in NHEJ has been associated with tumor development in humans; however, loss of 
artemis and DNA ligase IV have been associated with immunodeficiency (Simsek et al., 2011).

\subsection{Mismatch repair system}

As the name suggests, Mismatch repair (MMR) machinery rectifies the mismatches in the DNA. Apart from the base:base mismatches MMR also tackles the insertiondeletion loops (IDL). Base:base mismatches arise due to an occasional mistake in the proofreading by the DNA polymerase.

\subsubsection{Mechanism}

In E.coli, the mismatches are first recognized by the MutS homodimer which then recruits the MutL homodimer to the DNA (Jiricny, 2006). Subsequently, the formation of MutS, MutL and ATP complex activates MutH whose endonuclease activity is stimulated by the presence of aforementioned complex (Figure 1-12). The activated MutH nicks the newly synthesized strand, and UvrD, a helicase unwinds the nicked strand followed by exonucleolytic degradation. DNA polymerase III synthesizes new DNA strand followed by DNA ligase that seals the nick.

The mammalian system is more complex with many homologs and regulatory signaling (Pena-Diaz and Jiricny, 2012). Mammals have five homologs of MutS of which three participate in MMR namely, MSH2, MSH3 and MSH6. These proteins for heterodimers and the most abundant of them is MSH2-MSH6. The MSH2-MSH6 heterodimer is called as MutSa while the other major heterodimer MSH2-MSH3 is known as MutS $\beta$. In the mammals it is these two complexes that recognize the mismatches or the IDL and then recruit the MutL $\alpha$ (a heterodimer of MLH1 and PMS2). Replication factor C (RFC) is required for loading the PCNA but when the sliding clamp (MutSa) reaches the nicked end RFC is replaced with EXO1. EXO1 uses its exonuclease activity to degrade the DNA strand and Polठ synthesizes the new DNA strand. 


\subsubsection{Interplay in HRR}

MMR plays a critical role in HRR, by preventing DNA synthesis during strand invasion in regions with mismatches. This becomes especially important when the $\mathrm{HRR}$ is occurring between two divergent sequences. MMR can either reject the invading strand thus preventing HR or repair the mismatch before HRR can proceed (Pena-Diaz et al., 2012). In case of repair, the invading strand is repaired so as to attain proper base pairing with the template strand and this leads to change in the sequence of the repaired DNA strand. It has been recently shown that $\mathrm{hMSH} 2$ hMSH6 recognizes the mismatches in the D-loop and can reject the invading strand in case of divergent sequences (Honda et al., 2014).

\subsubsection{MMR and Colorectal cancers}

CRC cell lines can be broadly classified as Chromosomal instable (CIN) or Microsatellite instable (MSI) based on their MMR status. The cells with a proficient MMR status are CIN while the cells with deficient MMR are MSI. CIN contributes 7085\% (Worthley and Leggett, 2010) for the generation of CRC making it therefore a more interesting study. The cell lines SW480, SW620 used in this study fall under the category of CIN while the HCT 116 is MSI cell line.

Table 1.2 CRC cell lines used in the study and their p53 and MSI/CIN status MMR and DDR

\begin{tabular}{llll}
\hline Cell line & Type & p53 status & CIN/MSI \\
\hline SW480 & Colorectal & Mutant & CIN \\
SW620 & Colorectal & Mutant & CIN \\
SW837 & Colorectal & Mutant & CIN \\
HCT116 & Colorectal & Wild type & MSI \\
HCT116 p53-/- & Colorectal & Null & MSI \\
HT-29 & Colorectal & Mutant & MSS \\
HCT15 & Colorectal & Mutant & MSI \\
RKO & Colorectal & Wild type & MSI \\
LoVo & Colorectal & Wild type & MSI \\
Colo320 & Colorectal & Mutant & MSS \\
\hline
\end{tabular}


It is conceivable, that in the process of repairing the mismatches MMR may encounter replication fork stalls, as in the case of gemcitabine. The fork stalls lead to ssDNA which is a substrate for RPA which then activates the ATR pathway. Chk1, a substrate of ATR, upon activation can cause cell cycle arrest. Furthermore, it has been shown that MSH2 forms complexes with Chk2, Chk1 and ATR (Adamson et al., 2005).

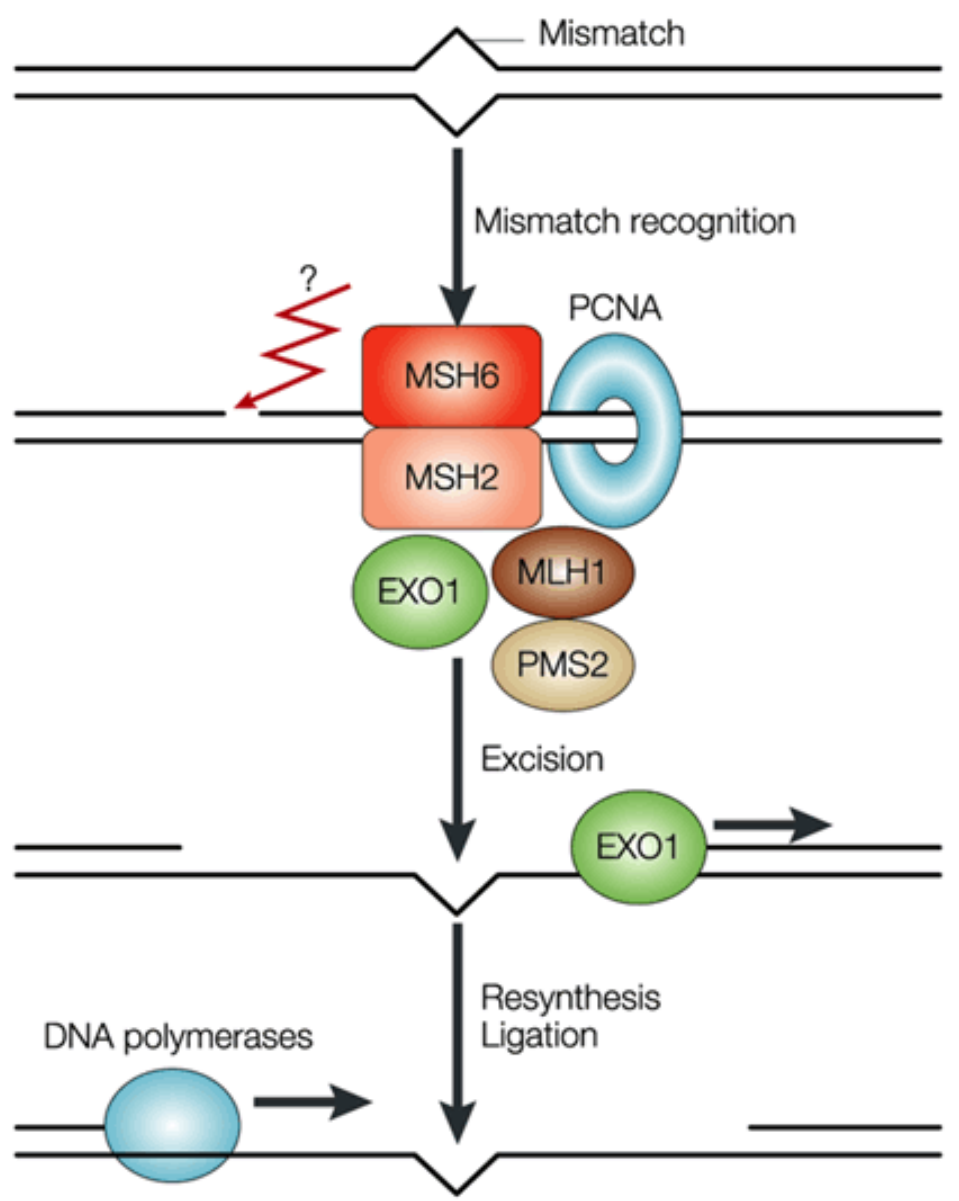

Figure 1.12 Mechanism of mismatch repair.

Mismatch repair system recognizes mismatches in DNA and then removes the lesions in the DNA followed by fresh DNA synthesis. MMR is a primary repair machinery that recognizes mismatches induced by 5-FU. Figure modified from (Pena-Diaz and Jiricny, 2012) 


\subsection{Scope of the thesis}

The major concern in the clinical treatment of CRC is the poor response rates of the current regimens in advanced colorectal tumors. Diagnosis of the tumors during stage I increase the response rates of 5-FU based therapies to over $90 \%$ whereas, the response rates fall to below $40 \%$ in the patients diagnosed in stage III and IV. Therefore, the challenge is to improve the response rates of the patients diagnosed in the late stages of the tumor and to find predictive biomarkers for tumors. As discussed earlier, HNPCC has been successfully used to predict the onset of CRC; however, a very small fraction of CRC's have germline mutations in HNPCC and most of the cases are due to spontaneous mutations leading to tumor formation. In this work, we aim to investigate the molecular mechanism behind the action of neoadjuvant therapy in context of DDR. We focus on 5-FU and NCS based therapy, and use SW480 cells, a CRC cell line as our main model. Apart from being CIN which enlarges the scope of our findings to most CRC types, SW480 cells are morphologically pliable and resistant to 5-FU. This makes them an apt choice for unraveling DDR in CRC. We also attempt to elucidate the molecular mechanism 5FU induced radiosensitization and the role of TS in 5-FU based regimens. Next, we compare the mechanisms and efficacy of gemcitabine in context of CRC. Our hope is that our studies will serve as a framework for devising better 5-FU based CRC therapies that exhibit improved response rates, especially in patients that develop tumor relapse. 


\section{Materials}

\subsection{Human cell culture}

Table 2.1 Human cell lines

\begin{tabular}{ll}
\hline Cell line & Origin \\
\hline SW480 & Colorectal cancer cell line; mutant p53;chromosomal instable \\
SW620 & Colorectal cancer cell line; mutant p53; chromosomal instable \\
HeLa & Cervical cancer cell line; no p53 expression \\
HCT116 & human colon carcinoma cell line \\
p53+/+ & \\
HCT116 p53-/- & p53-deficient human colon carcinoma cell line (Bunz, 1998) \\
\hline
\end{tabular}

Table 2.2 Media and reagents for eukaryotic cell culture

\begin{tabular}{ll}
\hline Reagent & Company \\
\hline Ciprofloxacin & Bayer \\
Dulbecco's Modified Eagle Medium (DMEM), powder & Gibco, Life Technologies \\
Fetal Calf Serum (FCS) & Gibco, Life Technologies \\
L-Glutamine & Gibco, Life Technologies \\
McCoy's Medium & Gibco, Life Technologies \\
PBS (tablets) & Gibco, Life Technologies \\
Penicillin/Streptomycin & Gibco, Life Technologies \\
Tetracyclin & Gibco, Life Technologies \\
Trypsin/EDTA & Gibco, Life Technologies \\
\hline
\end{tabular}

\begin{tabular}{lc}
\hline Dulbecco's Modified Eagle's Medium (DMEM) \\
\hline DMEM, powder & $10.0 \mathrm{~g} / \mathrm{l}$ \\
NaHCO3 & $3.7 \mathrm{~g} / \mathrm{l}$ \\
HEPES & $5.96 \mathrm{~g} / \mathrm{l}$ \\
\hline
\end{tabular}

dissolved in $\mathrm{H}_{2} \mathrm{O}$ 


\section{Dulbecco's Modified Eagle's Medium (DMEM) with supplements}

\section{DMEM}

FCS

$10 \%$

Penicillin/Streptomycin $50 \mathrm{U} / \mathrm{ml}$

L-Glutamine $\quad 200 \mu \mathrm{M}$

Ciprofloxacin $\quad 10 \mu \mathrm{g} / \mathrm{ml}$

dissolved in $\mathrm{H}_{2} \mathrm{O}$

\section{McCoy's Medium with supplements}

McCoy's medium

FCS

$10 \%$

Penicillin/Streptomycin

$50 \mathrm{U} / \mathrm{ml}$

L-Glutamine $200 \mu \mathrm{M}$

dissolved in $\mathrm{H}_{2} \mathrm{O}$

Chemotherapeutics and pharmacological inhibitors

\section{Table 2.3 Chemotherapeutics}

Name

5-Fluorouracil

Neocarzinostatin (NCS)

Gemcitabine
Company

Sigma-Aldrich, F6627

Sigma-Aldrich, \#N9162

Elli lilly, Gemzar 
Table 2.4 Inhibitors

\begin{tabular}{lll}
\hline Name & Target & Company \\
\hline MK2III & MK2 & Calbiochem, 475864 \\
Hydroxyurea & Rinonucleotide & Sigma, H8627 \\
& $\begin{array}{l}\text { reductase } \\
\text { Proteasome }\end{array}$ & Calbiochem, \#474791 \\
MG132 & Caspases & Sigma, \#V116-2mg \\
\hline
\end{tabular}

\subsection{Consumables}

Table 2.5 Consumables

\begin{tabular}{ll}
\hline Product & Company \\
\hline 96-well plates for flow cytometry & Becton Dickinson \\
96-well plates for microscopy, clear bottom & Becton Dickinson \\
96-well plates for microscopy, clear bottom & Corning \\
96-well plates for qPCR & 4 titude \\
96-well plates OptiplateTM 96 for luciferase & Perkin Elmer \\
assay & \\
Bacteria culture dishes & Sarstedt \\
Bacteria culture vials $(14 \mathrm{~cm})$ & Becton Dickinson \\
Cell culture dishes $(10 \mathrm{~cm}, 15 \mathrm{~cm})$ & Greiner \\
Cell culture plates $(6-$ well, $12-$ well) & Greiner \\
Cell scraper $(16 \mathrm{~cm}, 25 \mathrm{~cm})$ & Sarstedt \\
Cryo tubes Cryoline & Nunc, Thermo Scientific \\
Electroporation cuvette Gene Pulser & Bio-Rad Laboratories \\
Filter tips (10 $\mu l)$ & Starlab \\
Filter tips $(20 \mu l, 200 \mu l, 1,000 \mu l)$ & Sarstedt \\
Parafilm & Brand \\
Pipet tips (10 $\mu l, 20-200 \mu l, 1,000 \mu l)$ & Greiner \\
Pipet tips for screen $(50 \mu l, 200 \mu l)$ & Beckman Coulter \\
Protran nitrocellulose transfer membrane & Whatman \\
\hline
\end{tabular}




\begin{tabular}{ll}
\hline Reaction tube $(0.2 \mathrm{ml})$ & Sarstedt \\
Reaction tube $(0.5 \mathrm{ml}, 1.5 \mathrm{ml}, 2.0 \mathrm{ml})$ & Eppendorf \\
Reaction tube $(15 \mathrm{ml}, 50 \mathrm{ml})$ & Greiner \\
Reservoir & Beckman Coulter \\
Reservoir (divided by length) & Beckman Coulter \\
Safe-lock reaction tube $(1.5 \mathrm{ml})$ & Eppendorf \\
Sealing foil for 96 -well plate & Becton Dickinson \\
Sterile filter & Millipore, Merck \\
Syringe & Henke-Sass \\
Syringe cannula (different sizes) & B.Braun \\
Transparent sealing foil for $96-$ well plate & 4 titude \\
Whatman paper & Whatman \\
\hline
\end{tabular}

\subsection{Technical devices}

Table 2.6 Technical devices

\begin{tabular}{|c|c|}
\hline Device & Company \\
\hline Automated Cell Counter Countess ${ }^{\circledR}$ & Invitrogen, Life Technologies \\
\hline $\begin{array}{l}\text { Biomek } 2000 \text { Laboratory Automation } \\
\text { Workstation }\end{array}$ & Beckman Coulter \\
\hline Blotting chamber & Biozym \\
\hline $\begin{array}{l}\text { Cell counting chamber Neubauer } \\
\text { improved }\end{array}$ & Brand \\
\hline Centrifuge 5415R & Eppendorf \\
\hline Centrifuge 5810R & Eppendorf \\
\hline Centrifuge Megafuge 1.0R & Heraeus, Thermo Scientific \\
\hline $\begin{array}{l}\text { Chemiluminescence imager Chemocam } \\
\text { HR } 163200\end{array}$ & Intas Science Imaging Instruments \\
\hline Cytometer Celigo & Cyntellect \\
\hline DNA gel chamber & Biotech Service Blu \\
\hline Electrophoresis system for SDS-PAGE & Amersham Biosciences, GE Healthcare \\
\hline
\end{tabular}




\begin{tabular}{|c|c|}
\hline Electroporator GenePulser II & Bio-Rad Laboratories \\
\hline FACS machine EasyCyte plus & Guava Technologies, Millipore \\
\hline Foil swelding machine Vacupack plus & Krups \\
\hline Freezer $-20^{\circ} \mathrm{C}$ & Liebherr \\
\hline Freezer $-80^{\circ} \mathrm{C}$ & Heraeus, Thermo Scientific \\
\hline Heating Block & Grant Instruments \\
\hline Heating Block HLC & HLC Biotech \\
\hline Ice-machine B100 & Ziegra \\
\hline Incubator for bacteria & Memmert \\
\hline Incubator for bacteria Minitron & Infors HT \\
\hline Incubator for cell culture Hera Cell 150 & Heraeus, Thermo Scientific \\
\hline Laminar flow cabinet Hera Safe & Heraeus, Thermo Scientific \\
\hline Liquid nitrogen tank LS 4800 & Taylor-Wharton \\
\hline Luminometer DLReady ${ }^{\text {TM }}$ Centro LB 960 & Bertold Technologies \\
\hline Magnetic stirrer MR3001 & Heidolph \\
\hline Microscope Axovert 40C & Zeiss \\
\hline \multicolumn{2}{|l|}{ Microscope Axioscope 2 Plus } \\
\hline Microscope, automated Pathway 855 & Becton Dickinson \\
\hline Microwave & Cinex \\
\hline Mini Centrifuge MCF-2360 & LMS \\
\hline PCR machine for qPCR CFX96, C1000 & Bio-Rad Laboratories \\
\hline PCR machine Primus 25 advanced & Peqlab \\
\hline pH-meter WTW-720 & WTW \\
\hline Pipet Multipette & Eppendorf \\
\hline Pipet, electric Portable-XP & Drummond \\
\hline $\begin{array}{l}\text { Pipets Eppendorf Research Series } 2100 \\
(0.1-2.5 \mu \mathrm{L} ; \quad 0.5-10 \mu \mathrm{L} ; 10-100 \mu \mathrm{L} ; 100- \\
1000 \mu \mathrm{L})\end{array}$ & Eppendorf \\
\hline Pipette, multichannel Research Plus & Eppendorf \\
\hline Power supply unit Powerpack P25T & Biometra \\
\hline Refrigerator $4^{\circ} \mathrm{C}$ & Liebherr \\
\hline
\end{tabular}




\begin{tabular}{ll}
\hline Roller RM5 V-30 & CAT \\
Rotating wheel Test-tube rotator 34528 & Snijders \\
Rotator PTR 300 & Grant Instruments \\
Scales Acculab ALC-6100.1 & Sartorius \\
Scales LE623S & Sartorius \\
Scanner CanoScan 8600F & Canon \\
Sequencer, automated ABI 3100 & Applied Biosystems, Life Technologies \\
Shaker PROMAX 2020 & Heidolph \\
Sonication device Bioruptor & Diagenode \\
Spectrophotometer NanoDrop ND-1000 & PeqLab \\
Thermomixer comfort & Eppendorf \\
UV-transilluminator Intas UV system Gel & Intas Science Imaging Instruments \\
Jet Imager & \\
Vacuum pump & IBS Integra Biosciences \\
Vortex genie 2 & Scientific Industries \\
Water bath TW 20 & Julabo Labortechnik \\
\hline
\end{tabular}

\subsection{Chemicals and reagents}

Table 2.7 Chemicals and reagents

\begin{tabular}{ll}
\hline Substance & Company \\
\hline Acetic acid & Roth \\
Acrylamide/bisacrylamide (A/BA) & Roth \\
Adenosin triphosphate (ATP) & Fermentas, Thermo Scientific \\
Agar & Sigma-Aldrich \\
Agarose & Roth \\
Albumin Fraction V (Bovine Serum Albumine, & Roth \\
BSA) & \\
Ammonium persulfate (APS) & Roth \\
Ammonium sulfate ((NH4)2SO4) & Roth \\
Ampicillin & AppliChem \\
\hline
\end{tabular}




\begin{tabular}{ll}
\hline Aprotinin & AppliChem \\
Bromophenol blue & Sigma-Aldrich \\
Calcium chloride dihydrate $\left(\mathrm{CaCl}_{2} \times \mathrm{H}_{2} \mathrm{O}\right)$ & Roth \\
Chloroform & Roth \\
Complete Mini, EDTA-free Protease Inhibitor & Roche \\
Mix & \\
Coelenterazine & Promega \\
Coenzyme A sodium salt hydrate & Sigmal-Aldrich \\
Dimethyl sulfoxide (DMSO) & AppliChem \\
Dithiotreitol (DTT) & Sigma-Aldrich \\
D-Luciferin & ICN \\
DNA ladder GeneRuler & Fermentas, Thermo Scientific \\
Deoxyribonucleotide triphosphates (dNTPs) & Bio-Budget \\
Deoxyribonucleotide triphosphates (dNTPs) in & Primetech \\
single tubes & \\
Dipotassium phosphate (K2HPO4) & Roth \\
Dithiothreitol (DTT) & Roth \\
DNA stain clear G (39804) & Serva \\
Ethanol 99.8\% & Roth \\
Ethanol 99.9\% p.a. (EtOH) & Merck \\
Ethylene diamine tetraacetatic acid (EDTA) & Roth \\
Ethylene glycol tetraacetic acid (EGTA) & Roth \\
Fetal calf serum HyClone & Thermo Scientific \\
Formaldehyde, 37\% solution & Roth \\
Glycerol & Roth \\
Glycine & Roth \\
Glycogen blue & Amblied \\
Glycylglycine & AppliChem \\
Guava ICF Cleaning Solution & Millipore, Merck \\
HEPES & \\
Hi-Di Formamide & \\
& Roth \\
& \\
&
\end{tabular}




\begin{tabular}{|c|c|}
\hline Hoechst 33342 & Invitrogen, Life Technologies \\
\hline Hydrogen chloride $(\mathrm{HCl})$ & Roth \\
\hline Isoamyl alcohol & Roth \\
\hline Isopropanol & Th. Geyer \\
\hline Kanamycin sulfate & AppliChem \\
\hline Leupeptin Hemisulfat & AppliChem \\
\hline Lipofectamine $^{\mathrm{TM}} 2000$ (LF2000) & Invitrogen, Life Technologies \\
\hline Magnesium chloride $(\mathrm{MgCl} 2)$ for PCR & Fermentas, Thermo Scientific \\
\hline $\begin{array}{l}\text { Magnesium chloride hexahydrate }(\mathrm{MgCl} 2 \times \\
\left.6 \mathrm{H}_{2} \mathrm{O}\right)\end{array}$ & Roth \\
\hline Magnesium sulfate (MgSO4) & AppliChem \\
\hline Methanol >99\% (MetOH) & Roth \\
\hline N-ethylmaleimide (04260) & Fluka \\
\hline Nonidet P-40 substitute (NP-40) & Sigma Aldrich \\
\hline Nuclease free water & Ambion, Life Technologies \\
\hline Page Ruler ${ }^{\top M}$ Prestained Protein Ladder & Fermentas, Thermo Scientific \\
\hline Passive Lysis Buffer (E1941) & Promega \\
\hline Pefabloc SC protease inhibitor & Roth \\
\hline Pepstatin A & AppliChem \\
\hline Ponceau S & Roth \\
\hline Potassium chloride $(\mathrm{KCl})$ & Roth \\
\hline Potassium hydrogenphosphate (KH2PO4) & Roth \\
\hline Powdered milk & Roth \\
\hline Propidium iodide $(\mathrm{PI})$ & Sigma-Aldrich \\
\hline Protein A Sepharose (PAS) & Invitrogen, Life Technologies \\
\hline Protein G Sepharose (PGS) & GE Healthcare \\
\hline RNase inhibitor & Fermentas, Thermo Scientific \\
\hline Roti-Phenol & Roth \\
\hline Rotiphorese Gel 30 & Roth \\
\hline Sodium acetate (NaAc) & Roth \\
\hline Sodium azide $\left(\mathrm{NaN}_{3}\right)$ & AppliChem \\
\hline Sodium bicarbonate $\left(\mathrm{NaHCO}_{3}\right)$ & Roth \\
\hline
\end{tabular}




\begin{tabular}{|c|c|}
\hline Sodium chloride $(\mathrm{NaCl})$ & Roth \\
\hline Sodium deoxycholate & AppliChem \\
\hline Sodium dodecyl sulfate (SDS) & Roth \\
\hline $\begin{array}{l}\text { Sodium hydrogenphosphate heptahydrate } \\
\left(\mathrm{Na}_{2} \mathrm{HPO}_{4} \times 7 \mathrm{H}_{2} \mathrm{O}\right)\end{array}$ & Roth \\
\hline Sodium hydroxide $(\mathrm{NaOH})$ & Sigma-Aldrich \\
\hline Sucrose & Sigma-Aldrich \\
\hline SYBR Green & Invitrogen, Life Technologies \\
\hline Tetracycline & Sigma-Aldrich \\
\hline Tetramethylethylenediamine (TEMED) & Roth \\
\hline Thymidine & Sigma-Aldrich \\
\hline Trasylol & Bayer, Leverkusen \\
\hline Trehalose & Sigma-Aldrich \\
\hline TRIS & Tris(hydroxymethyl)aminomethane \\
\hline Trisamine (Tris) & Roth \\
\hline Triton X-100 & Applichem \\
\hline Trizol & Invitrogen, Life Technologies \\
\hline Tween 20 & Applichem \\
\hline Yeast extract & Sigma-Aldrich \\
\hline$\beta$-Mercaptoethanol & Roth \\
\hline
\end{tabular}

\subsection{Buffers and Solutions}

\begin{tabular}{ll}
\hline \multicolumn{2}{l}{ RIPA lysis buffer, $\mathbf{p H} 7.5$} \\
\hline Triton X-100 & $1.0 \%$ \\
Sodium & $1.0 \%$ \\
deoxycholate & \\
SDS & $0.1 \%$ \\
$\mathrm{NaCl}$ & $150 \mathrm{mM}$ \\
EDTA & $10 \mathrm{mM}$ \\
Tris- $\mathrm{HCl}, \mathrm{pH} 7.5$ & $20 \mathrm{mM}$ \\
\hline
\end{tabular}

\section{SDS running buffer}

\begin{tabular}{ll}
\hline Tris & $25.0 \mathrm{mM}$
\end{tabular}

Glycin

$86.1 \mathrm{mM}$

SDS

$3.5 \mathrm{mM}$

dissolved in $\mathrm{H}_{2} \mathrm{O}$ 


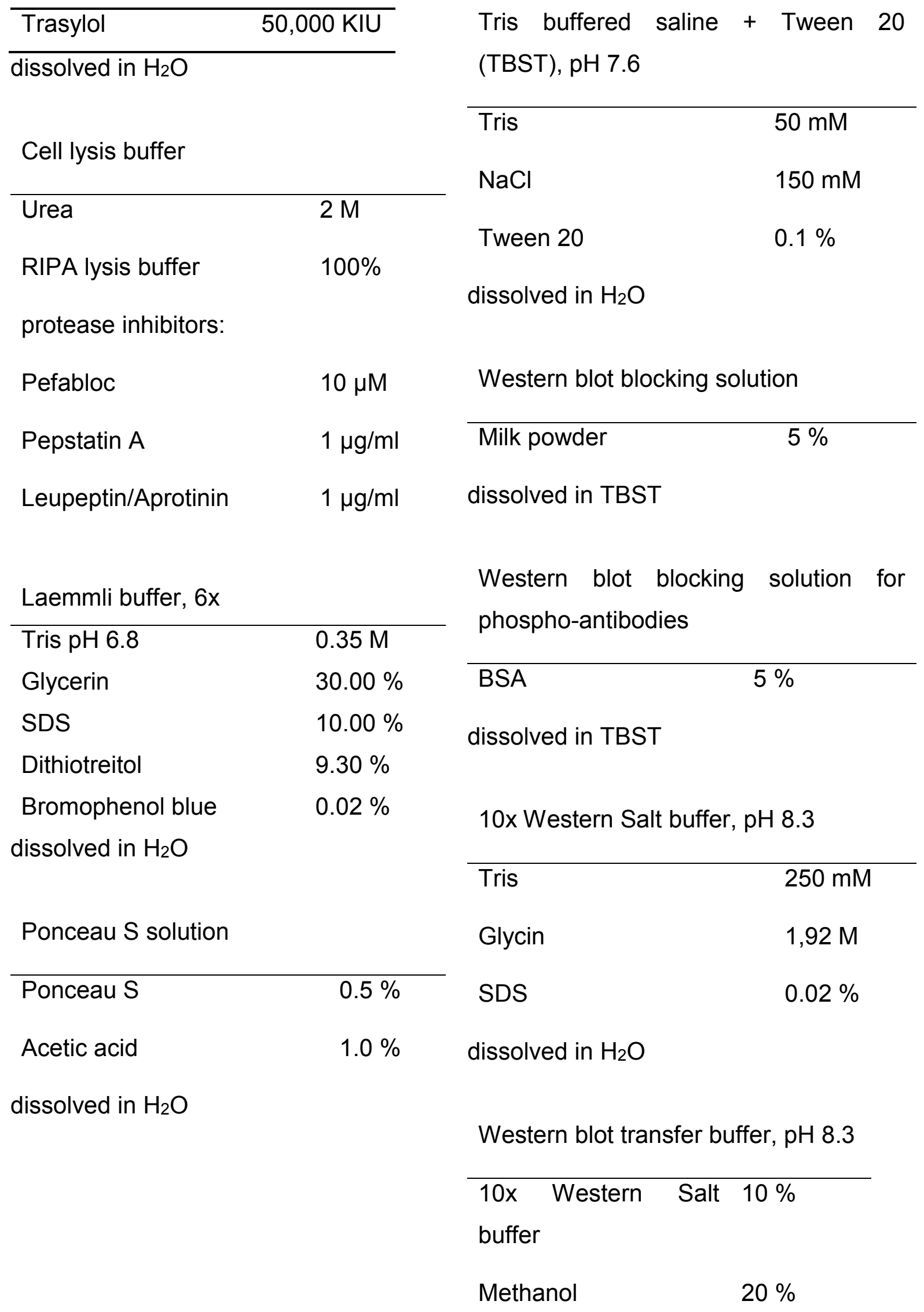


10x Phosphate buffered saline dissolved in $\mathrm{H}_{2} \mathrm{O}$ (PBS), pH 7.5

\begin{tabular}{ll}
\hline $\mathrm{NaCl}$ & $240.0 \mathrm{mM}$ \\
$\mathrm{KCl}$ & $2.7 \mathrm{mM}$ \\
$\mathrm{Na}_{2} \mathrm{HPO}_{4} \times 7 \mathrm{H}_{2} \mathrm{O}$ & $8.1 \mathrm{mM}$ \\
$\mathrm{KH}_{2} \mathrm{PO}_{4}$ & $1.5 \mathrm{mM}$ \\
dissolved in $\mathrm{H}_{2} \mathrm{O}$ &
\end{tabular}

DNA gel loading buffer, $6 x$

\begin{tabular}{ll}
\hline Sucrose & $40 \%$ \\
Glycerin & $10 \%$ \\
Bromophenol blue & $0.25 \%$ \\
dissolved in $\mathrm{H}_{2} \mathrm{O}$ &
\end{tabular}

TAE buffer

\begin{tabular}{ll}
\hline Tris & $40 \mathrm{mM}$ \\
Acetic acid & $20 \mathrm{mM}$ \\
EDTA & $2 \mathrm{mM}$
\end{tabular}

dissolved in $\mathrm{H}_{2} \mathrm{O}$

IF blocking solution

\begin{tabular}{ll}
\hline FCS & $5 \%$
\end{tabular}
Triton X-100
$0.1 \%$

dissolved in PBS 


\subsection{Enzymes and buffers}

Table 2.8 Enzymes and buffers

\begin{tabular}{|c|c|}
\hline Reagent & Company \\
\hline Buffer for HindlII & Fermentas, Thermo Scientific \\
\hline Buffer for M-MuLV RT, 10x & New England Biolabs (NEB) \\
\hline Buffer for Taq $\left(\mathrm{KCl}+,-\mathrm{MgCl}_{2}\right), 10 \mathrm{x}$ & Fermentas, Thermo Scientific \\
\hline Calf Intestine Alkaline Phosphatase & Fermentas, Thermo Scientific \\
\hline Cloned Pfu reaction buffer, 10x & Stratagene \\
\hline Kpnl & Fermentas, Thermo Scientific \\
\hline M-MuLV Reverse transcriptase (RT) & New England Biolabs (NEB) \\
\hline Pfu Turbo DNA polymerase $(2.5 \mathrm{U} / \mu \mathrm{l})$ & Stratagene \\
\hline RNase A (1 mg/ml) & Qiagen, Venlo, Netherlands \\
\hline T4 ligase (200 U/ul) & Fermentas, Thermo Scientific \\
\hline T4 ligase buffer & Fermentas, Thermo Scientific \\
\hline Taq DNA polymerase (Taq) & Fermentas, Thermo Scientific \\
\hline Taq DNA polymerase (Taq) for qPCR & Primetech \\
\hline Xbal & Fermentas, Thermo Scientific \\
\hline
\end{tabular}

\subsection{Kits}

Table 2.9 Kits

\begin{tabular}{ll}
\hline $\begin{array}{l}\text { Name } \\
\text { Guava Check Kit }\end{array}$ & $\begin{array}{l}\text { Company } \\
\text { Immobilon Western HRP Substrate }\end{array}$ \\
$\begin{array}{l}\text { Solution } \\
\text { Invisorb Spin Plasmid Mini Kit Two }\end{array}$ & Peroxide, Merck \\
Pierce ${ }^{\circledR}$ BCA Protein Assay Kit & Invitec, Stratec \\
PureYield ${ }^{\text {TM }}$ Plasmid Midiprep System & Thermo Scientific \\
QIAquick PCR Purification Kit (250) & Promega \\
SuperSignal West Femto Maximum Sensitivity & Qiagen \\
\hline
\end{tabular}




\subsection{Oligonucleotides}

Table 2.10 Small interfering RNAs from Ambion/Life Technologies

\begin{tabular}{|c|c|c|}
\hline Target & Sequence & siRNA ID \\
\hline Chk1 & $\begin{array}{l}\text { sense: 5'-GCAACAGUAUUUCGGUAUAtt-3' } \\
\text { antisense: 5'-UAUACCGAAAUACUGUUGCca- } \\
\text { 3' }\end{array}$ & $\begin{array}{l}\text { AM51331 } \\
\text { (silencer) }\end{array}$ \\
\hline $\begin{array}{l}\text { control siRNA } \\
\text { scrambled No. } 1\end{array}$ & undisclosed & $\begin{array}{l}4390844 \\
\text { (silencer } \\
\text { select) }\end{array}$ \\
\hline $\begin{array}{l}\text { control siRNA } \\
\text { scrambled No. } 2\end{array}$ & undisclosed & $\begin{array}{l}4390847 \\
\text { (silencer } \\
\text { select) }\end{array}$ \\
\hline Rad51-1 & $\begin{array}{l}\text { sense: 5'-GGUAGAAUCUAGGUAUGCAtt-3' } \\
\text { antisense: 5'-UGCAUACCUAGAUUCUACCat- } \\
\text { 3' }\end{array}$ & s11734 \\
\hline Rad51-2 & $\begin{array}{l}\text { sense: 5'-CAGUGGUAAUCACUAAUCAtt-3' } \\
\text { antisense: 5'-UGAUUAGUGAUUACCACUGct- } \\
\text { 3' }\end{array}$ & S11735 \\
\hline MK2 & $\begin{array}{l}\text { sense: 5‘-GGAUCAUGCAAUCAACAAAtt-3’' } \\
\text { sense: 5‘-UUUGUUGAUUGCAUGAUCCaa-3’ }\end{array}$ & S569 \\
\hline RRM2\#1 & $\begin{array}{l}\text { sense: 5-GCCUCACAUUUUCUAAUGAtt-3' } \\
\text { antisense: } \\
\text { UCAUUAGAAAAUGUGAGGCca-3' }\end{array}$ & S12362 \\
\hline RRM2\#2 & sense: 5-CCAUUUGACUUUAUGGAGAtt-3' & S12361 \\
\hline
\end{tabular}


antisense:5'-UCUCCAUAAAGUCAAAUGGgt-

3'

RRM2\#3

sense: 5-GCAGAUGUAUAAGAAGGCtt-3'

$\mathrm{S} 12360$

antisense:5‘-UGCCUUCUUAUACAUCUGCca-

3'

Table 2.11 Primers

\begin{tabular}{|c|c|c|}
\hline Name & Sequence & Application \\
\hline $\begin{array}{l}\text { CMV promoter } \\
\text { forward }\end{array}$ & 5'-CGC AAA TGG GCG GTA GGC GTG-3' & $\begin{array}{l}\text { sequencing } \\
\text { of plasmids }\end{array}$ \\
\hline anchored oligo-dT & $5^{\prime}-\mathrm{dT} 23 \mathrm{VN}-3^{\prime}$ & RT-PCR \\
\hline random nonamer & 5'-NNNNNNNNN-3' & RT-PCR \\
\hline GAPDH forward & $\begin{array}{l}\text { 5'-TGA AGG TCG GAG TCA ACG GAT TTG } \\
\text { GT-3' }\end{array}$ & qPCR \\
\hline GAPDH reverse & $\begin{array}{l}\text { 5'-GCA GAG ATG ATG ACC CTT TTG GCT } \\
\text { C-3' }\end{array}$ & \\
\hline Chk1 forward & 5'-TGG CGG GAA AAG CGC TGCA T-3‘ & qPCR \\
\hline Chk1 reverse & 5'-TGG ACA GTC TAC GGC ACG CT-3، & \\
\hline
\end{tabular}

\subsection{Plasmids}

Table 2.12 Plasmids

\begin{tabular}{ll}
\hline Name & Description \\
pcDNA3-GFP & expression vector for green fluorescent protein (GFP) \\
DRGFP & Plasmid for reporter assay for HRR \\
NHEJ plasmid & Plasmid for reporter assay for NHEJ \\
DsRed & Invitrogen \\
\hline
\end{tabular}




\subsection{Antibodies}

Table 2.13 Primary antibodies for Western blot

\begin{tabular}{|c|c|c|c|c|c|}
\hline Antibody & Source & Company & Cat. No. & Application & Dilution \\
\hline$\beta$-Actin & mouse & Abcam & ab6276-100 & WB & $50,000 x$ \\
\hline Caspase 3 & rabbit & Cell Signaling & 9662 & WB & $1000 x$ \\
\hline Chk1 (2G1D5) & mouse & Cell Signaling & 2360 & WB & $1000 x$ \\
\hline Chk2 & mouse & Calbiochem & CC44 & WB & $300 x$ \\
\hline cleaved Caspase 3 & rabbit & Cell Signaling & 9664 & WB & $800 x$ \\
\hline p53 (DO1) & mouse & Santa Cruz & sc-126 & WB & $1000 x$ \\
\hline PARP & mouse & Calbiochem & AM30 & WB & $1000 x$ \\
\hline $\begin{array}{l}\text { phospho-Chk1 } \\
\text { (Ser317) }\end{array}$ & rabbit & Cell Signaling & 2344 & WB & $1000 x$ \\
\hline phospho-Chk2 (Thr68) & rabbit & Cell Signaling & 2661 & WB & $1000 x$ \\
\hline $\begin{array}{l}\text { phospho-H2AX } \\
\text { (Ser319) }\end{array}$ & mouse & Millipore & $05-636$ & WB & $2000 x$ \\
\hline Rad51 & rabbit & Santa Cruz & Sc-8349 & WB & $1000 x$ \\
\hline Rad51 & mouse & Abcam & $a b 213$ & WB & $1000 x$ \\
\hline RPA1 & Mouse & Calbiochem & \#NA13 & WB & $1000 x$ \\
\hline RPA2 & Mouse & Calbiochem & \#NA18 & WB & $1000 x$ \\
\hline Ku70 & Mouse & Santa Cruz & Sc5309 & WB & $1000 x$ \\
\hline
\end{tabular}


All primary antibodies were diluted in Western blot blocking solution with $5 \%$ milk powder. Antibodies against phospho-Chk1 and phospho-Chk2 were diluted in Western blot blocking solution with $5 \%$ BSA.

Table 2.14 Primary antibodies for immunofluorescence

\begin{tabular}{lllll} 
Antibody & Source & Company & Cat. No. & Dilution \\
\hline 53BP1 & rabbit & Santa Cruz & sc-22760 & $300 x$ \\
\hline H2AX pS139 & mouse & Millipore & 05-636 & $1500 x$ \\
\hline H2AXpS139 & Rabbit & Millipore & 07-164 & $1000 x$ \\
\hline RPA1 & Mouse & Calbiochem & \#NA13 & 500x \\
\hline RPA2 & Mouse & Calbiochem & \#NA18 & $500 x$ \\
\hline Rad51 & rabbit & Santa Cruz & Sc-8349 & $100 x$ \\
\hline Rad51 & mouse & Abcam & ab213 & $100 x$
\end{tabular}

All primary antibodies were diluted in IF blocking solution with $5 \%$ FCS.

Table 2.15 Secondary antibodies for Western blot

Antibody Company Cat. No. Dilution

\begin{tabular}{lllll}
\hline HRP-coupled & AffiniPure & Jackson Immunoresearch & $711-036-152$ & $10,000 x$
\end{tabular}

$F\left(a b^{\prime}\right) 2$ fragment, anti-mouse

$\lg \mathrm{G}(\mathrm{H}+\mathrm{L})$

\begin{tabular}{lllll}
\hline HRP-coupled & AffiniPure & Jackson, Immunoresearch & $715-036-150$ & $10,000 x$
\end{tabular}

$F(a b ') 2$ fragment, anti-rabbit

$\lg \mathrm{G}(\mathrm{H}+\mathrm{L})$

\begin{tabular}{lllll}
\hline HRP-coupled & AffiniPure & Jackson, Immunoresearch & $705-036-147$ & $10,000 x$
\end{tabular}

$F\left(a b^{\prime}\right) 2$ fragment, anti-goat $\lg G$

$(\mathrm{H}+\mathrm{L})$

All secondary antibodies were diluted in Western blot blocking solution with $5 \%$ milk powder. 
Table 2.16 Secondary antibodies for immunofluorescence

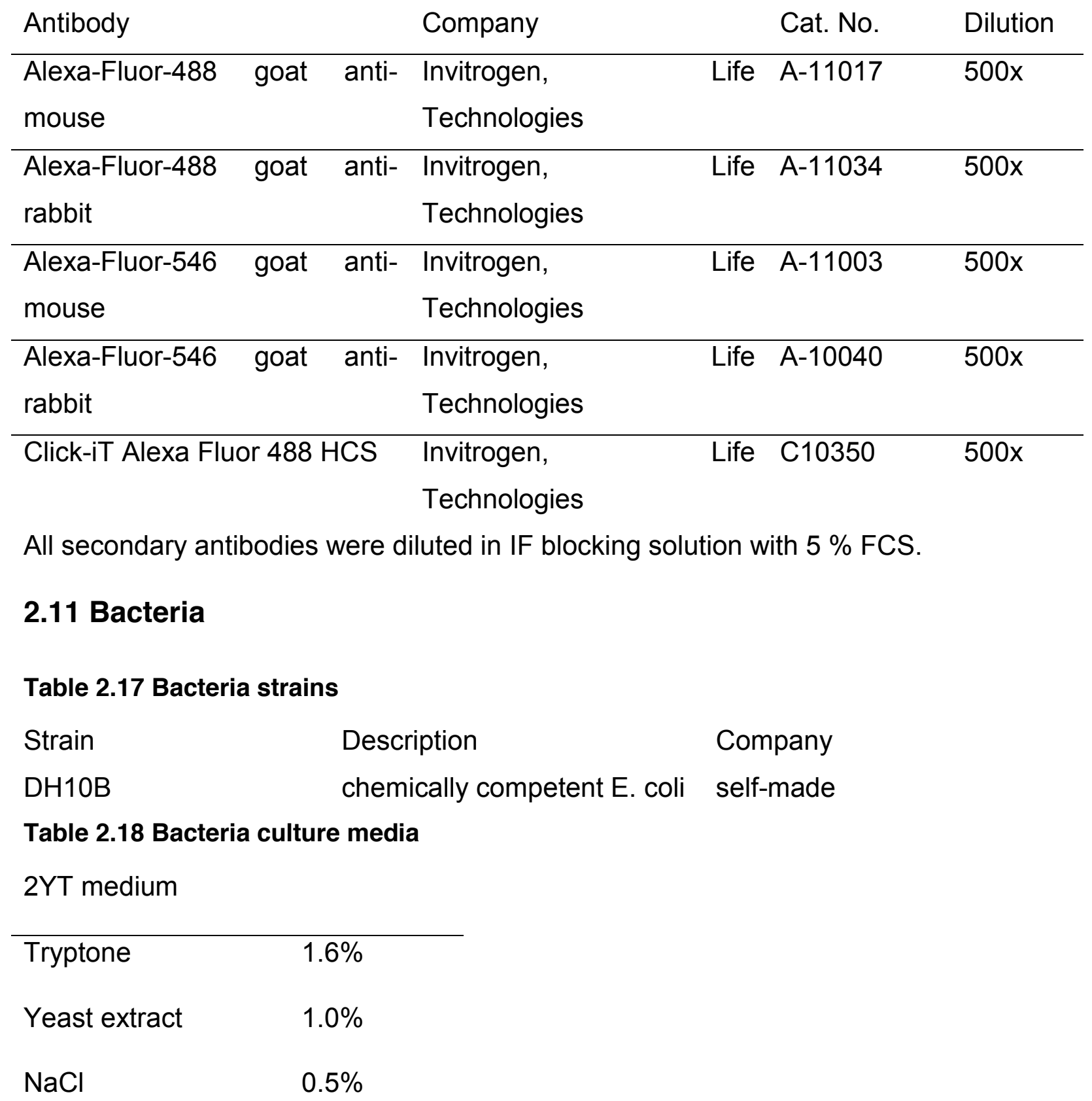




\subsection{Software and databases}

Table 2.19 Software

\begin{tabular}{|c|c|}
\hline Name & Company \\
\hline Adobe Photoshop CS5 & Adobe Systems, San Jose, CA, United States \\
\hline AttoVision (BD Pathway) & Becton Dickinson \\
\hline BioEdit v7.0.5 & $\begin{array}{l}\text { Tom Hall, Ibis Biosciences, Carlsbad, CA, } \\
\text { United States }\end{array}$ \\
\hline Celigo Software & Cyntellect \\
\hline $\begin{array}{l}\text { CFX Manager Software (qPCR } \\
\text { cycler) }\end{array}$ & Bio-Rad \\
\hline Excel & Microsoft \\
\hline FociCounter & Open source \\
\hline Guava Express Software & Millipore, Merck \\
\hline Intas ChemoStar Imager & Intas Science Imaging Instruments \\
\hline ModFit LT & $\begin{array}{l}\text { Verity Software House, Topsham, ME, United } \\
\text { States }\end{array}$ \\
\hline NanoDrop Software & Peqlab \\
\hline UV imager software & Intas Science Imaging Instruments \\
\hline MS word & Microsoft \\
\hline Inkscape & Open source GNU \\
\hline
\end{tabular}




\section{Methods}

\subsection{Cell biology}

\subsubsection{Thawing cell lines}

Human tumor cell lines preserved in liquid nitrogen for long term storage were thawed at $37^{\circ} \mathrm{C}$ and immediately transferred to a pre warmed $10 \mathrm{ml}$ cell culture medium in a falcon tube and centrifuged at $0.8 \times \mathrm{g}$ for $5 \mathrm{~m}$. Supernatant was removed in a sterile cell culture hood and the pellet was re-suspended in fresh cell culture media. The cells were cultured in a $10 \mathrm{~cm}^{2}$ petri dish and incubated at $37^{\circ} \mathrm{C} / 5 \% \mathrm{CO}_{2}$ till they reached a confluency of $70-80 \%$.

\subsubsection{Passaging human tumor cell lines}

Human tumor cell lines were maintained in culture by regularly passaging them in appropriate culture media and growth conditions. Passaging cells is essential as failure to do so leads to reduced mitotic index and eventually cell death. Cultured cells upon attaining a confluency of $70-80 \%$ were passaged. Media was removed using a glass Pasteur pipette in a sterile cell culture hood and cells were washed with $5 \mathrm{ml}$ of PBS. The cells were incubated with trypsin in the incubator $\left(37^{\circ} \mathrm{C} / 5 \%\right.$ $\mathrm{CO}_{2}$ ) till they detached from the surface of the plate. Equal volume of fresh culture media was added to the trypsinised cells to prevent further action of trypsin. The cells were collected in a $15 \mathrm{ml}$ falcon tube and centrifuged at $0.8 \times \mathrm{g}$ for $5 \mathrm{~m}$, supernatant was removed using a glass Pasteur pipette and the pellet was resuspended in fresh culture media. New passages were made by adding the cells to fresh complete cell culture media in appropriate dilutions. The cell culture plates were incubated at $37^{\circ} \mathrm{C} / 5 \% \mathrm{CO}_{2}$ till they reached a confluency of $70-80 \%$.

\begin{tabular}{lll}
\hline Cell line & Cell culture media & Passaging ratio \\
\hline SW480 & RPMI 1640 & $1: 10$ \\
SW620 & RPMI 1640 & $1: 10$ \\
HeLa & DMEM & $1: 8$ \\
HCT116 & McCoy's 5a & $1: 10$ \\
HT29 & McCoy's 5a & $1: 10$ \\
\hline
\end{tabular}




\subsubsection{Counting and seeding cells for experiments}

Cells after trypsinisation were resuspended in fresh culture media and collected in a $15 \mathrm{ml}$ falcon tube and centrifuged at $0.8 \times \mathrm{g}$ for $5 \mathrm{~m}$. The supernatant was discarded and the pellet was resuspended in fresh culture media. $10 \mu \mathrm{l}$ of the suspension was added in the Neubauer chamber and the cells counted as per the instructions of the manufacturer. The resuspended cells were diluted in fresh culture media to obtain the required cell count.

\begin{tabular}{lll}
\hline Plate type & Volume used & Cells seeded \\
\hline 6 well & $2 \mathrm{ml}$ & 100,000 \\
12 well & $1 \mathrm{ml}$ & 50,000 \\
96 well & $100 \mu \mathrm{l}$ & 8000 \\
\hline
\end{tabular}

\subsubsection{Treatment of cells with chemotherapeutics}

Chemotherapeutics were dissolved in water/DMSO to attain a requisite stock concentration as prescribed by the manufacturer. The stock chemotherapeutics were dissolved in cell culture media before the treatment of the cells. The solubility, stock concentrations and working concentrations of the chemotherapeutics is listed below-

\begin{tabular}{lllll}
\hline Compound & Solubility & $\begin{array}{l}\text { Stock } \\
\text { concentration }\end{array}$ & $\begin{array}{l}\text { Working } \\
\text { concentration }\end{array}$ & Storage \\
\hline 5-FU & DMSO & $5 \mathrm{mM}$ & $5 \mu \mathrm{M}-500 \mu \mathrm{M}$ & $-20^{\circ} \mathrm{C}$ \\
Gemcitabine & Water & $64 \mathrm{mM}$ & $5 \mathrm{nM}-200 \mathrm{nM}$ & $-20^{\circ} \mathrm{C}$ \\
B02 & DMSO & $10 \mathrm{mM}$ & $50 \mu \mathrm{M}$ & $-20^{\circ} \mathrm{C}$ \\
Raltitrexed & Water & $7 \mathrm{mM}$ & $7 \mathrm{nM}-700 \mu \mathrm{M}$ & $-20^{\circ} \mathrm{C}$ \\
NCS & Water & $1 \mathrm{mg} / \mathrm{ml}$ & $100 \mathrm{ng} / \mathrm{ml}$ & $+4^{\circ} \mathrm{C}$ \\
Hydroxyurea & Water & $3 \mathrm{M}$ & $1 \mathrm{mM}$ & $-20^{\circ} \mathrm{C}$ \\
UCN01 & DMSO & $10 \mathrm{mM}$ & $1 \mathrm{mM}$ & $-20^{\circ} \mathrm{C}$ \\
ZVAD & DMSO & $20 \mathrm{mM}$ & $20 \mu \mathrm{M}$ & $-20^{\circ} \mathrm{C}$ \\
\hline
\end{tabular}




\subsubsection{Reporter assay for assessing homologous recombination repair}

Homologous recombination repair is a DNA repair process employed by cells in the S/G2 phases of the cell cycle to repair double strand DNA breaks

\section{Principle of DRGFP assay}

The DRGFP plasmid contains a truncated GFP cassette on the N-terminal region, within which is located a restriction endonuclease site for the meganuclease, l-sce1. I-sce1 when co expressed along with the DRGFP plasmid, cleaves the plasmid producing a double strand break. If the break is repaired by non-homologous end joining pathway, functional GFP cassette is not produced and therefore the cell does not express GFP and can be confirmed by no fluorescence in flow cytometry. On the other hand, if the cells employ homologous recombination repair using the truncated GFP cassette near C-terminus, functional GFP cassette is restored. Therefore, the cells employing homologous recombination repair would express GFP which can be measured by flow cytometry (Figure 4.4b).

100,000 HeLa cells were seeded per well in a 6 well cell culture plate. The cells were allowed to grow till they reached a confluency of $\sim 80 \%$. Lipofectamine 2000 based plasmid transfections were performed with DRGFP, DsRed and I-sce1 plasmids, as prescribed by the manufacturer. $4 \mathrm{~h}$ after transfection media was changed from the wells, wells washed and treated with $5 \mu \mathrm{M} 5$-FU/DMSO for $24 \mathrm{~h}$. This was followed by $24 \mathrm{~h}$ of treatment with $100 \mathrm{ng} / \mathrm{ml} \mathrm{NCS}$. After the treatments, wells were washed with PBS and trypsinised. Following trypsinisation, cells were collected in a $2 \mathrm{ml}$ Eppendorf TM tube and centrifuged at $0.8 \times \mathrm{g}$ for $5 \mathrm{~m}$. The supernatant was removed and cell pellet was washed with PBS, centrifuged, suspended in PBS and the GFP positive cells were measured using Guava flow cytometer as per the instructions of the manufacturer.

\subsubsection{Reporter assay for assessing Non-homologous end joining}

The other repair pathway employed by a cell to repair the double strand breaks is the Non-homologous end joining (NHEJ). 
Principle

The NHEJ plasmid contains a GFP cassette, split into two non-functional sequences. Interspersed between these sequences is an exon $A D$, derived from mouse. The truncated GFP cassette at the $\mathrm{N}$-terminus contains sequence recognized and cleaved by HindIII. The splice donor and acceptor sites are represented in the Figure $4.4 \mathrm{~d}$. If the cell employs NHEJ to repair the DNA, transcript coding for functional GFP is transcribed. Therefore, cells employing NHEJ express GFP whereas the ones that do not employ NHEJ do not express GFP.

100,000 HeLa cells were seeded per well in a 6 well cell culture plate. The cells were allowed to grow till they reached a confluency of ca $80 \%$. Lipofectamine 2000 based plasmid transfections were performed with linearized NHEJ plasmid and DsRed as prescribed by the manufacturer. $4 \mathrm{~h}$ after transfection media was changed and the wells washed and treated with $5 \mu \mathrm{M} 5$-FU/DMSO for $24 \mathrm{~h}$. This was followed by $24 \mathrm{~h}$ of treatment with $100 \mathrm{ng} / \mathrm{ml}$ NCS. The wells were washed with PBS and trypsinised. Following trypsinisation, cells were collected in a $2 \mathrm{ml}$ Eppendorf TM tube and centrifuged at $0.8 \times \mathrm{g}$ for $5 \mathrm{~m}$. The supernatant was removed and the cell pellet was washed with PBS, centrifuged, resuspended in PBS and the GFP positive cells were measured using Guava flow cytometer as per the instructions of the manufacturer.

\subsubsection{GFP measurements for HRR and NHEJ assays}

After the respective incubations and treatments, the cells were trypsinised, centrifuged at $0.8 \times \mathrm{g}$, washed and resuspended in PBS. The samples were immediately measured for GFP expression using Guava easyCyte ${ }^{\mathrm{TM}}$ flow cytometer as per the instructions of the manufacturer. The GFP expression was normalized by dividing the GFP and DsRed positive cells with the total DsRed positive cells (internal normalization) followed by normalization to the DMSO control and plotted as a bar diagram.

\subsubsection{Transient siRNA transfections}

The length of the siRNA usually varies between 20-24 nucleotides. siRNA forms a complex with RISC and associated factors, binds to the target mRNA leading to its recognition and cleavage. 
In order to transfect cells with siRNA, master mixes for siRNA and LF2000 were prepared. For transient transfections in a 12 well plate, $0.3 \mu \mathrm{l}$ of siRNA (stock $50 \mu \mathrm{M}$ ) was dissolved in pre warmed cell culture media without any FCS or antibiotics and incubated at room temperature for $5 \mathrm{~m}$. Simultaneously, LF2000 master mix was prepared by dissolving $2 \mu \mathrm{L}$ LF2000 in $100 \mu \mathrm{l}$ media and incubated at room temperature for $5 \mathrm{~m}$. After incubation, the LF2000 master mix was added to the siRNA master mix and incubated for $20 \mathrm{~m}$ at room temperature. $200 \mu \mathrm{l}$ of this mix was added per well along with 100,000 cells. The cells were incubated at $37^{\circ} \mathrm{C} / 5 \%$ $\mathrm{CO}_{2}$ for $16 \mathrm{~h}$ followed by exchange of media and treatment of cells with the chemotherapeutics.

\begin{tabular}{lll}
\hline Plate type & Volume of siRNA & Final concentration \\
\hline 12 well & $0.3 \mu \mathrm{l}$ & $10 \mathrm{nM}$ \\
6 well & $0.6 \mu \mathrm{l}$ & $10 \mathrm{nM}$ \\
96 well & $0.03 \mu \mathrm{l}$ & $10 \mathrm{nM}$ \\
\hline
\end{tabular}

\subsubsection{Propidium lodide staining}

Propidium iodide (PI) staining is employed to gauge the cell cycle distribution. $\mathrm{PI}$ is a DNA intercalating agent and readily permeates into live cells. PI staining is proportional to the DNA content of a cell and therefore can be used to distinguish $\mathrm{G} 1$ phase with $2 X$ chromosomes from G2 phase (when DNA replication is complete) with $4 \mathrm{X}$ chromosomes. $S$ phase typically lies between $\mathrm{G} 1$ and $\mathrm{G} 2$ and has staining intensity between $\mathrm{G} 1$ and $\mathrm{G} 2$ phases.

In brief, SW480/HeLa cells were seeded in a 6 well plate and allowed to grow overnight a $37^{\circ} \mathrm{C} / 5 \% \mathrm{CO}_{2}$. The cells were treated with $5 \mu \mathrm{M} 5$-FU for $24 \mathrm{~h}$ followed by treatment with $100 \mathrm{ng} / \mathrm{ml} \mathrm{NCS}$ for 2, 8 and $24 \mathrm{~h}$. Following the incubation times the cells were harvested using trypsin as described previously. The cells were centrifuged at $1 \times \mathrm{g}$ for $5 \mathrm{~m}$. The supernatant was removed and cells washed once with PBS. The pellet was suspended in $500 \mu \mathrm{PBS}$ and fixed using $70 \%$ ethanol (added drop wise to final volume of $2 \mathrm{ml}$ ) overnight at $4^{\circ} \mathrm{C}$. The fixed samples were centrifuged at $1 \times \mathrm{g}$ for $5 \mathrm{~m}$ followed by washing once with PBS. The pellet was 
suspended in $200 \mu \mathrm{l}$ of $0.5 \mathrm{mg} / \mathrm{ml}$ RNaseA and incubated at $37^{\circ} \mathrm{C}$ for $30 \mathrm{~m}$. The samples were then diluted in PBS to attain a final cell count of 500 cells $/ \mu \mathrm{l}$ and measured as per the instructions of the manufacturer.

\subsubsection{Cell proliferation assay}

Cell proliferation assay is used to study the effect of chemotherapeutics on cellular growth. There are many methods described in literature for cell viability assays like MTT assay, crystal violet assay etc.

Cells were seeded in 96 well corning star 3603 plates and incubated at $37^{\circ} \mathrm{C} / 5 \%$ $\mathrm{CO}_{2}$ for $24 \mathrm{~h}$. They were treated with $5 \mu \mathrm{M} 5$-FU/DMSO/gemcitabine/MK2i for $24 \mathrm{~h}$ followed by $100 \mathrm{ng} / \mathrm{ml}$ NCS for $24 \mathrm{~h}$. The wells were washed with PBS and fresh media was added. Cell confluency was measured using cyntellect Celigo $^{\mathrm{TM}}$ automated cell cytometer every day at intervals of $24 \mathrm{~h}$. Cell confluency denotes the total surface area covered by the cells in the wells and was analysed by the software provided from the cyntellect Celigo ${ }^{\mathrm{TM}}$.

\subsection{Biochemistry}

\subsubsection{SDS PAGE and Immunoblotting}

\section{Sample preparation}

The cells after the respective treatments and incubations were harvested on ice using a cell scraper. The harvesting was done with the culture media and no washing was done prior to harvesting. The harvest was collected in an Eppendorf TM tube and centrifuged at $0.8 \times \mathrm{g}$ for $5 \mathrm{~m}$. The supernatant was removed with the help of a syringe tip and vacuum. The pellet was suspended in PBS (to wash away excess culture media) and centrifuged at $0.8 \times \mathrm{g}$ for $5 \mathrm{~m}$; PBS was removed as explained above. The pellet was suspended in appropriate volume of RIPA buffer.

\section{Protein estimation}

The samples suspended in RIPA buffer were centrifuged at $12000 \mathrm{x} \mathrm{g}$ for $10 \mathrm{~m}$ to pellet any cell debris. The protein was estimated using BCA kit from thermo scientific as described by the manufacturer. $5 \mu \mathrm{l}$ of the protein sample was added to $40 \mu \mathrm{l}$ of 
the master reagent (reagent A: reagent B: 49:1). The samples were incubated at $37^{\circ} \mathrm{C}$ for $30 \mathrm{~m}$, followed by protein estimation using nano-drop at $562 \mathrm{~nm}$.

\section{SDS-PAGE}

$12 \%$ SDS PAGE gels were cast with ingredients as shown in the table below. The samples were loaded in the pockets in equal concentrations. The gels were run at a constant voltage of $80 \mathrm{~V}$.

\section{Immunoblotting}

The immunoblotting buffer was pre cooled at $4^{\circ} \mathrm{C}$. Whatman filter papers were cut and soaked in immunobloting buffer along with sponges. The nitrocellulose membrane was cut in $8 \times 8 \mathrm{~cm}$ size and was soaked transiently in the immunoblotting buffer. The apparatus for immunoblotting was set up as instructed by the manufacturer and a voltage of $100 \mathrm{~V}$ was applied for $1 \mathrm{~h} 30 \mathrm{~min}$ at $4^{\circ} \mathrm{C}$. After the transfer of proteins, the nitrocellulose membrane was incubated in Ponceau $S$ and scanned. The nitrocellulose membrane was washed with water for $10 \mathrm{~m}$ to remove the Ponceau S stain. Next, the membrane was blocked in 5\% BSA for one hour at room temperature. The membrane was cut in to strips based on the molecular weight as indicated by the PAGE marker ${ }^{T M}$ followed by incubation of the membrane strips in the primary antibodies overnight at $4^{\circ} \mathrm{C}$. The membrane strips were washed with TBST two times for fifteen $\mathrm{m}$ each at room temperature. After washing, the membranes were incubated in secondary antibodies for one hour at room temperature. The strips were washed again with TBST two times at room temperature and then developed with ECL from Millipore. The images of the membranes were taken using Intas image ${ }^{\mathrm{TM}}$.

\subsubsection{Chromatin fractionation}

DNA in a cell is wound around histone octamers. The complex of DNA and the associated proteins is called chromatin. In the absence of DNA damage, DNA repair proteins are localized in the cytoplasm or in nucleus but are not associated with the DNA. Upon DNA damage, these proteins relocalize and associate with chromatin to perform DNA repair. Chromatin fractionation is a technique employed to specifically collect the proteins on the chromatin. The soluble fraction contains the unbound proteins, including the cytoplasmic proteins. 
200,000 SW480 cells were seeded in 6 well plates for $24 \mathrm{~h}$ and incubated at $37^{\circ} \mathrm{C} / 5 \% \mathrm{CO}_{2}$. Cells were treated with $5 \mu \mathrm{M} 5$-FU/DMSO for $24 \mathrm{~h}$ followed by 100 $\mathrm{ng} / \mathrm{ml} \mathrm{NCS}$ for $24 \mathrm{~h}$. Treated cells were harvested at different time points and collected in an Eppendorf tube. Cells were washed twice with PBS, resuspended in $200 \mu \mathrm{l}$ of buffer $A$ with $0.1 \%$ Triton-X-100 and incubated on ice for $8 \mathrm{~m}$. The samples were centrifuged at $1300 \times \mathrm{g}$ for $5 \mathrm{~m}$ and the supernatant (S1) was collected. Pellet (P1) was washed with buffer $A$ and suspended in buffer $B$ for $3 \mathrm{~m}$ on ice. P1 was centrifuged at $1700 \times \mathrm{g}$ for $5 \mathrm{~m}$, the supernatant was collected and the pellet was resuspended in buffer $\mathrm{B}$. Laemlli buffer was added and the samples boiled at $70^{\circ} \mathrm{C}$ for $20 \mathrm{~m}$.

\subsection{Molecular biology}

\subsubsection{Plasmid preparation}

Chemically competent E.coli strain, $\mathrm{DH} 10 \mathrm{~B}$ was incubated with $1 \mu \mathrm{l}$ of desired plasmid for $30 \mathrm{~m}$ on ice. Heat shock was applied by incubating the cells at $37^{\circ} \mathrm{C}$ for $10 \mathrm{~m}$ followed by immediate transfer on to ice. The bacterial cells were plated on agar plates containing either ampicillin $(100 \mathrm{mg} / \mathrm{ml})$ or kanamycin $(50 \mathrm{mg} / \mathrm{ml})$ and incubated at $37^{\circ} \mathrm{C}$ overnight. Colonies were picked and inoculated in 2YT medium supplemented with either ampicillin or kanamycin overnight at $37^{\circ} \mathrm{C}$. The culture was centrifuged at 5,000 $\mathrm{xg}$ for $10 \mathrm{~m}$ and the supernatant was discarded. The pellet was first resuspended in cell resuspension solution and then incubated for $3 \mathrm{~m}$ with cell lysis solution. Post lysis, neutralization buffer was added and incubated for $3 \mathrm{~m}$ at room temperature. The lysate was centrifuged at $15000 \mathrm{xg}$ for $15 \mathrm{~m}$ and the clear supernatant was passed through the clearing column. The binding column was washed with $20 \mathrm{ml}$ of wash solution and the bound DNA was eluted with the sterile water. The plasmid DNA was collected in an Eppendorf tube, concentration measured and stored at $-80^{\circ} \mathrm{C}$.

\subsubsection{Total RNA isolation}

200,000 cells were seeded in 6 well plates and incubated at $37^{\circ} \mathrm{C} / 5 \% \mathrm{CO}_{2}$ for $24 \mathrm{~h}$. Cells were treated with $5 \mu \mathrm{M} 5$-FU/DMSO for $24 \mathrm{~h}$ followed by $100 \mathrm{ng} / \mathrm{ml} \mathrm{NCS}$ for 24 
h. After the treatments, cells were trypsinised and collected in $2 \mathrm{ml}$ Eppendorf tubes and centrifuged at $0.8 \times \mathrm{g}$ for $5 \mathrm{~m}$. Supernatant was removed and the pellet washed with PBS. The pellet was resuspended in $600 \mu \mathrm{l}$ Trizol $^{\mathrm{TM}}$ and incubated at room temperature for $5 \mathrm{~m}$. To separate the phases, $120 \mu \mathrm{l}$ of chloroform was added to the samples and incubated at room temperature for $3 \mathrm{~m}$ with vigorous shaking. The samples were centrifuged at $15,000 \times \mathrm{g}$ for $15 \mathrm{~m}$ at $4^{\circ} \mathrm{C}$. The aqueous phase, containing RNA was collected and purified with $500 \mu$ isopropanol. Samples were thoroughly mixed, incubated for $10 \mathrm{~m}$ at room temperature and centrifuged at 15,000 $\mathrm{x} \mathrm{g}$ for $10 \mathrm{~m}$ at $4^{\circ} \mathrm{C}$. The pellet was washed with $75 \%$ ethanol and the finally dissolved in water. To eliminate protein impurities the RNA was precipitated with 300 $\mathrm{mM}$ sodium acetate and $50 \%$ ethanol. The pellet was resuspended in water, concentration and purity measured using nanodrop. RNA was stored at $-80^{\circ} \mathrm{C}$ for further studies.

\subsection{Quantitative Immunofluorescence}

In a 96 well BD falcon ${ }^{\mathrm{TM}}$ plate, 8000 cells were seeded and incubated at $37^{\circ} \mathrm{C} / 5 \%$ $\mathrm{CO}_{2}$ for $24 \mathrm{~h}$. The cells were treated with $5 \mu \mathrm{M} 5$-FU/DMSO/RTXD/gemcitabine for $24 \mathrm{~h}$ followed by $100 \mathrm{ng} / \mathrm{ml}$ NCS for 2,8 or $24 \mathrm{~h}$. The cells treated with DMSO served as negative control. Following the treatment, the cells were fixed with $4 \%$ PFA at room temperature and permeabilized with $0.5 \%$ Triton $X 100$. Blocking was done with $5 \%$ BSA at room temperature for $30 \mathrm{~m}$. Wells were incubated with $100 \mu \mathrm{l}$ primary antibodies $(\mathrm{y}-\mathrm{H} 2 \mathrm{AX})$ diluted in $3 \% \mathrm{BSA}$ at appropriate concentrations, overnight at $4{ }^{\circ} \mathrm{C}$. The wells were washed with blocking solution before incubation with $70 \mu \mathrm{l}$ secondary antibodies (Alexa 488 or Alexa 594), diluted in 3\% BSA, for $1 \mathrm{~h}$ at room temperature in dark. The cells were counterstained with Hoechst 33342 along with the secondary antibody incubation. $200 \mu$ PBS was added in each well and the plate was covered with aluminum foil and fluorescence intensity measurements were made using the BD pathway 855 automated microscope. Fluorescence intensity was measured from ROI (region of interest) defined by the software limiting the reading to the nuclei. The average fluorescence intensity was 
determined and used for plotting histograms. In each of the experiments a minimum of 1000 ROI's were chosen for plotting the histograms.

\subsection{Confocal microscopy}

SW480 cells were grown on coverslips in a 24 well cell culture plate. Cells were treated with $5 \mu \mathrm{M} 5$-FU/DMSO for $24 \mathrm{~h}$ followed by treatment with $100 \mathrm{ng} / \mathrm{ml} \mathrm{NCS}$ for 2, 8 or $24 \mathrm{~h}$. Cells treated with DMSO were used as negative controls. Cells were fixed with $4 \%$ PFA at room temperature and permeabilized with $0.5 \%$ Triton $\times 100$. Blocking was done with $3 \%$ BSA in PBS for $30 \mathrm{~m}$ at room temperature. Samples were incubated with primary antibodies, diluted in 3\% BSA with appropriate concentrations, overnight at $4^{\circ} \mathrm{C}$. Coverslips were washed with PBS and incubated with secondary antibodies, diluted in $3 \% \mathrm{BSA}$, for $1 \mathrm{~h}$ at room temperature in dark. Coverslips were washed with PBS and mounted on slides. The cells were counterstained with Hoechst 33342. The images were taken with Carl Zeiss LSM 510 meta at $63 X$. The RPA2 foci were quantified using FociCounter, free software available at http://focicounter.sourceforge.net/ (accessed on 1-11-2014).

\subsection{Gamma radiation exposure of cells}

Cells to be irradiated were grown in cell culture flasks and incubated at $37^{\circ} \mathrm{C} / 5 \%$ $\mathrm{CO}_{2}$ for $24 \mathrm{~h}$. The cells were treated with $5 \mu \mathrm{M} 5$-FU/DMSO for $24 \mathrm{~h}$. After the respective treatments the flasks were irradiated with $5 \mathrm{~Gy}$ of gamma radiation. The cells were incubated at $37^{\circ} \mathrm{C} / 5 \% \mathrm{CO}_{2}$ and harvested at 2,8 or $24 \mathrm{~h}$ post irradiation.

\subsection{BrdU assay for ssDNA}

8000 cells were seeded in a 96 well plate and incubated for $24 \mathrm{~h}$ at $37^{\circ} \mathrm{C} / 5 \% \mathrm{CO}_{2}$. Cells were incubated with BrdU for $24 \mathrm{~h}$, treated with $5 \mu \mathrm{M} 5$-FU/DMSO for $24 \mathrm{~h}$ followed by treatment with $100 \mathrm{ng} / \mathrm{ml} \mathrm{NCS}$ for $24 \mathrm{~h}$. Following the treatments the cells were pre extracted for $5 \mathrm{~m}$, fixed with $4 \%$ PFA, washed with PBS and blocked with $5 \%$ BSA. Cells were incubated for $1 \mathrm{~h}$ at room temperature with BrdU primary 
antibody diluted in 5\% BSA. Post incubation, cells were washed with PBS and incubated with secondary antibody in dark for $1 \mathrm{~h}$ at room temperature. Following incubation with secondary antibody, cells were washed with PBS; plate covered with aluminum foil and the fluorescent intensity was measured using BD automated fluorescence microscope.

\subsection{EdU assay}

8000 cells were seeded in a 96 well plate and incubated for $24 \mathrm{~h}$ at $37^{\circ} \mathrm{C} / 5 \% \mathrm{CO}_{2}$. Cells were treated with $5 \mu \mathrm{M} 5$-FU/DMSO for $24 \mathrm{~h}$ followed by treatment with 100 $\mathrm{ng} / \mathrm{ml} \mathrm{NCS}$ for $24 \mathrm{~h} .2 \mathrm{~h}$ prior to fixation, cells were treated with $10 \mathrm{mM}$ EdU. Post treatment, cells were fixed with 4\% PFA, washed with PBS, permeabilised with 0.5 $\%$ Triton X 100 and blocked with 5\% BSA. Cells were incubated with Click $\mathrm{iT}^{\mathrm{TM}}$ reaction master mix for $30 \mathrm{~m}$ at room temperature. Cells were washed with PBS and incubated with Hoechst for $45 \mathrm{~m}$ at room temperature in dark, washed with PBS. 200 $\mu$ I PBS was added to each well and the plate was covered with aluminum foil to avoid bleaching of fluorescence. The fluorescent intensity was measured using BD automated fluorescence microscope and the total percentage of cells with EdU incorporation were plotted to estimate the $S$ phase population.

\subsection{Statistical analysis}

Statistical calculations were performed using graph pad Prism ${ }^{\mathrm{TM}}$. Statistical significance was calculated for at least 3 independent biological experiments using two tailed student's t-test. Significance was assumed for $p$ value lower than 0.05 , asterisk were used to denote the significance in the figures: ${ }^{*} p<0.05,{ }^{* *} p<0.01$, ${ }^{* * *} p<0.001$. 


\section{Results}

\subsection{5-FU and NCS combination results in persistent $\mathrm{y}-\mathrm{H} 2 \mathrm{AX}$}

Chemoradiotherapy of CRC involves bolus 5-FU treatment followed by radiotherapy. In order to elucidate the molecular mechanisms behind the synergisms between 5FU and y-radiation, a combination of 5-FU and NCS was used in CRC cell lines. Phosphorylated $\mathrm{H} 2 \mathrm{AX}$ is a known marker for assessing double strand breaks in cells; we therefore used it to evaluate the DNA damage induced during our treatments. Further, NCS and y-radiation are known to induce DNA double strand breaks.

Since gamma-irradiation depends on a source, we replaced this treatment by NCS. Our goal was to set up an experimental system that allows us to faithfully recapitulate the treatment of patients. In the most successful treatment regimens, patients are first treated with 5-FU, followed by irradiation. In our studies, we replaced the patients' tumors with CRC cell lines. These cells were first treated with $5 \mu \mathrm{M}$ 5-FU (unless specified). Secondly, we exposed the cells to $100 \mathrm{ng} / \mathrm{ml} \mathrm{NCS}$ (unless specified), thus approximating gamma irradiation. Subsequently, the accumulation of $\mathrm{y}-\mathrm{H} 2 \mathrm{AX}$ was monitored as readout for the DNA damage response.

In order to determine the combined effect of 5-FU and NCS on the DNA damage response in colorectal cancer cells, we treated cells with a combination of 5-FU and NCS at concentrations of $5 \mu \mathrm{M}$ and $100 \mathrm{ng} / \mathrm{ml}$ respectively. We had performed 5-FU titrations which confirmed synergism with NCS at a low concentration of $5 \mu \mathrm{M}$ (data not shown).

Immunoblotting of samples treated with 5-FU in combination with NCS showed a large accumulation of $\mathrm{Y}-\mathrm{H} 2 \mathrm{AX}$ that persisted for $24 \mathrm{~h}$ post-NCS treatment in HeLa and SW480 cells (Figure 4.1A and 4.1B). This indicated that the DNA damage induced $2 \mathrm{~h}$ post NCS treatment remained unrepaired. However, in both cases treatment with 5-FU alone, did not show any significant accumulation of $\mathrm{y}-\mathrm{H} 2 \mathrm{AX}$ at the indicated time points. NCS treatment led to increase in $\mathrm{Y}-\mathrm{H} 2 \mathrm{AX}$ levels at $2 \mathrm{~h}$, but declined over time indicating DNA repair (Figure 4.1). We next performed 
quantitative immunofluorescence (see 3.4) and quantified the fluorescent intensity in SW480 cells. Average $\mathrm{Y}-\mathrm{H} 2 \mathrm{AX}$ intensities shown as box plots reaffirm the observation of persistent $\mathrm{Y}-\mathrm{H} 2 \mathrm{AX}$ in response to 5-FU and NCS (Figure 4.1C).

We next used the constraint function of the $\mathrm{BD}$ attovision ${ }^{\mathrm{TM}}$ image analysis software to select nuclei with $\mathrm{y}-\mathrm{H} 2 \mathrm{AX}$ intensity greater than 800 (arbitrary units) and found that combination treatment of $5-\mathrm{FU}$ and NCS causes $80-90 \%$ cells to have high $\mathrm{y}$ H2AX (Figure 4.1D). The constraint was chosen by us and the reason for this selection was to eliminate $\mathrm{y}-\mathrm{H} 2 \mathrm{AX}$ arising from spontaneous DNA damage in the cells. It is basically used to remove any background levels of fluorescent intensity. NCS induced damage was evident in about $40 \%$ cells whereas the 5-FU treatment did not cause accumulation of high levels of $\mathrm{y}-\mathrm{H} 2 \mathrm{AX}$. These experiments proved that 5 -FU pretreatment not only sensitizes the cells to NCS but also causes persistent $\gamma$ $\mathrm{H} 2 \mathrm{AX}$ in a majority of the cells. 
(A)

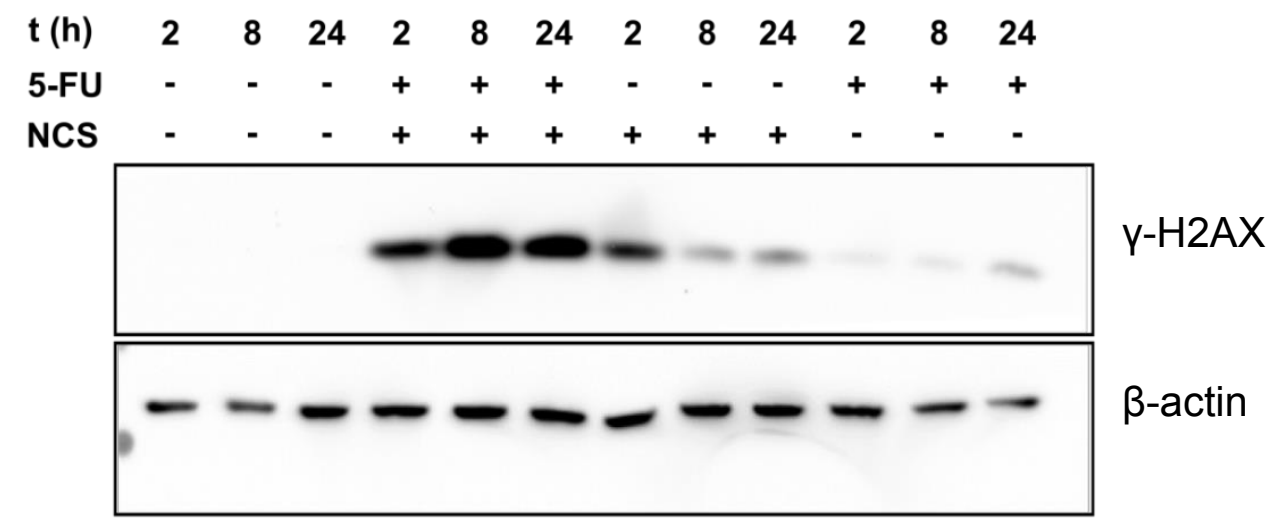

(B)

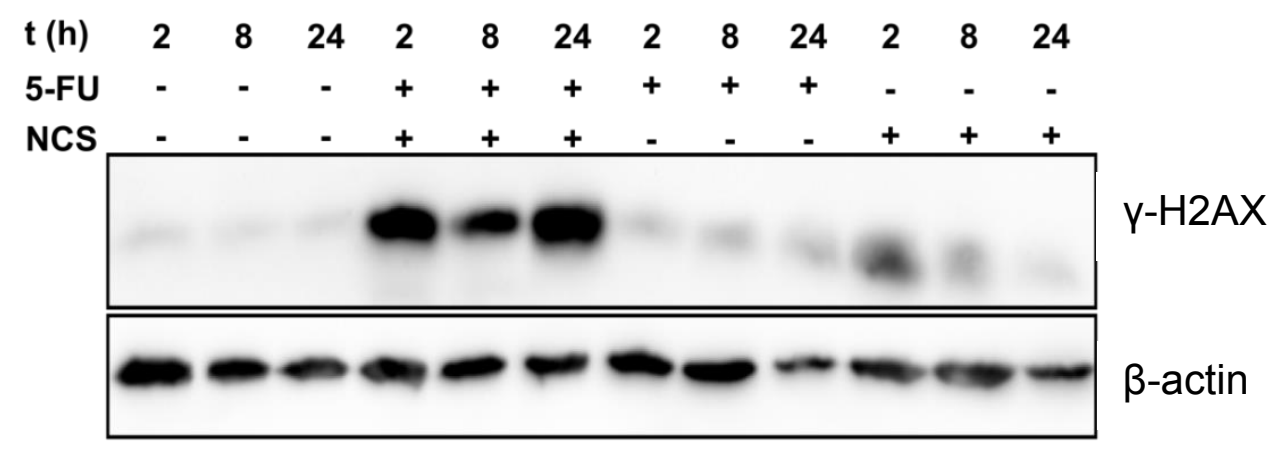

(C)

(D)
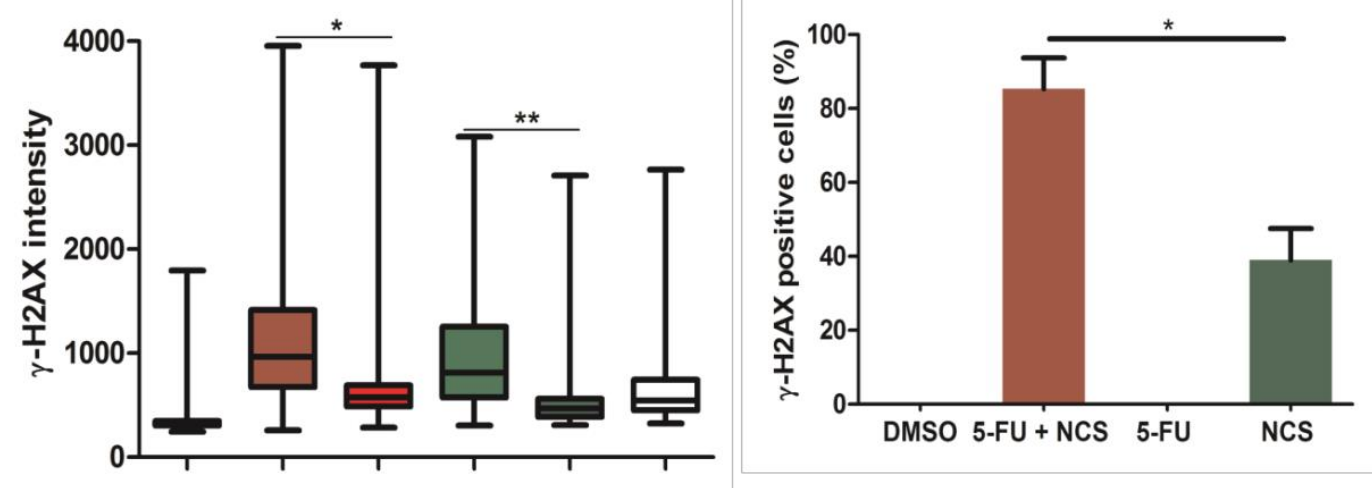

$\begin{array}{llllll}\text { NCS } & - & + & - & + & -\end{array}+$

Figure 4.1 5-FU and NCS in combination cause persistent $\mathrm{y}-\mathrm{H} 2 \mathrm{AX}$.

(A) SW480, (B) HeLa cells were treated with $5 \mu \mathrm{M} 5$-FU/DMSO for $24 \mathrm{~h}$ followed by treatment with $100 \mathrm{ng} / \mathrm{ml} \mathrm{NCS}$ for 2,8 and $24 \mathrm{~h}$ while continuing the 5 -FU treatment. The cells were harvested and whole cell lysates were analyzed by immunoblotting. Antibodies to $\mathrm{y}-\mathrm{H} 2 \mathrm{AX}$ were used to quantify the extent of the DNA damage response, whereas $\beta$-actin was detected as a loading control. (C) Following the same treatment scheme as in A or B, SW480 cells were fixed with 4\% PFA for 15 
min at room temperature, and then stained for $\mathrm{y}-\mathrm{H} 2 \mathrm{AX}$. Automated microscopy and image analysis were performed using the BD pathway system, and the results are shown as a box plot $(n=3)$ as detailed in section 3.4. ${ }^{*}=p<0.05:{ }^{* *}=p<0.01$ (Student's t-test) (D) Percentage of cells with greater than 800 arbitrary units intensity, as determined by the BD Attovision ${ }^{\mathrm{TM}}$ software, is plotted for each treatment. The columns represent the mean of three independent experiments; the error bars represent the standard error of the mean.

\subsection{NCS and y-radiation produce similar cellular effects on the kinetics of $\mathrm{Y}-\mathrm{H} 2 \mathrm{AX}$ accumulation}

To verify whether NCS and $y$-radiation have similar effects on the kinetics of $y-\mathrm{H} 2 \mathrm{AX}$ accumulation and removal particularly to see if the immediate increased accumulation is sustained in case of cells pre-treated with 5-FU. To this end, we treated SW480 cells with 5-FU and exposed them to $5 \mathrm{~Gy}$ of $\mathrm{y}$-radiation. This $\mathrm{y}$ radiation dose was chosen as it correlated with the NCS concentrations used in the study. As observed previously with NCS (Figure 4.1), combination of 5-FU and yradiation led to persistence of $\mathrm{y}-\mathrm{H} 2 \mathrm{AX}$ (Figure 4.2), however treatment with $\mathrm{\gamma}$ radiation alone, showed an accumulation of $\mathrm{y}-\mathrm{H} 2 \mathrm{AX} 2 \mathrm{~h}$ post radiation that diminished over time indicating repair of the damaged DNA. This observation was similar to that with NCS indicating similar cellular response.

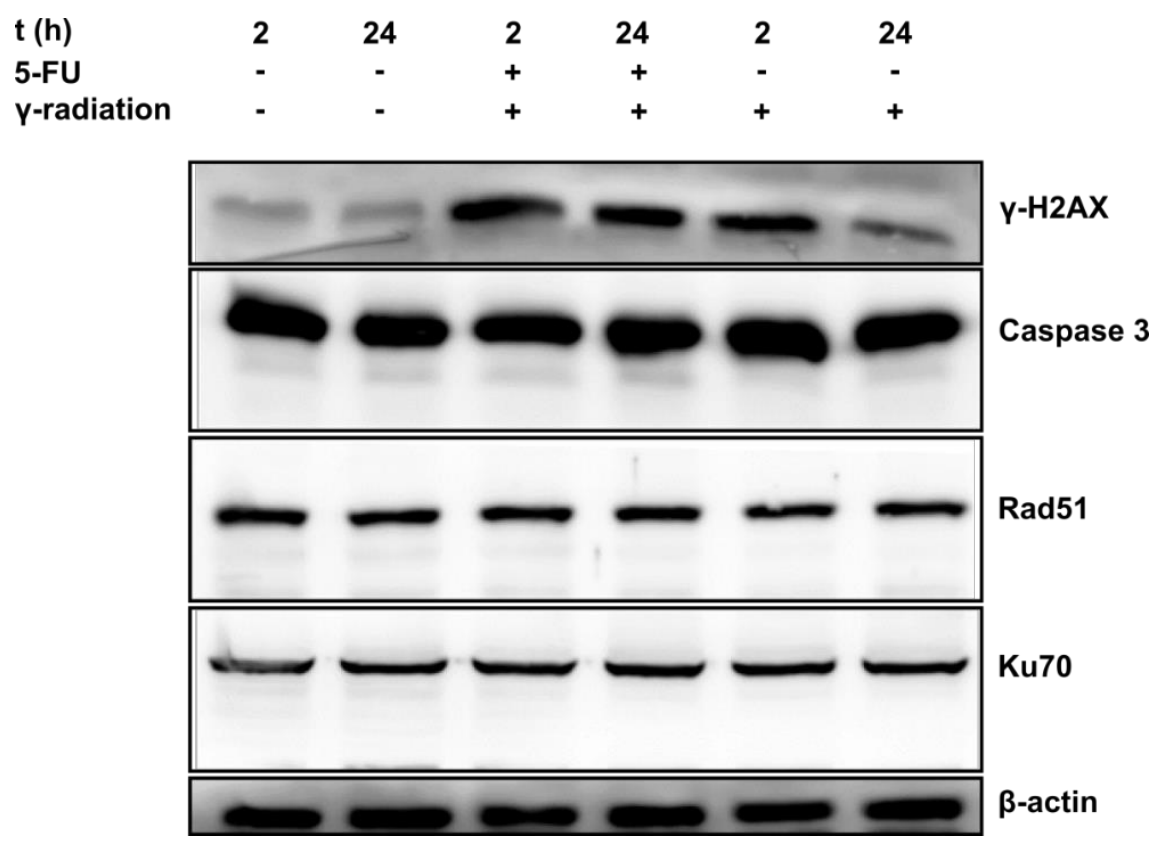

Figure 4.2 Kinetics of $\mathrm{Y}-\mathrm{H} 2 \mathrm{AX}$ accumulation is similar between NCS and $\mathrm{Y}-\mathrm{H} 2 \mathrm{AX}$. 
SW480 cells were treated with $5 \mu \mathrm{M} 5$-FU/DMSO for $24 \mathrm{~h}$ followed by 5 Gy of irradiation while continuing the 5 -FU treatment. Cells were harvested $2 \mathrm{~h}$ or $24 \mathrm{~h}$ post-irradiation and whole cell lysates were analyzed by immunoblotting using the indicated antibodies. Antibodies to $\mathrm{y}-\mathrm{H} 2 \mathrm{AX}$ were used to quantify the extent of the DNA damage response, whereas $\beta$-actin was detected as a loading control.

We next looked for the effect of radiation on the total protein levels of two key DNA repair protein Rad51 and Ku70, but did not find any significant changes indicating that the overall levels if these proteins remain the same even after the treatments. This together with the observation that there was no cleaved caspase 3 , indicating absence of apoptosis, confirmed the sole contributor of $\mathrm{y}-\mathrm{H} 2 \mathrm{AX}$ to be DNA damage response. This therefore proves that the kinetics of $\mathrm{Y}-\mathrm{H} 2 \mathrm{AX}$ accumulation in response to $\mathrm{y}$-radiation is similar to NCS and validates its use as a substitute to $\mathrm{y}$ radiation.

\subsection{5-FU and NCS in combination reduce cell proliferation and survival}

In order to examine the effect of combination therapy on cell proliferation, we performed the long term cell proliferation assay on CRC cell lines. Cell proliferation assays elucidate the effect of drugs on cells over a long period of time, telling us the consequences of the treatment in a long term. $5 \mu \mathrm{M} \mathrm{5-FU}$ was added on day2 followed by $100 \mathrm{ng} / \mathrm{ml}$ NCS on day3. Following this the media was changed every 2 days. This treatment severely impaired the cell proliferation (Figure 4.3a), however treatment with 5-FU alone reduced the rate of cell proliferation but cells recovered from initial lag to resume proliferation (Figure 4.3a). NCS on the other hand had no significant effect on the cell proliferation. This therefore confirmed that combination of 5-FU and NCS severely impairs the proliferation and affects the cell survival.

We next used lower NCS concentrations (10 and $20 \mathrm{ng} / \mathrm{ml}$ ) to verify if the synergistic effect of the combination treatment depends on the initial DNA damage induced by NCS. As seen in the (Figure 4.3b) combination of $5-\mathrm{FU}$ with $10 \mathrm{ng} / \mathrm{ml}$ NCS did not show any synergistic effect; however treatment with $20 \mathrm{ng} / \mathrm{ml}$ NCS showed synergistic effects as observed earlier with $5 \mu \mathrm{M} 5-\mathrm{FU}$ and $100 \mathrm{ng} / \mathrm{ml} \mathrm{NCS}$, indicating that this is the minimum NCS concentration at which synergism with 5-FU 
is seen. Furthermore, at high 5-FU concentrations of $100 \mu \mathrm{M}$, cell survival decreased drastically (Figure 4.3c) hindering any further synergism studies.

We also investigated effects of combination treatment on HT-29, a CRC cell line that is known to be radioresistant. As shown by the cell survival in (Figure 4.3d) we found HT-29 to be radioresistant, but surprisingly very sensitive to $5-\mathrm{FU}$ even at $5 \mu \mathrm{M}$; therefore we did not pursue further synergism studies with these cells. These results indicated that the combination of 5-FU $(5 \mu \mathrm{M})$ with NCS $(100 \mathrm{ng} / \mathrm{ml})$ severely impaired the cell proliferation and this effect is dependent on the concentration of 5FU as well as NCS and also depends on cell lines being studied.

Taken together our results indicate that combination of $5 \mu \mathrm{M} 5-\mathrm{FU}$ and $100 \mathrm{ng} / \mathrm{ml}$ NCS severely impair the cell proliferation and reduce the cell survival in SW480 cells. Use of higher concentrations of 5-FU $(100 \mu \mathrm{M})$ reduce the survival of SW480 cells, possibly leading to apoptosis. We could also show that the synergism between $5 \mu \mathrm{M} 5$-FU and NCS begins at the concentration of $20 \mathrm{ng} / \mathrm{ml}$ of NCS. On the other hand HT-29 cells were fund to be very sensitive to 5-FU and exhibited almost no survival with $5 \mu \mathrm{M} 5-\mathrm{FU}$. These results also indicate that the persistent $\mathrm{y}-\mathrm{H} 2 \mathrm{AX}$ observed in the case of cells treated with a combination of 5-FU and NCS indicate severe DNA damage which affect their proliferation and if unrepaired for longer duration may lead to cell death. 
(a)

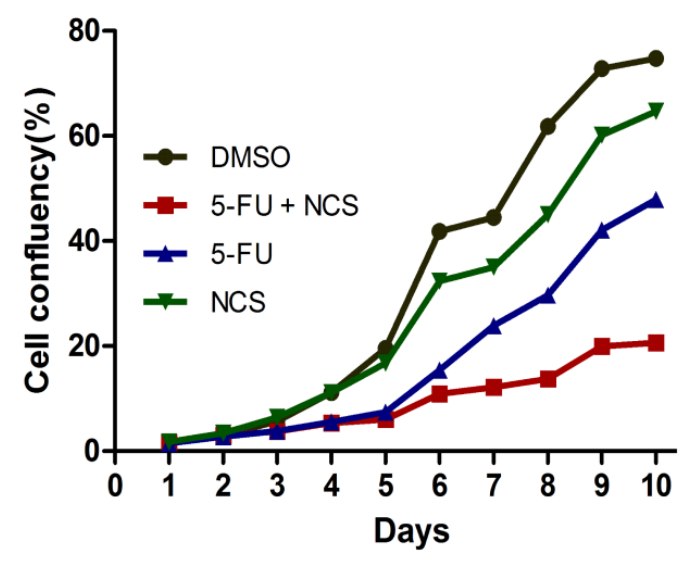

(c)

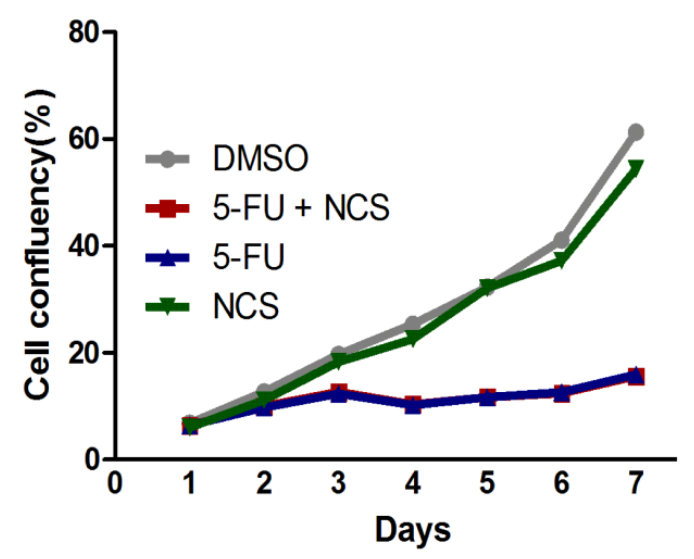

(b)

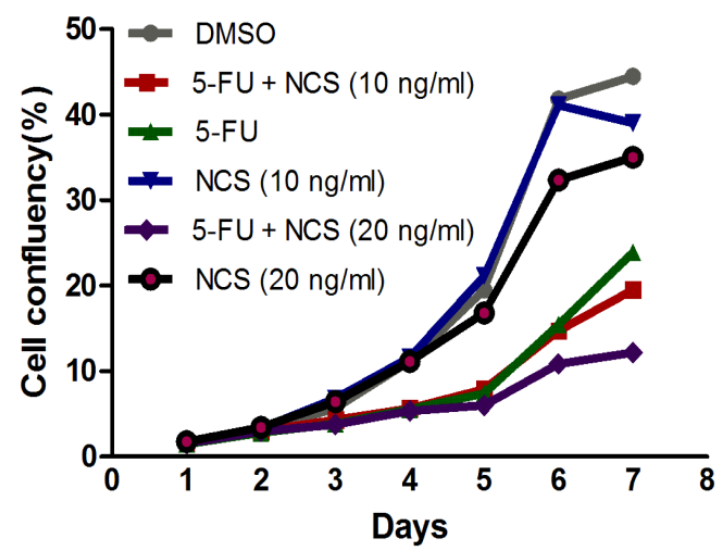

(d)

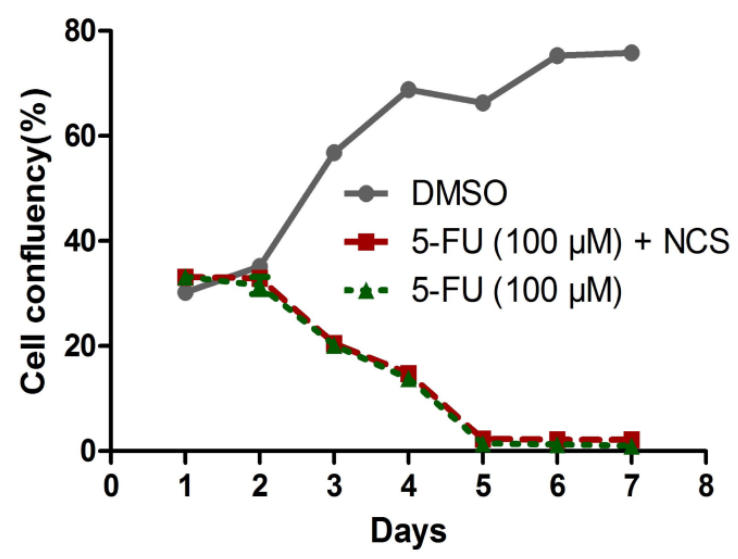

Figure 4.3 5-FU and NCS in combination severely impairs cell proliferation in colorectal cancer cells.

Cells were treated with $5 \mu \mathrm{M} 5$-FU/DMSO on day 2 followed by $100 \mathrm{ng} / \mathrm{ml}$ NCS on day 3; cell confluency was measured every day using Cyntellect ${ }^{\mathrm{TM}}$ celigo as described in 3.1.10. SW480 cells treated with (a) $5 \mu \mathrm{M} 5-\mathrm{FU}$ and/ or $100 \mathrm{ng} / \mathrm{ml} \mathrm{NCS}$, (b) $5 \mu \mathrm{M} 5-\mathrm{FU}$ and 10 or 20 $\mathrm{ng} / \mathrm{ml} \mathrm{NCS}$, (c) HT-29 cells treated with $5 \mu \mathrm{M} 5-\mathrm{FU}$ and/ or $100 \mathrm{ng} / \mathrm{ml} \mathrm{NCS}$ (d) SW480 cells treated with $100 \mu \mathrm{M} 5$-FU and/or $100 \mathrm{ng} / \mathrm{ml}$ NCS.

\subsection{5-FU reduces the ability to perform HRR but does not affect NHEJ}

We next wondered why does the combination of 5-FU and NCS induces such a catastrophic effect on cell survival and DNA damage as seen by the persistently high $\mathrm{Y}-\mathrm{H} 2 \mathrm{AX}$. We knew that NCS and y-radiation primarily induce DSB in DNA; though with different molecular mechanisms. We had previously observed that cells treated with 5-FU and NCS show persistent $\mathrm{y}-\mathrm{H} 2 \mathrm{AX}$ (Figure 4.1), indicating a defect in DNA 
DSB repair in these cells. Since a mammalian cell can employ either HRR or NHEJ to repair DSBs, we investigated these pathways using plasmid based reporter assays in HeLa cells (section 3.1.5 and 3.1.6). HeLa cells were chosen because of the ease of transfection and high transfection efficiency. We had observed the persistent $\mathrm{y}-\mathrm{H} 2 \mathrm{AX}$ in HeLa cells too and therefore deemed it to be a safe model system to perform the assays.

DRGFP assay (Figure 4.4b) involves transfection of DRGFP plasmid along with pCBAScel in cells along with DsRed that was used to normalize transfection efficiency. The DRGFP plasmid has an I-scel restriction endonuclease site and therefore upon expression of I-Scel produces a double strand break in the plasmid. Apart from the restriction site, it has two truncated GFP cassettes that do not express GFP. If the cell repairs the DNA double strand break using the iGFP as a template, a functional GFP cassette is formed on the plasmid. Therefore, cells employing HRR express GFP while the ones that do not use HRR to repair the break do not express GFP. We employed DRGFP assay to assess HRR in cells treated with 5-FU and NCS and found that 5-FU reduced the efficiency of HRR. NCS on the other hand did not affect the HRR (Figure 4.4a). The combination of NCS with 5-FU also showed a reduction; however, no significant effect was observed due to NCS treatment in these samples. We therefore concluded that $5-\mathrm{FU}$ alone is responsible for the reduction of homologous recombination repair in cells.

We next employed a plasmid based reporter assay to assess NHEJ in mammalian cells. The NHEJ reporter plasmid has a split GFP cassette neither of which produces GFP (section 3.1.6). An intron Ad is present between the split GFP cassettes and has a HindIII restriction endonuclease sites. Repair of the double strand breaks by NHEJ allows the cell to transcribe a functional GFP and therefore only the cells employing NHEJ will express GFP while others will not.

As shown in Figure 4.4c, 5-FU did not significantly reduce the NHEJ either alone or in combination with NCS; NCS also did not show any effect on the NHEJ. In conclusion, 5-FU pretreatment reduces cells capacity to perform HRR while NHEJ is not affected. This result also explains the persistence of $\mathrm{y}-\mathrm{H} 2 \mathrm{AX}$ in cells pretreated with 5-FU and exposed to NCS. The cells treated with 5-FU have a compromised 
HRR and when challenged with NCS cannot repair the double strand breaks leading to persistent $\mathrm{Y}-\mathrm{H} 2 \mathrm{AX}$. On the other hand persistent $\mathrm{Y}-\mathrm{H} 2 \mathrm{AX}$ is not seen in $5-\mathrm{FU}$ treated cells as 5-FU alone does not induce such high levels of DNA double strand breaks. NCS treated cells expectedly show a reduction in $\mathrm{y}-\mathrm{H} 2 \mathrm{AX}$ levels as the treatment does not affect the homologous recombination repair.

(a)

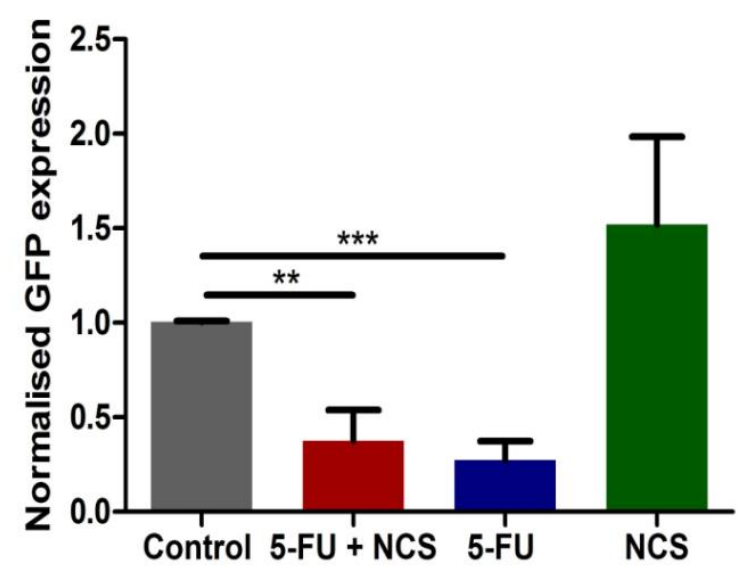

(c)

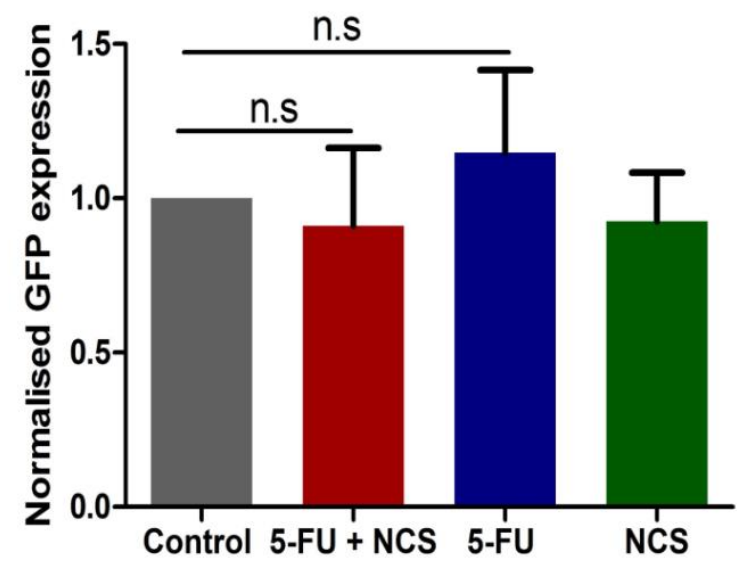

(b)

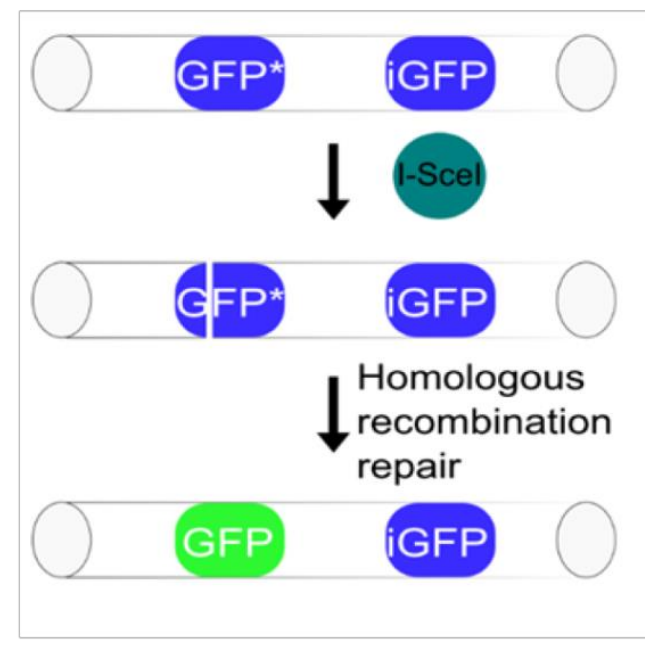

(d)

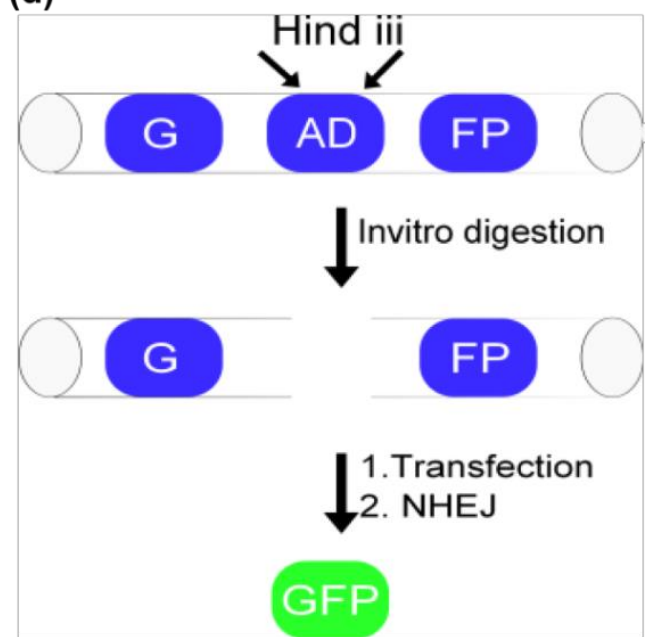

Figure 4.4 5-FU reduces the homologous recombination repair but does not affect the non-homologous end joining.

(a) HeLa cells were transfected with the DRGFP, Iscel and DsRed plasmid followed by treatment with 5-FU/DMSO for $24 \mathrm{~h}$ and then with NCS for $24 \mathrm{~h}$. GFP positive cells were quantified using guava easycyte ${ }^{\mathrm{TM}}$ flow cytometer. (b) Schematic representation of the principle of DRGFP assay, (c) linearized NHEJ plasmid along with DsRed plasmid were transfected in HeLa cells followed by treatment with $5 \mu \mathrm{M} 5$-FU/DMSO for $24 \mathrm{~h}$ and then with $100 \mathrm{ng} / \mathrm{ml} \mathrm{NCS}$ for $24 \mathrm{~h}$. GFP positive cells were quantified using guava easycyte ${ }^{\mathrm{TM}}$ flow cytometer. (d) Schematic representation of the principle of NHEJ assay. Error bars indicate standard errors of the mean. For normalization methods please refer section 3.1.7. 


\subsection{5-FU causes $S$ phase arrest}

We had observed that the cells treated with $5-\mathrm{FU}$ had a reduced capability to perform HRR (Figure 4.4). We next asked if this was a result of cell cycle arrest in G1 phase. The activation of the DSB repair pathways is dependent on the cell cycle phase with HRR most active in S/G2 phase while NHEJ is favored in G1 phase. Since we had observed that HRR was reduced in the presence of 5-FU, this could have been due to accumulation of cells in phases of the cell cycle that do not permit HRR. We therefore investigated whether 5-FU might cause arrest in G1. In light of our observations on HRR (Figure 4.4), we investigated the effect of 5-FU and NCS on cell cycle using Propidium iodide $(\mathrm{PI})$ staining. Propidium iodide intercalates in DNA and can be used as a measure to determine the quantity of DNA and therefore the phase of cell cycle. Cells in G1 phase have 2N DNA content while in G2 phase they double their DNA content to $4 \mathrm{~N}$. The cells in $\mathrm{S}$ phase have DNA content in between $2 \mathrm{~N}$ and $4 \mathrm{~N}$. $5 \mu \mathrm{M}$ 5-FU treatment led to $S$ phase arrest in $80 \%$ of the cells (Figure $4.5 \mathrm{c}, 4.5 \mathrm{e}$, and $4.5 \mathrm{f}$ ) while NCS alone causes a strong G2 arrest (Figure 4.5d and $4.5 \mathrm{e}$ ). Interestingly, the combination of $5-\mathrm{FU}$ and NCS also exhibited S phase arrest in similar percentage of cells without any additive effect of NCS (Figure 4.5b, 4.5e, and 4.5f). Taken together, we conclude that 5-FU does not induce detectable G1 arrest. Thus, the reduction of HRR that we had observed cannot simply be ascribed to a shift in the cell cycle.

We next performed EdU incorporation assay, to determine the proportion of cells specifically in $S$ phase. EdU is incorporated into DNA during replication and the alkyne group in EdU is then detected using fluorescent azides by click chemistry. The fluorescent intensity was then quantified using the BD pathway ${ }^{\top \mathrm{M}}$ automated microscope. The advantage of this method over BrdU staining is that the samples do not have to be denatured before the measurements. Since only actively replicating cells can incorporate EdU, this can be used to quantify the cells in $S$ phase. 
$5 \mu \mathrm{M}$ 5-FU treatment showed $80-90 \%$ cells in S phase (Figure $4.5 \mathrm{f}$ ), both with and without NCS treatment while there were fewer than $20-25 \%$ NCS treated cells in S phase corroborating our PI staining results.

Taken together, our results indicate that 5-FU treatment induces an S phase arrest in majority of the cells while NCS treatment causes a predominant G2 arrest. Interestingly, both $S$ and $G 2$ phases are favorable for HRR and we still saw a 5-FU induced reduction of HRR (Figure 4.4b) indicating that arrest in unfavorable cell cycle phase is not the reason for the reduced homologous recombination repair in response to $5-\mathrm{FU}$.
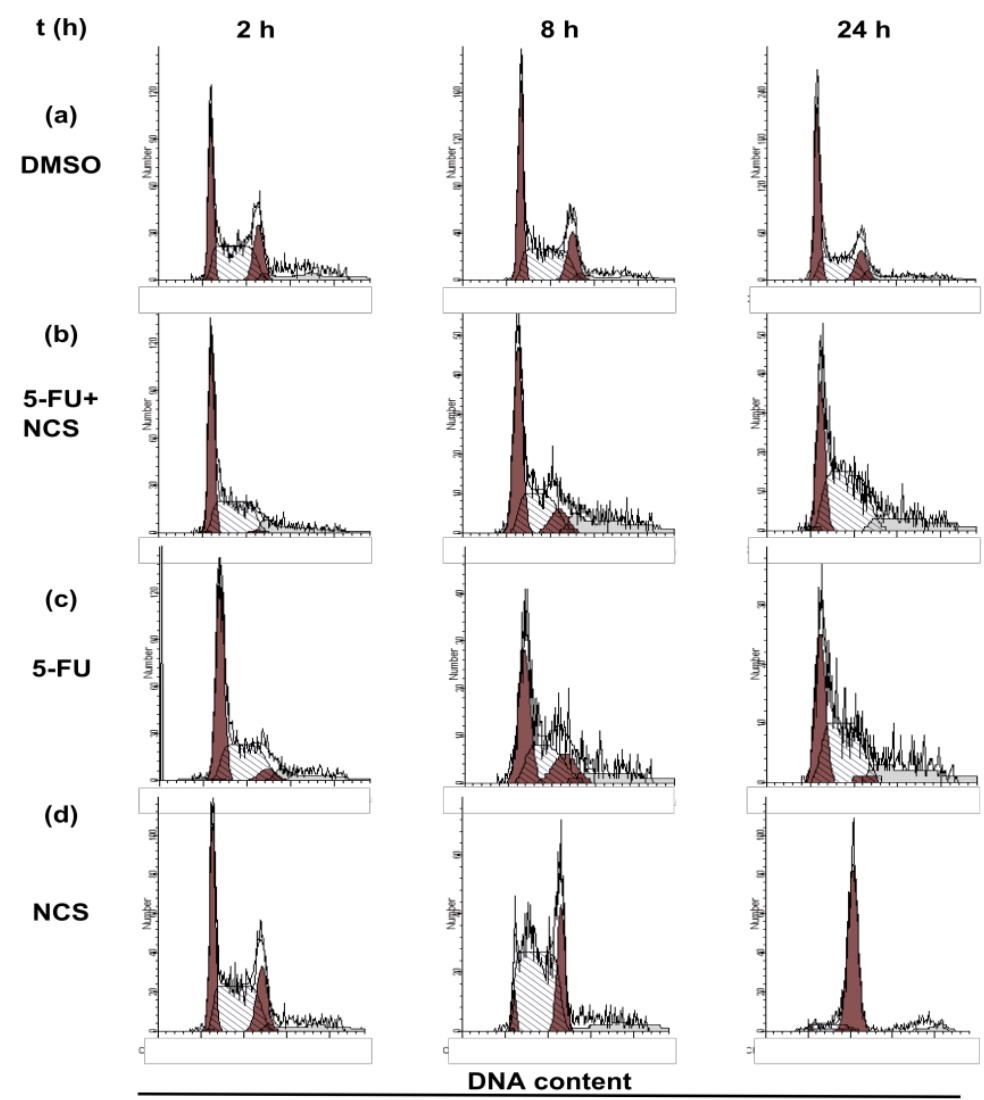

DNA content

(e)

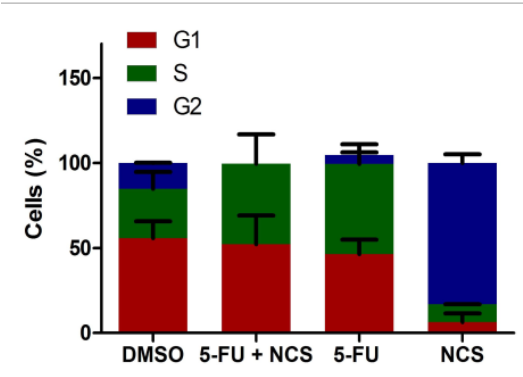

(f)

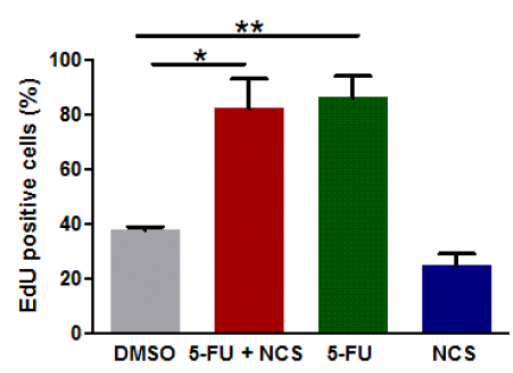


Figure 4.5 5-FU causes $S$ phase arrest.

SW480 cells were treated with DMSO/5-FU $(5 \mu \mathrm{M})$ for 2,8 and $24 \mathrm{~h}$ followed by treatment with $100 \mathrm{ng} / \mathrm{ml} \mathrm{NCS}$ for $24 \mathrm{~h}$. Cell cycle distribution was analyzed using PI staining , (a) DMSO, (b) 5-FU + NCS, (c) 5-FU, (d) NCS. The peak on the left of the histogram represents G1 phase while the peak on the right represents G2 phase. The area between these two peaks represents $S$ phase. (e) Quantification of cell cycle distribution was done using Modfit $^{\mathrm{TM}}$ Verity software house (f) SW480 cells were treated with DMSO/5-FU $(5 \mu \mathrm{M})$ for 24 $\mathrm{h}$ followed by treatment with NCS for $24 \mathrm{~h} .2 \mathrm{~h}$ prior to the addition of the drugs cells were treated with $15 \mu \mathrm{M}$ EdU. Samples were fixed with 4\% PFA followed by permeabilisation with $0.5 \%$ triton-x-100 for $15 \mathrm{~m}$. After blocking with $5 \%$ BSA samples were incubated with primary antibody for $1 \mathrm{~h}$ in dark. After washing, samples were incubated with Alexa $488 \mathrm{HCS}$ for $45 \mathrm{~m}$ in dark. EdU positive cells were quantified using BD Attovision ${ }^{\mathrm{TM}}$ as described in section 3.8. Error bars indicate the standard error of the mean.

\subsection{Existence of DSB repair proteins on chromatin indicates ongoing repair in cells treated with 5-FU and NCS}

We had previously observed that 5-FU treatment compromises the cells ability to perform homologous recombination repair (Figure 4.4). One reason for the reduction in the repair processes could be the lack of recruitment of repair proteins onto chromatin. In order to understand the molecular basis for the reduced homologous recombination repair in 5-FU treated cells, we checked for the recruitment of several known repair proteins like RPA, Rad51 and Ku70.

We first employed chromatin fractionation, a technique that is used to separate proteins bound to chromatin specifically from the soluble proteins. The presence of proteins on chromatin would indicate that the upstream repair signaling processes are intact, and the cell has the requisite repair machinery to carry out the DNA repair. We found that, $2 \mathrm{~h}$ post NCS treatment, combination of 5-FU and NCS led to minor increase in Rad51 (a key protein involved in HRR, section 1.9.2) recruitment while 5-FU alone did not affect its recruitment (Figure 4.6f). However; $24 \mathrm{~h}$ post NCS treatment, combination treatment caused a marked increase in Rad51 recruitment to the chromatin, with 5-FU alone also showing substantial recruitment (Figure 4.6f). At both the time points NCS alone did not show any significant recruitment of Rad51. This confirmed that in response to DNA damage induced by NCS in 5-FU pretreated cells Rad51 recruitment is not affected. 
Next, we looked at RPA2 recruitment which showed an interesting trend, with $5 \mu \mathrm{M}$ 5 -FU treatment causing a significantly higher enrichment from 2 to $24 \mathrm{~h}$ as compared to combination treatment. However, NCS showed a reduction in the RPA2 levels on chromatin at $24 \mathrm{~h}$ time point. Treatment with 5-FU and/or NCS did not show any effect on the recruitment of Ku70, a protein involved in NHEJ repair (Figure 4.6f).

We then employed immunofluorescence staining and quantified RPA2 foci in 5-FU and NCS treated cells, and found that 5-FU pretreatment led to a very strong and rapid recruitment ( $2 \mathrm{~h}$ post NCS treatment) compared to 5-FU and NCS alone treated cells (Figure 4.6 a-e).

In conclusion, 5-FU and/or NCS do not affect the recruitment of the repair proteins onto chromatin and 5-FU pretreatment accelerates the RPA2 foci formation indicating the severity and extensiveness of the induced DNA damage. As RPA recruitment is a sign of presence of SSDNA, that can arise due to end resection during HRR, we can confirm that indeed the signaling upstream to activate the repair proteins for recruitment is intact and the process of repair proteins coming to the site of DNA damage are also functioning. This also indicates that treatment with 5-FU does not affect the recruitment of repair proteins and therefore rules out the hypothesis that the reduction in HRR observed in response to 5 -FU occurs due to a reduction in the repair proteins on chromatin. 


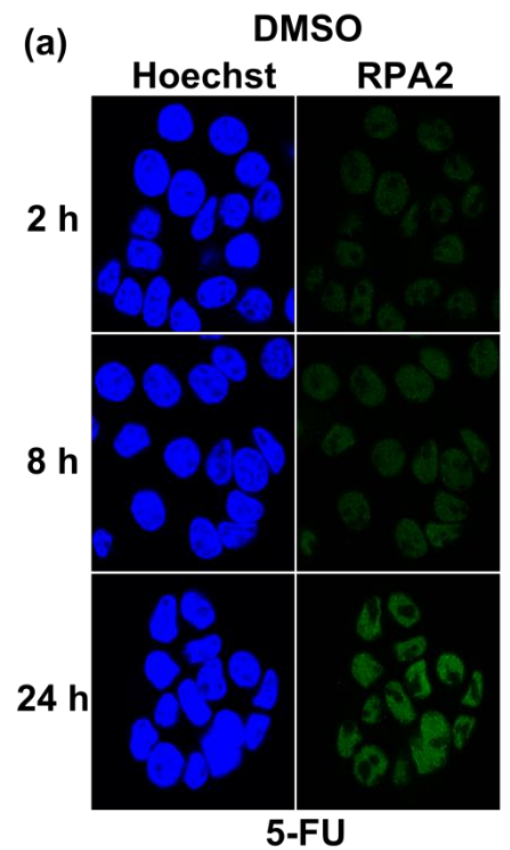

(b) 5-FU+NCS
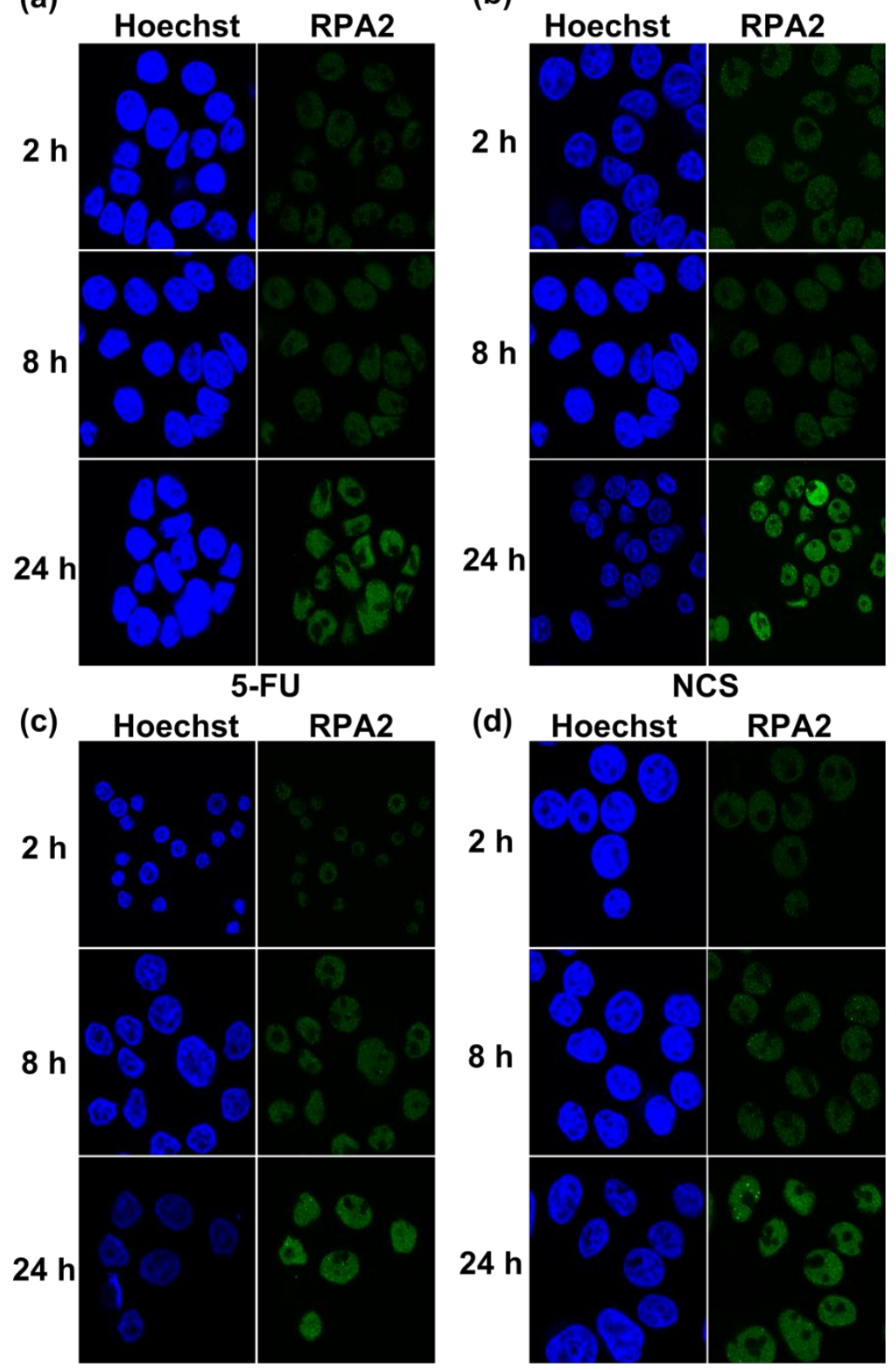

(d) Hoechst RPA2

(e)

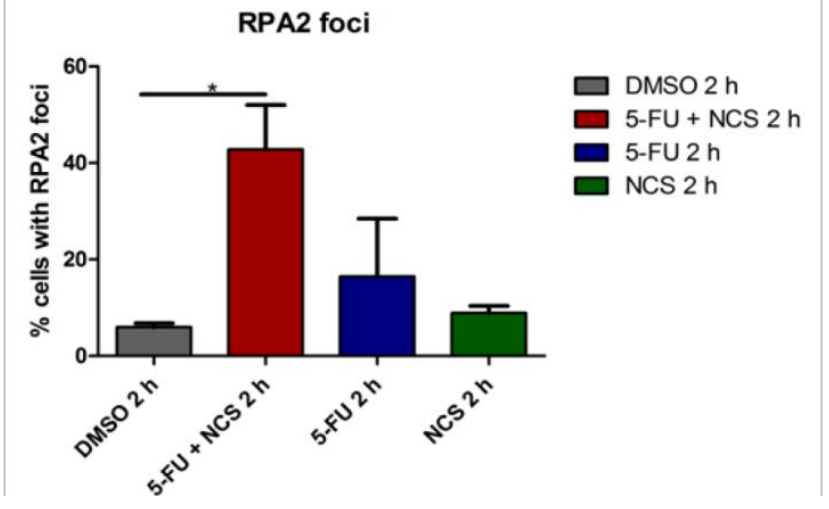


(f)

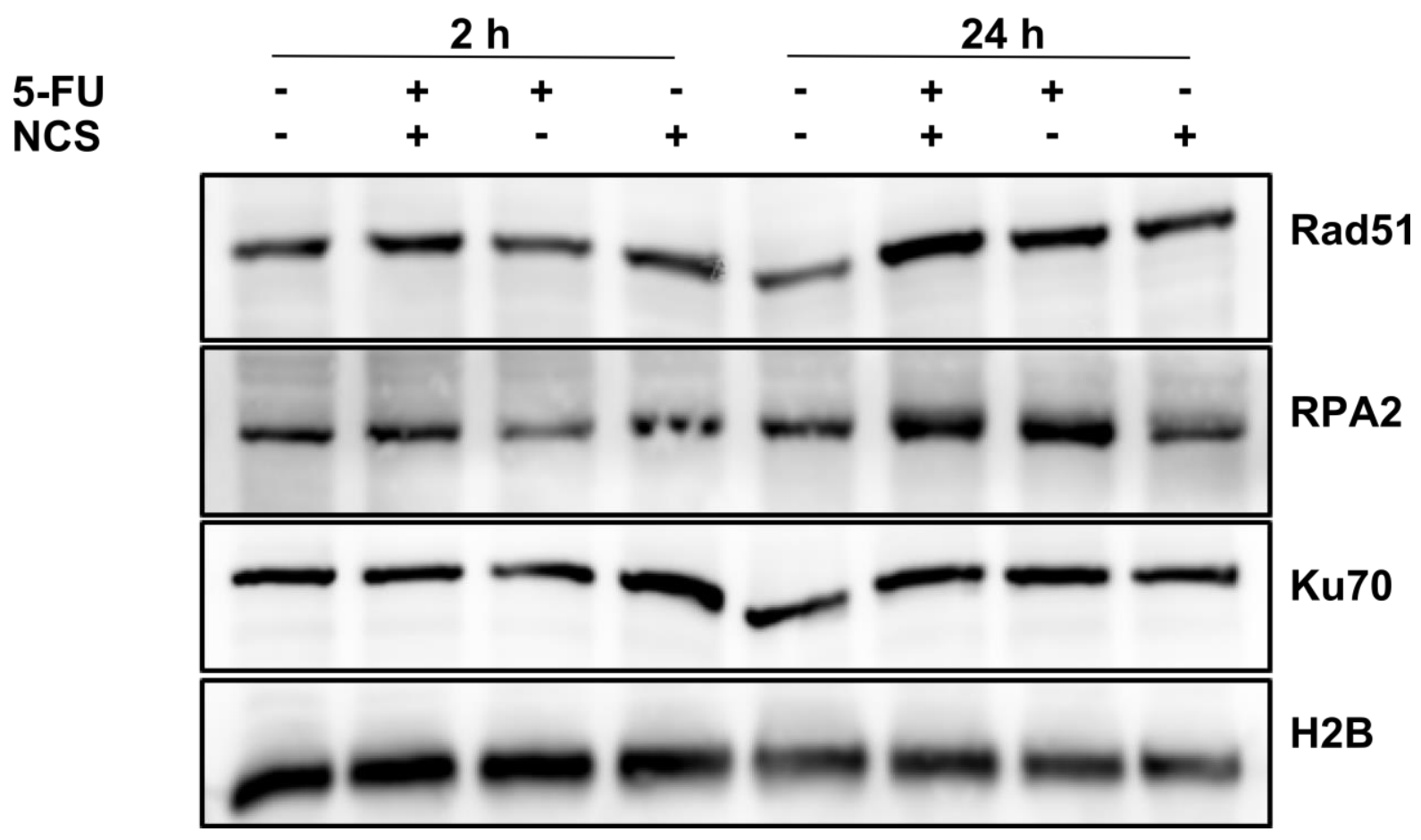

Figure 4.6 Recruitment of repair proteins in response to 5-FU and NCS.

SW480 cells were treated with (a) DMSO, (b) 5-FU (5 $\mu \mathrm{M})+\mathrm{NCS}(100 \mathrm{ng} / \mathrm{ml})$, (c) 5-FU (5 $\mu \mathrm{M})$, and (d) NCS (100 ng/ml); for 2, 8 and $24 \mathrm{~h}$. Cells were fixed with $4 \%$ PFA for $15 \mathrm{~m}$ followed by blocking and incubation with RPA2 overnight at $4^{\circ} \mathrm{C}$. Next, cells were washed with blocking solution and incubated with Alexa 488 goat-anti-mouse for $1 \mathrm{~h}$ in dark. The images were taken using LSM 510 meta (e) RPA2 foci were quantified using FociCounter and percentage of RPA2 positive cells were plotted. Error bars indicate the standard error of the mean. (f) SW480 cells were fractionated into chromatin and soluble fractions. The cells were harvested $2 \mathrm{~h}$ or $24 \mathrm{~h}$ post NCS treatment, fractionated into chromatin and soluble fractions as described in 3.2.2. The samples were analyzed by immunoblotting using indicated antibodies.

\subsection{Ribonucleotide supplementation rescues cells from the persistent $\mathrm{Y}-\mathrm{H} 2 \mathrm{AX}$}

Our first hypothesis that reduction in HRR may be caused due to impaired repair protein recruitment was proved false (Figure 4.6). Since, HRR requires active DNA synthesis, we therefore asked if nucleotide deprivation due to TS inhibition by 5-FU could be causing the observed reduction in HRR. 5-FU treatment 5-FU acts as an anti-cancer chemotherapeutic by causing DNA and RNA damage and TS inhibition (section 1.4.3). TS produces dTMP required for DNA synthesis and its inhibition causes nucleotide pool disruption. 
To this end, we supplemented cells with ribonucleotides wondering if this would allow cells to repair the damaged DNA as they will have the substrates to carry forward the DNA synthesis. As shown earlier, 5-FU alone is capable of reducing HRR (Figure 4.5a), we therefore used a high 5-FU concentration $(100 \mu \mathrm{M})$ to increase the DNA damage in cells. The high 5-FU concentration increased the accumulation of $\mathrm{Y}-\mathrm{H} 2 \mathrm{AX}$ accompanied by apoptosis, as indicated by cleaved caspase 3 . In corroboration of the aforementioned hypothesis, we found that supplementing ribonucleotides markedly decreased the accumulation of $\mathrm{y}-\mathrm{H} 2 \mathrm{AX}$ and cleaved caspase 3. This indicates that the 5-FU generated reduction in HRR efficiency depends on its ability to inhibit TS (Figure 1.7). As we had already ruled out the effect of 5-FU on the recruitment of repair proteins as a possible cause of the reduction in the lack of nucleotides appears to be the only reason for the reduction of $\mathrm{HRR}$ and therefore the persistent $\mathrm{y}-\mathrm{H} 2 \mathrm{AX}$ in cells.

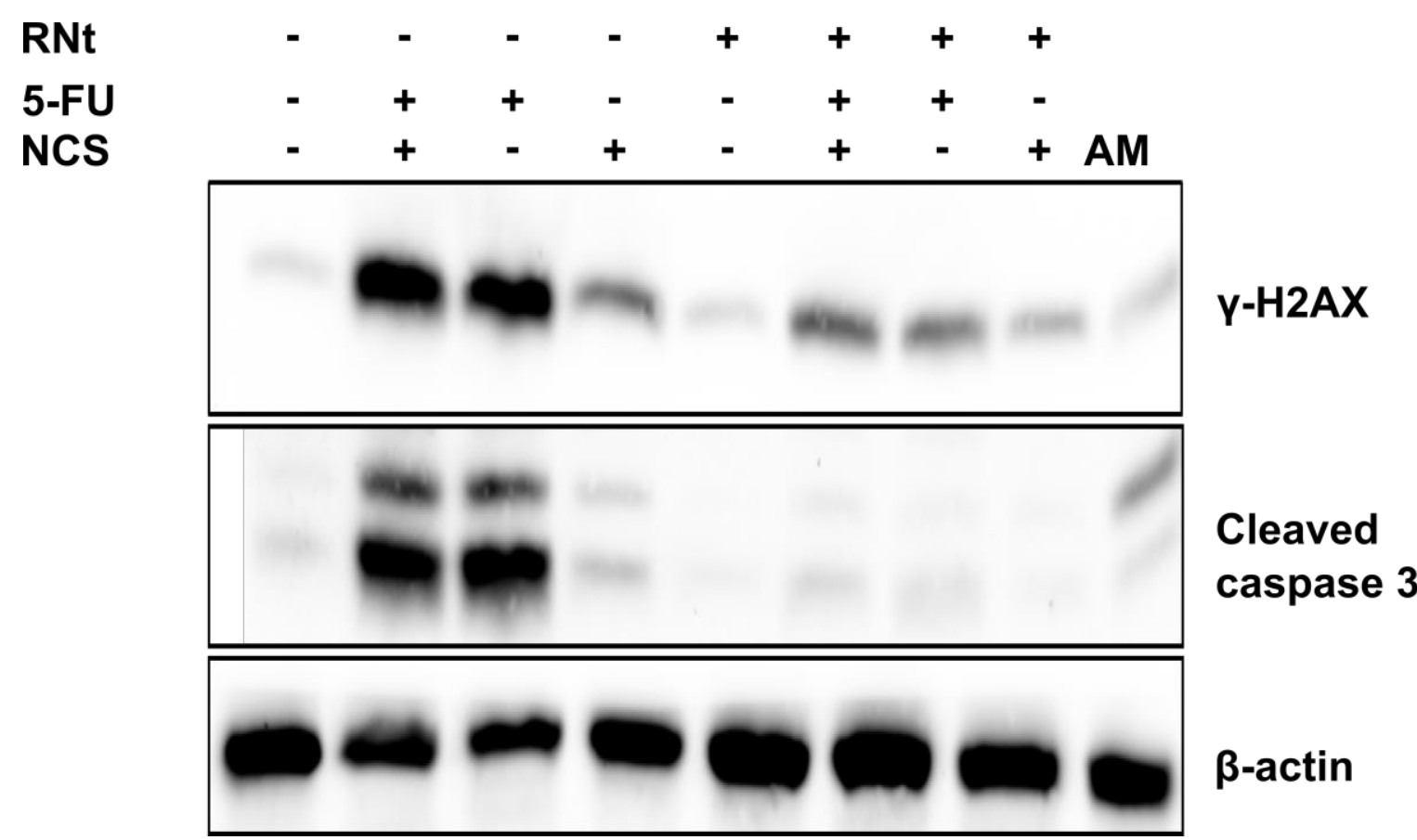

Figure 4.7 Ribonucleotide supplementation reduces the DNA damage and apoptosis in 5-FU and NCS treated cells.

SW480 cells were treated with $100 \mu \mathrm{M} 5$-FU/DMSO for $24 \mathrm{~h}$ followed by treatment with 100 $\mathrm{ng} / \mathrm{ml} \mathrm{NCS}$ and/or ribonucleotides (300 mM of each ribonucleotide) for $24 \mathrm{~h}$. Cells were harvested and whole cell lysates were analyzed by immunoblotting. Immunoblots showing marked reduction of $\mathrm{Y}-\mathrm{H} 2 \mathrm{AX}$ accumulation in cells treated with a combination of 5-FU and NCS or 5-FU alone. AM is a sample treated with cis-platin and served as a positive control for apoptosis. Cleaved caspase 3 was used to detect apoptosis and $\beta$-actin served as a loading control. 


\subsection{Comparison of RNA expression of repair proteins in tumor and mucosa}

We next evaluated the m-RNA expression of repair proteins in human tumors, to check if the expression of repair proteins is affected in tumors. For this purpose we collaborated with Prof. Tim Beißbarth (Department of Medical Statistics, University of Göttingen). The analysis was performed by Dr. Jerzy Dyczkowski based on data set generated by Dr. Jochen Gaedcke (UMG, Göttingen). The data set was derived from colorectal cancer patients undergoing preoperative therapy. Though the patients were administered 5-FU based regimens, information on the drug cocktail and responses for all the patients were not available.

Data set was part of the larger microarray set obtained from Jochen Gaedcke. It contains samples of colorectal tumour and healthy mucosa from 181 patients, which were analysed by Agilent microarrays. Gene expression was normalized and the highest expressed probe was used. Differential expression was analysed by by ttest. Nevertheless, the analysis revealed that proteins involved in HRR namely Rad51 (Figure 4.8a), and BRCA2 (Figure 4.8b) are overexpressed in tumors compared to normal mucosa and the proteins involved in NHEJ namely XRCC5 (Figure 4.8c) and XRCC6 (Figure 4.8d) also were overexpressed. The expression levels indicate the importance of DSB repair pathway for tumors. However, the data set did not allow us to correlate the expression pattern with the benefits of regimens used. In any case, the overexpression of the proteins involved in HRR indicates the reliance of tumors on this pathway. 

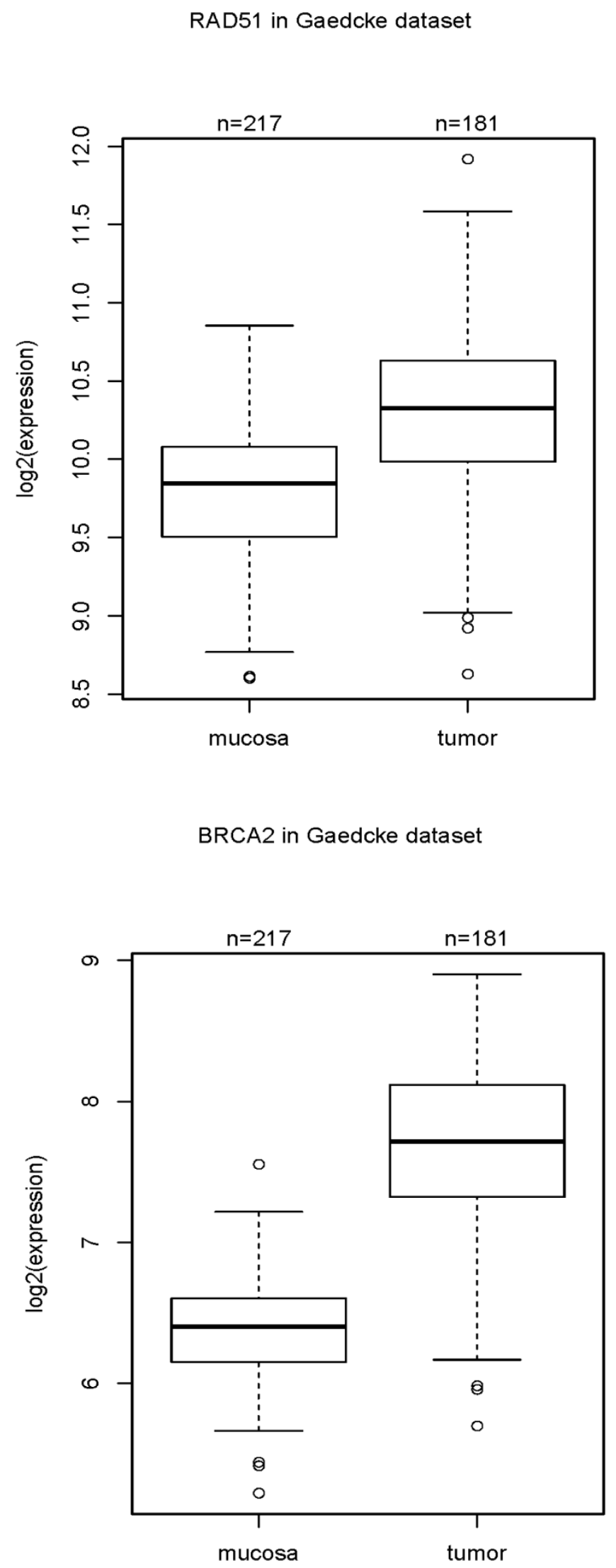

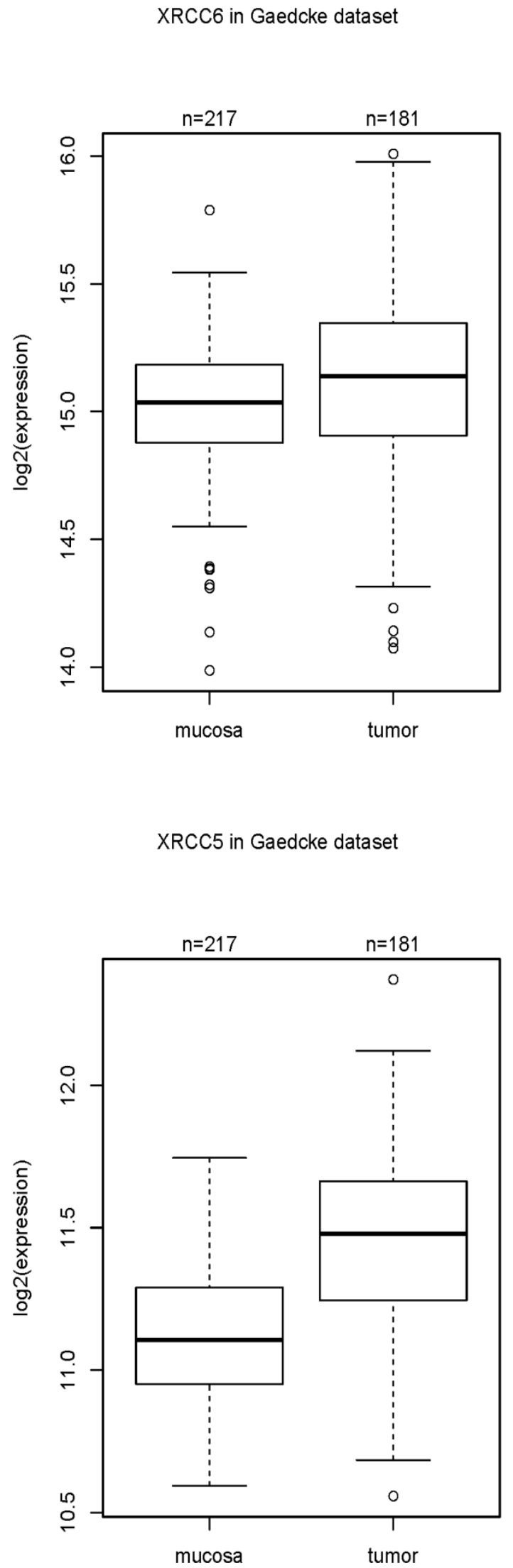
Figure 4.8 Tumors overexpress components of HRR and NHEJ.

Analysis of expression profiles between tumors and mucosa was performed using Gaedcke data set by Jerzy Dyczkowski (Department of Medical Statistics, University of Göettingen). Expression of (a) Rad 51, (b) BRCA2, (c) XRCC5, (d) XRCC6 in human colorectal tumors vs healthy mucosa shown as a boxplot. Refer to text for the method and analysis. $n=$ number of patients analyzed in each set.

\subsection{TS inhibition does not synergize with NCS to induce DNA damage}

From our earlier finding, that lack of nucleotide substrates was causing reduction in HRR efficiency upon 5-FU treatment (Figure 4.7), we decided to deplete cells of TS by knockdown or pharmacological inhibition by Raltitrexed ${ }^{\mathrm{TM}}$ (RTXD). As described earlier, TS affects the dNTP pools, we therefore speculated that TS knockdown should synergize with NCS treatment like 5-FU. So we asked ourselves the question, is the inhibition of TS by 5-FU sufficient to reduce the HRR or the other functions of 5-FU, namely DNA and RNA damage also important for compromising the HRR? We again looked for persistent $\mathrm{y}-\mathrm{H} 2 \mathrm{AX}$ as a marker for the extent of DNA damage.

TS depletion combined with NCS treatment, did not show any synergism (Figure 4.9a) with respect to $\mathrm{Y}-\mathrm{H} 2 \mathrm{AX}$ accumulation and neither the pharmacological inhibition showed any synergism with NCS. Different concentrations of RTXD were used $(700 \mu \mathrm{M}$ to $7 \mathrm{nM})$ to identify synergisms between TS inhibition and NCS treatment (Figure 4.9b). Interestingly, in none of these concentrations could we see any synergisms between RTXD and NCS. This pointed to the fact that synergisms observed with 5-FU were not due to TS inhibition alone.

But to be absolutely certain that TS depletion or inhibition is not the only reason for reduced HRR seen with 5-FU, we depleted TS using siRNA in the SW480 cells and asked if the treatment with NCS will cause persistent $\mathrm{y}-\mathrm{H} 2 \mathrm{AX}$. We observed that depletion of TS followed by treatment with NCS did not produce persistent $\mathrm{Y}-\mathrm{H} 2 \mathrm{AX}$ as was seen with 5-FU (Figure 4.9a). Interestingly, the cells treated with scrambled siRNA and NCS also showed $\mathrm{y}-\mathrm{H} 2 \mathrm{AX}$ and this can be attributed to the lipofectamine based transfections which are known to stress the cells. This therefore proves that inhibition of TS is not the only reason for reduced HRR. 
We next studied the effect of 5-FU on TS knockdown wondering if the lack of TS would render cells more sensitive or resistant to 5-FU. Since, 5-FU inhibits TS, one possibility could be that the effect of 5-FU would be greatly reduced in the absence of its substrate, while the other possibility could be, greater misincorporation of the 5FU metabolite FdUTP leading to more DNA damage. Surprisingly, we found that in the absence of TS, 5-FU treatment increased the $\mathrm{Y}-\mathrm{H} 2 \mathrm{AX}$ accumulation (Figure 4.9c). This points to the validity of the second possibility that in the absence of TS the misincorporation of FdUTP increases causing more DNA damage.

In conclusion, we could not see any synergism between TS inhibition by RTXD and TS depletion by siRNA and NCS indicating that molecular reason for synergism observed between 5-FU with NCS is dependent not only on TS inhibition but also rely on the DNA and RNA damage induced by $5-\mathrm{FU}$. The fact that there was no $\mathrm{Y}$ $\mathrm{H} 2 \mathrm{AX}$ accumulation $24 \mathrm{~h}$ post NCS treatment also indicates that TS inhibition alone is not sufficient to compromise the HRR as was observed with 5-FU. The activation of DNA damage response and $\mathrm{Y}-\mathrm{H} 2 \mathrm{AX}$ accumulation in TS depleted cells treated with 5-FU is surprising but as described earlier could be the result of increased misincorporation of the FdUTP. 
(a)

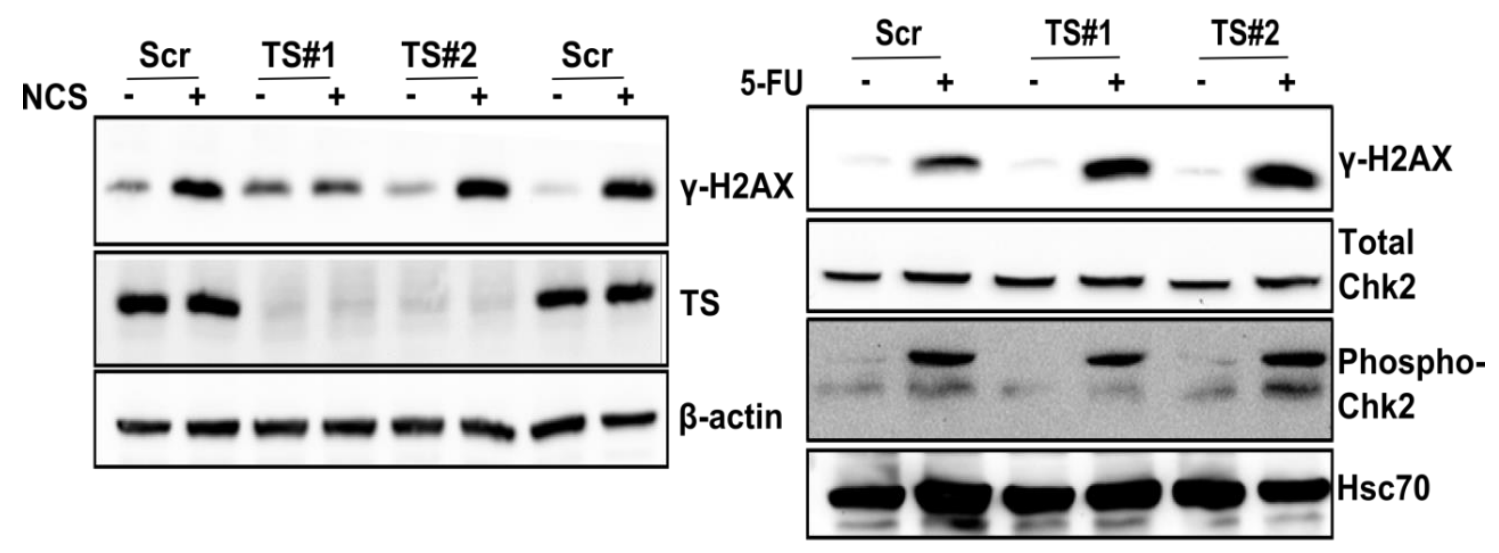

(c)

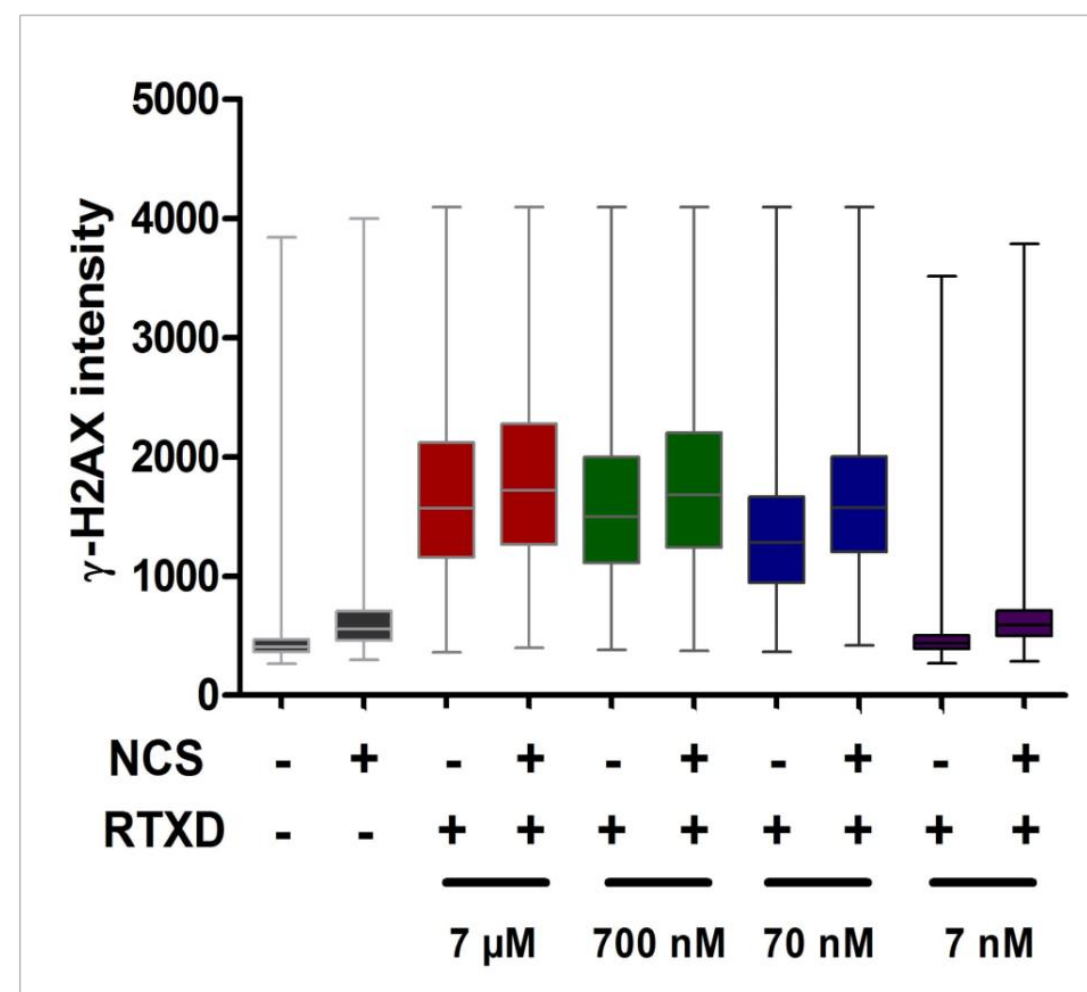

Figure 4.9 Depletion of TS using siRNA or pharmacological inhibition does not synergize with NCS.

(a) \& (b) SW480 cells were depleted of thymidylate synthetase (TS) using siRNA mediated transfections. $16 \mathrm{~h}$ post transfections, cells were treated with 5-FU or NCS for $24 \mathrm{~h}$ respectively. Cells were harvested and lysates were analyzed by immunoblotting using the indicated antibodies. (c) SW480 cells were treated with Raltitrexed (RTXD) for $24 \mathrm{~h}$ followed by $100 \mathrm{ng} / \mathrm{ml} \mathrm{NCS}$ for $24 \mathrm{~h}$. Cells were fixed, stained for $\mathrm{Y}-\mathrm{H} 2 \mathrm{AX}$ and fluorescence intensity quantified as described in section 3.4. The $\mathrm{y}-\mathrm{H} 2 \mathrm{AX}$ intensities were plotted as boxplots. Scr-Scrambled siRNA. TS-Thymidylate synthetase. 


\subsection{MK2 knock down does not rescue SW480 cells from the effects of 5- FU}

Mitogen activated protein kinase- activated protein kinase 2 (MK2) was recently shown to reduce the $\mathrm{y}-\mathrm{H} 2 \mathrm{AX}$ accumulation in response to gemcitabine, another nucleoside analog used in cancer treatment (Köpper et al., 2013). We asked if MK2 depletion or inhibition could have a similar effect on 5-FU induced DNA damage. The reason behind this assumption was that both these nucleoside analogues are capable of misincorporation in DNA and we wanted to know if MK2 expression can be correlated to the outcome of 5-FU treatment.

To this end, we depleted MK2 in cells using siRNA and treated them with 5-FU. The immunoblotting showed that there was no rescue in terms of $\mathrm{y}-\mathrm{H} 2 \mathrm{AX}$ level reduction as reported for gemcitabine (Figure $4.10 \mathrm{a}$ ). We had used two different 5-FU concentrations namely, $100 \mu \mathrm{M}$ and $5 \mu \mathrm{M}$ to see if the extent of DNA damage induced may dictate the involvement of MK2. But in neither case did we see any significant effect of MK2 depletion and this gave us a hint that MK2 cannot rescue the cells from the effects of 5-FU induced DNA damage.

We next performed cell proliferation assays that showed no significant increase of cell proliferation in cells treated with a combination of MK2 inhibitor and 5-FU (Figure 4.10 b). Additionally, the DNA damage induced by NCS alone was also not significantly altered by the presence of MK2 inhibitor (Figure 4.10a) and the effect on cell proliferation was also not drastic in NCS treated cells (Figure $4.10 \mathrm{c}$ ). Similarly, MK2 did not show any rescue effect in cells treated with 5-FU in combination with NCS. These observations led us to conclude that MK2 does not participate in 5-FU induced DNA damage like it does for gemcitabine induced DNA damage. This also means that the expression of MK2 may not play a significant role in deciding the fate of 5-FU based regimens. 
(a)

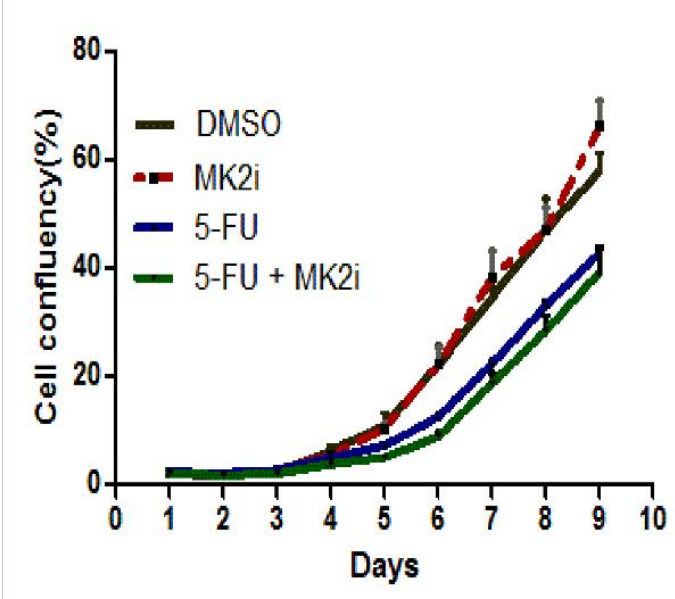

(c)

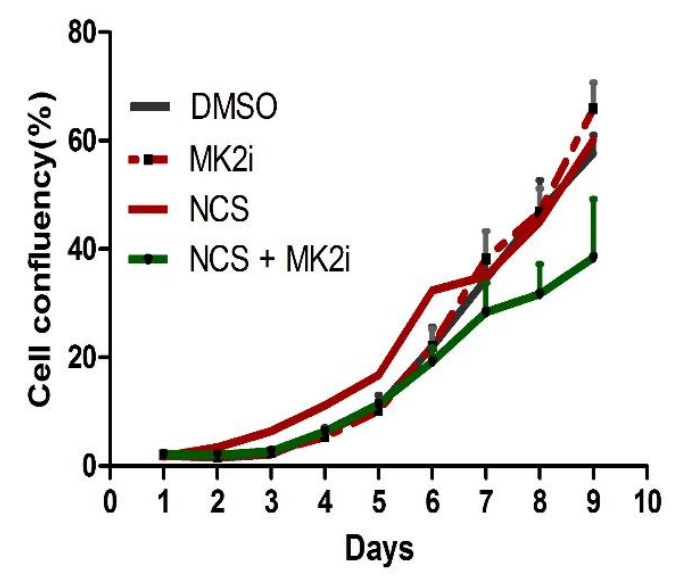

(b)

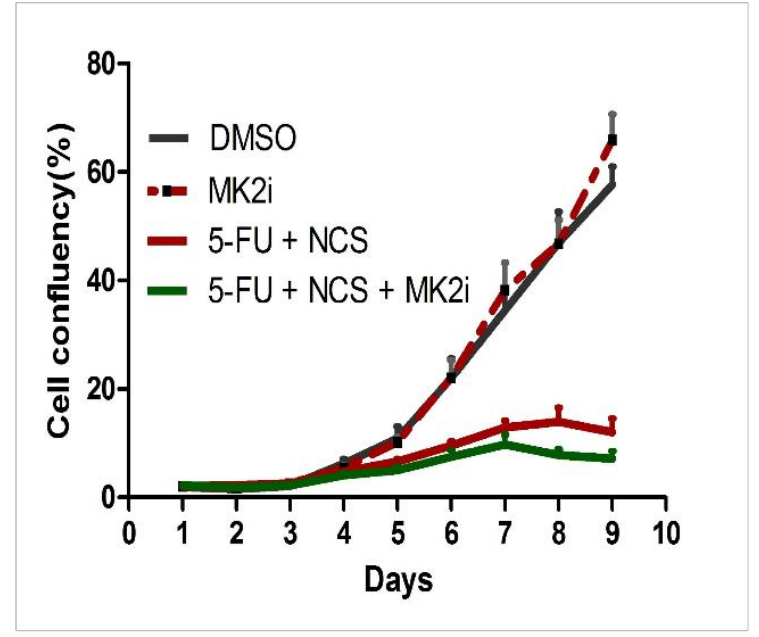

(d)

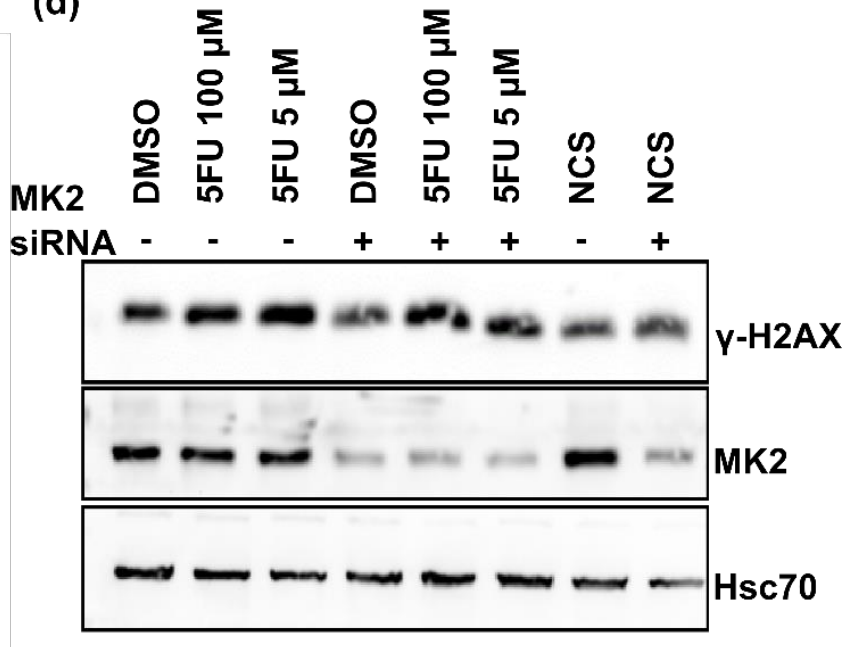

Figure 4.10 5-FU induced DNA damage is not rescued by MK2 inhibition.

MK2 was either depleted using siRNA or using a pharmacological inhibitor (MKi) in SW480 cells. (a) Cells treated with 5-FU for $24 \mathrm{~h}$. (b) Cells treated with 5-FU/DMSO with or without MK2 inhibitor for $24 \mathrm{~h}$ followed by NCS for $24 \mathrm{~h}$ (c) cells treated with $100 \mathrm{ng} / \mathrm{ml} \mathrm{NCS}$ for $24 \mathrm{~h}$ with or without MK2 inhibitor, cell confluency was measured every day using cyntellect celigo $^{\mathrm{TM}}$. See section 3.1.10 for method (d) Cells depleted of MK2 were treated with 5FU/DMSO for $24 \mathrm{~h}$ followed by treatment with $100 \mathrm{ng} / \mathrm{ml} \mathrm{NCS}$ for $24 \mathrm{~h}$, the samples were harvested and whole cell lysates analyzed by immunoblotting using the indicated antibodies.

\subsection{Gemcitabine also leads to accumulation of $\mathrm{Y}-\mathrm{H} 2 \mathrm{AX}$ but is accompanied with apoptosis in SW480 cells}

Since it is known that 5-FU as well as gemcitabine disrupt the nucleotide pools (see section 1.4.4), we next investigated if the treatment of colorectal cancer cells with 
gemcitabine would produce similar effects as $5-\mathrm{FU}$ in synergizing with NCS. The question we addressed was, is 5-FU unique in reducing the HRR or do other nucleoside analogues like gemcitabine that also effect the nucleotide pools also able to show similar behavior?

We investigated the accumulation of $\mathrm{Y}-\mathrm{H} 2 \mathrm{AX}$ using immunoblotting and quantitative immunofluorescence. We found that gemcitabine, at concentrations of $100 \mathrm{nM}$ caused accumulation of $\mathrm{Y}-\mathrm{H} 2 \mathrm{AX}$ in SW480 cells albeit with accompanying apoptosis, as confirmed by the presence of cleaved Caspase 3. This meant the source of $y$ $\mathrm{H} 2 \mathrm{AX}$ could not be attributed to DDR alone as apoptosis also leads to $\mathrm{y}-\mathrm{H} 2 \mathrm{AX}$ accumulation.

In order to avoid the interference of apoptosis in the accumulation of $y-H 2 A X$, we used ZVAD-FMK, a pan-caspase inhibitor. Here, we observed persistent $\mathrm{Y}-\mathrm{H} 2 \mathrm{AX}$, in the immunoblots, with gemcitabine without any apoptosis however we did not find any synergism with NCS (Figure 4.11a). In fact, gemcitabine alone was able to induce large accumulation of $\mathrm{y}-\mathrm{H} 2 \mathrm{AX}$ indicating that the SW480 cells are very sensitive to gemcitabine.

We speculated that gemcitabine at this concentration $(100 \mathrm{nM})$ was capable of overwhelming cells repair machinery which led us to perform titrations to look for concentrations at which synergisms with NCS could be possible. To our surprise, even at a broad range of gemcitabine concentrations (500-5 nM) we did not find any synergism with NCS (Figure 4.11d).

We next performed cell proliferation assay to assess the effect of gemcitabine on rate of cell proliferation. At $100 \mathrm{nM}$ gemcitabine concentration we observed acute cytotoxicity but could not attribute this cell death to synergism with NCS (Figure 4.11c). At a lower concentration of gemcitabine $(10 \mathrm{nM})$ there was some reduction in proliferation with NCS but here too the synergistic effect was missing. At $5 \mathrm{nM}$ gemcitabine concentration there was no effect on cell proliferation with or without NCS (Figure 4.11b). We therefore concluded that gemcitabine does not synergize with NCS at various concentrations tested in this study in SW480 cells. As there was no synergism observed between gemcitabine and NCS we could not see any effect on persistence of $\mathrm{y}-\mathrm{H} 2 \mathrm{AX}$ as gemcitabine alone was able to induce equal amount of 
DNA damage as in combination with NCS. Therefore in the scope of current studies we could not conclude the effect of gemcitabine on HRR in SW480 cells.

(a)

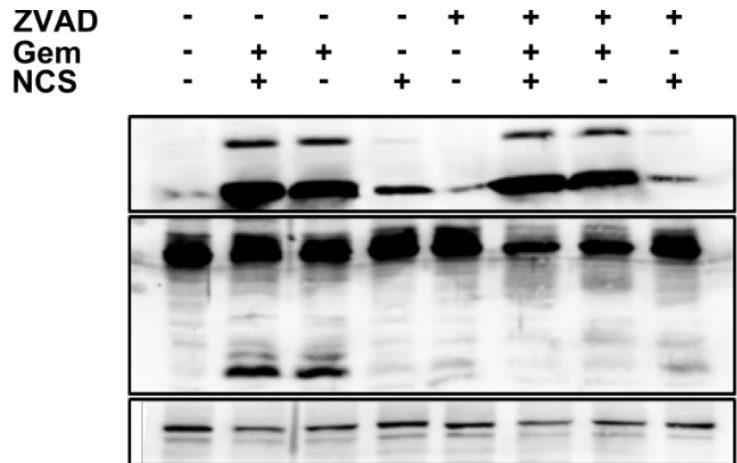

$\mathrm{Y}-\mathrm{H} 2 \mathrm{AX}$

Caspase 3

Cleaved

caspase 3

$\beta$-actin

(b)

(c)
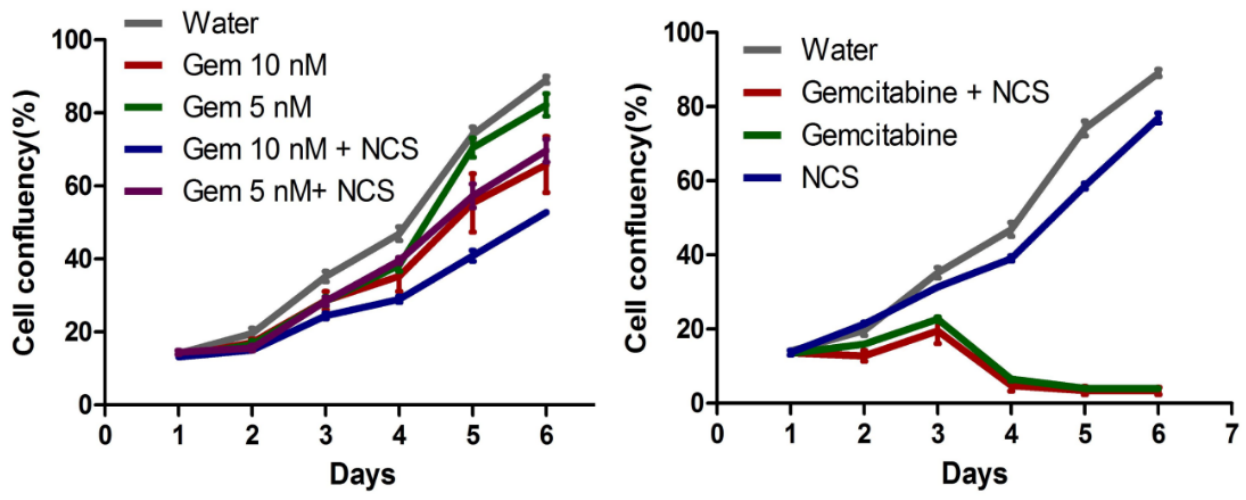

(d)

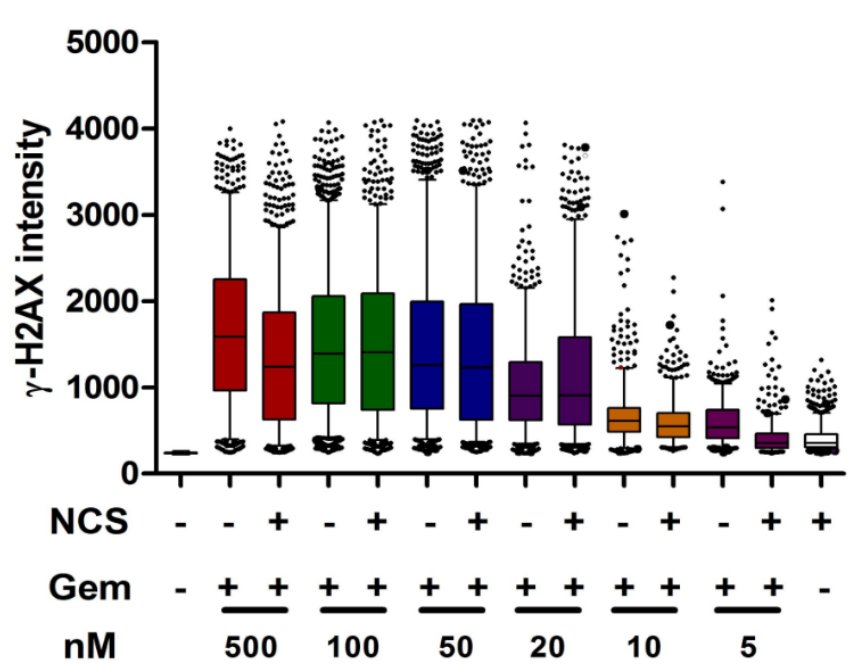

Figure 4.11 Gemcitabine exhibits concentration dependent cytotoxicity but does not synergize with NCS.

SW480 cells were treated with $100 \mathrm{nM}$ gemcitabine for $24 \mathrm{~h}$ followed by NCS for $24 \mathrm{~h}$. ZVAD was added to prevent apoptosis. Cells were harvested and whole cell lysates were analyzed by immunoblotting using the indicated antibodies.(b) SW480 cells were treated with 5 and $10 \mathrm{nM}$ gemcitabine for $24 \mathrm{~h}$ followed by treatment with NCS for $24 \mathrm{~h}$. (c) SW480 cells were treated with $100 \mathrm{nM}$ gemcitabine on day 1 and $100 \mathrm{ng} / \mathrm{ml}$ NCS on day2. 
Measurements were made at $24 \mathrm{~h}$ intervals using cyntellect celigo ${ }^{\mathrm{TM}}$ as described in section 3.1.10. (d) SW480 cells were treated with indicated gemcitabine concentrations ( $500 \mathrm{nM}$ to 5 $\mathrm{nM}$ ) for $24 \mathrm{~h}$ followed by $100 \mathrm{ng} / \mathrm{ml} \mathrm{NCS}$ for $24 \mathrm{~h}$. The cells were fixed and stained for $\mathrm{Y}-$ $\mathrm{H} 2 \mathrm{AX}$ as described in section 3.4. Automated microscopy and image analysis was performed using BD pathway ${ }^{T M}$ system and results shown as box plot $(n=3)$.

\subsection{Ribonucleotide supplementation does not rescue gemcitabine treated cells}

As earlier with 5-FU (Figure 4.7), we then investigated if the DNA damage induced by gemcitabine could be overcome by supplementing ribonucleotides as was observed with 5-FU (Figure 4.9). To this end we supplemented SW480 cells with $300 \mathrm{mM}$ each of all the four ribonucleotides. The idea was that if the treatment of gemcitabine completely inhibited the function of $R R$, the supplementation of ribonucleotides should not have any effect on the DNA damage repair. Expectedly, supplementation of gemcitabine treated cells with ribonucleotides did not reduce $\mathrm{Y}$ $\mathrm{H} 2 \mathrm{AX}$ levels (Figure 4.12). This was so because gemcitabine had already compromised the ability of cells to produce deoxynucleotides from ribonucleotides indicating absolute inhibition of RR. Not surprisingly, DDR was not attenuated either as seen by the high levels of phosphorylated Chk2. In comparison, 5-FU induced DNA damage and DDR could be effectively attenuated by ribonucleotide supplementation. In conclusion, ribonucleotide supplementation rescued 5-FU treated cells but not gemcitabine treated cells indicating that RR inhibition by gemcitabine is absolute in SW480 cells at a concentration of $100 \mathrm{nM}$ gemcitabine. 


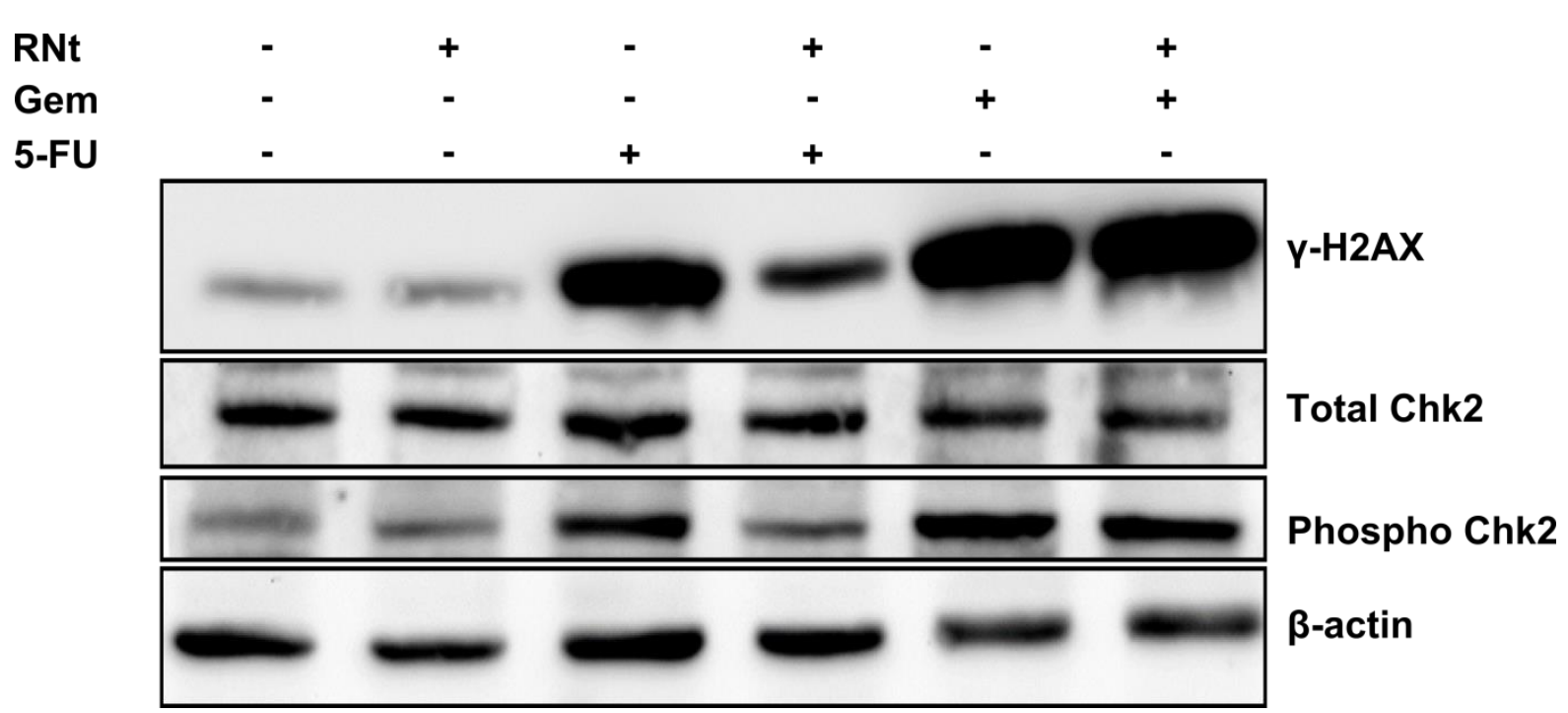

Figure 4.12 Ribonucleotide supplementation does not rescue gemcitabine treated cells.

SW480 cells were treated with $5 \mu \mathrm{M} 5-\mathrm{FU} / 100 \mathrm{nM}$ gemcitabine/DMSO for $24 \mathrm{~h}$ followed by $1 \mathrm{X}$ ribonucleotides and/or $100 \mathrm{ng} / \mathrm{ml}$ NCS for $24 \mathrm{~h}$. Samples were harvested and whole cell lysates were analyzed by immunoblotting using the indicated antibodies. Antibodies to $y$ H2AX were used to quantify the extent of the DNA damage response, pChk2 was used to check for activation of DNA double strand break signaling, whereas $\beta$-actin was detected as a loading control.

\subsection{HU induced ribonucleotide reductase inhibition or depletion of RRM2 does not synergize with NCS in SW480 cells}

We next questioned, what would be the effect of specifically inhibiting ribonucleotide reductase (RR) on $\mathrm{Y}-\mathrm{H} 2 \mathrm{AX}$ persistence in SW480 cells? This was of interest as inhibiting or depleting RR would cause disruptions in nucleotide pools. As shown earlier, disruption of nucleotide pools along with DNA and RNA damage inducing properties of 5-FU are responsible for the reduction in HRR, we therefore asked, does the inhibition of RR also would cause persistent $\mathrm{y}-\mathrm{H} 2 \mathrm{AX}$. Gemcitabine, apart from inhibiting RR also causes termination of DNA synthesis (section 1.4.4) therefore the extent of the role of RR cannot be clearly understood. In order to probe the role of RR in DNA damage repair, we used a specific RR inhibitor, hydroxyurea (HU). SW480 cells treated with $1 \mathrm{mM} \mathrm{HU}$ showed a large accumulation of $\mathrm{y}-\mathrm{H} 2 \mathrm{AX}$, but this was accompanied by apoptosis as was confirmed by the presence of cleaved PARP and cleaved caspase 3 (Figure 4.13a). We therefore concluded that $\mathrm{HU}$ is lethal to SW480 cells and therefore not suitable for continuing the studies on 
$R R$ inhibition and studying the effects of RR inhibition on persistent $\mathrm{y}-\mathrm{H} 2 \mathrm{AX}$ and later the effect on HRR.

Since the inhibition of RR by HU was lethal to CRC cells, we decided to deplete RR from cells using siRNA. RR functions as a heterodimeric tetramer consisting of a large RRM1 and a smaller RRM2 subunit. We targeted the RRM2 using siRNA and depleting the cells of RRM2 led to the accumulation of $\mathrm{Y}-\mathrm{H} 2 \mathrm{AX}$ (Figure 4-13 b and c) indicating the stress induced by the depletion. Combining the knockdown of RRM2 with NCS induced higher $\mathrm{Y}-\mathrm{H} 2 \mathrm{AX}$ accumulation though there was no synergism between RR inactivity and (Figure 4.13c). This suggested that no significant radiosensitization is achieved upon depletion of RRM2 in CRC cells. 5-FU in RRM2 depleted cells caused an increase in the $\mathrm{y}-\mathrm{H} 2 \mathrm{AX}$ levels but this was additive in nature and not synergistic. Further, depleting the cells of RRM2 did not cause activation of Chk2 but its combination with 5-FU resulted in additive effect on Chk2 activation.

In conclusion, hydroxyurea is too toxic even at small concentrations to show synergism with NCS. Depletion of RRM2 shows some additive effects with NCS but no synergism and RRM2 depletion with 5-FU $(5 \mu \mathrm{M})$ treatment also show additive effects which may be attributed to their individual effects. Taken together, inhibition of RR by a specific inhibitor HU could not be used to confirm the effect of RR inhibition on the persistent $\mathrm{Y}-\mathrm{H} 2 \mathrm{AX}$ while the depletion of RRM2 by siRNA indicates that there is some additive effect but no effect on persistence of $y-H 2 A X$. This therefore indicates that RR inhibition or depletion in combination with NCS does not synergize to produce persistent $\mathrm{y}-\mathrm{H} 2 \mathrm{AX}$. The large $\mathrm{y}-\mathrm{H} 2 \mathrm{AX}$ levels seen upon inhibition or depletion of RR or its components indicate that the cells are stressed and incur DNA damage but this is independent of the NCS treatment. The combination of $5-\mathrm{FU}$ with RR depletion also does not produce any synergisms indicating that the $\mathrm{y}-\mathrm{H} 2 \mathrm{AX}$ observed is from the additive effect. 
(a)

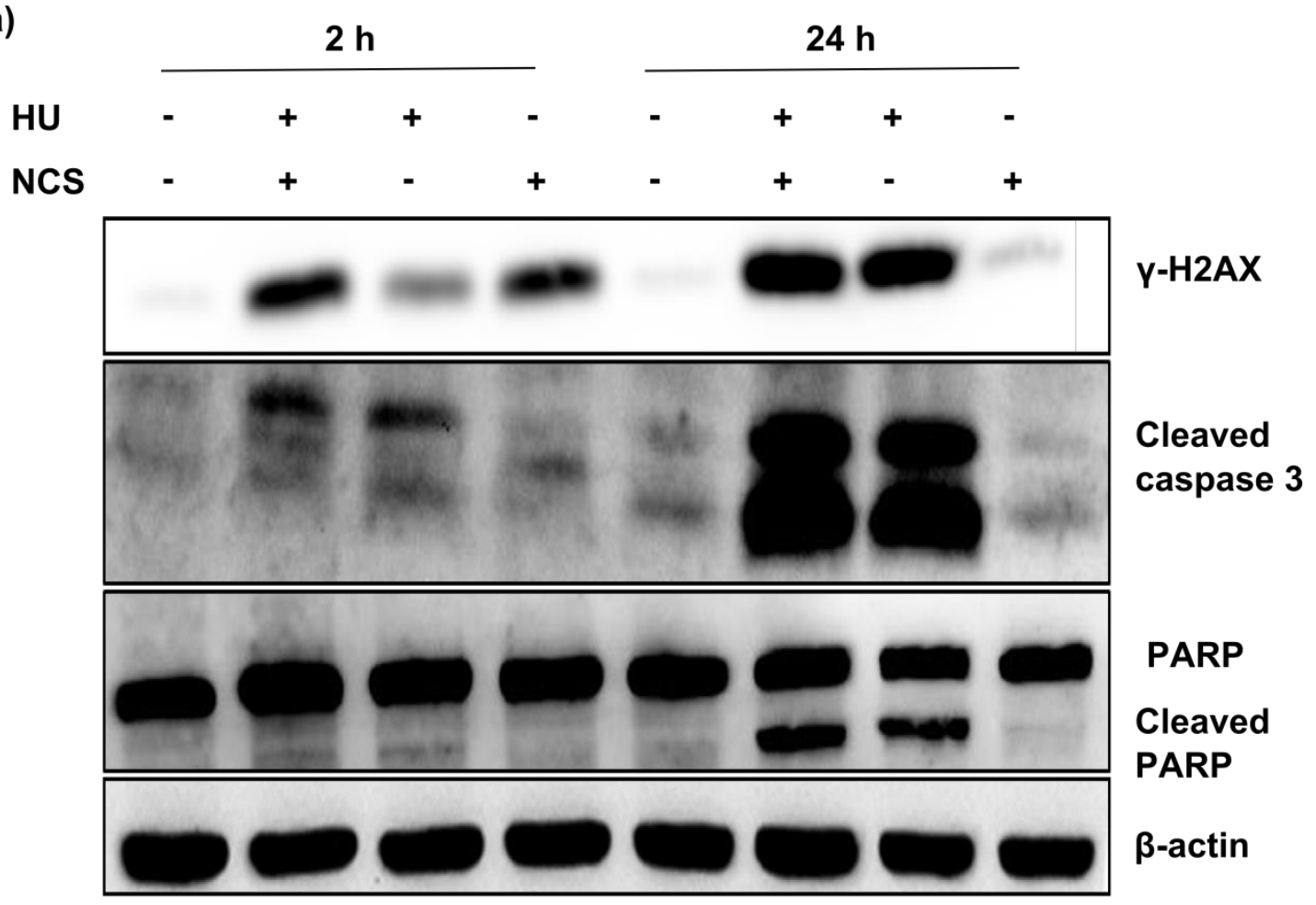

(b)

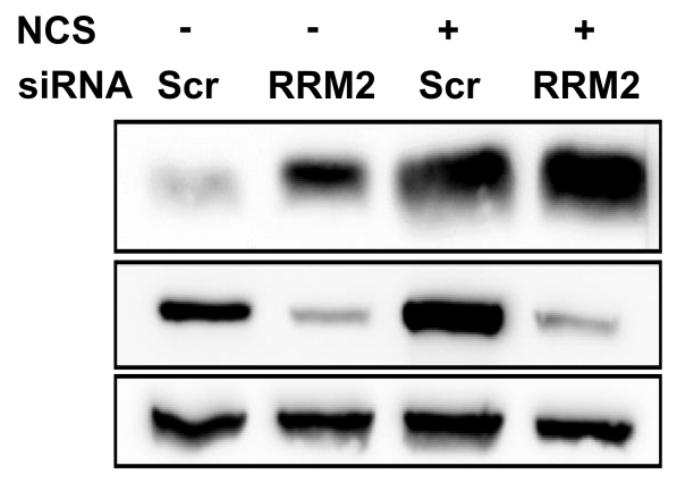

(c)

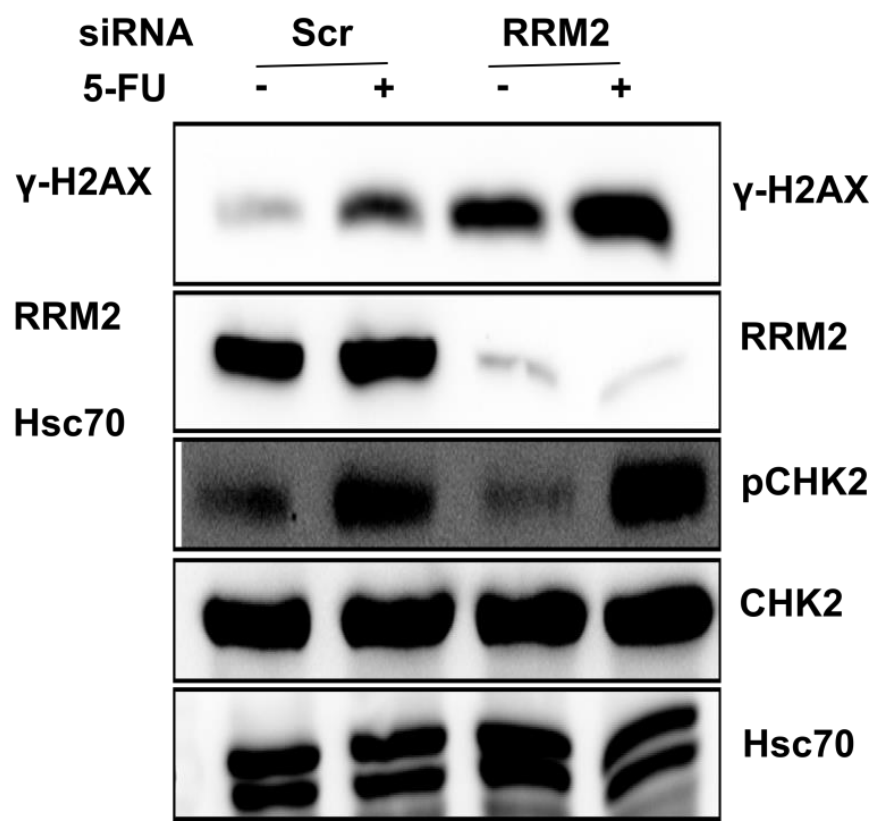

Figure 4.13 Ribonuleotide reductase inhibition or depletion of RRM2 causes DNA damage but does not synergize with NCS.

(a) SW480 cells were treated with $1 \mathrm{mM} \mathrm{HU}$ for $24 \mathrm{~h}$ followed by $100 \mathrm{ng} / \mathrm{ml} \mathrm{NCS}$ for 2 or 24 h. (b) SW480 cells were depleted of the cellular RRM2 using siRNA mediated knockdowns SW480 cells treated with $100 \mathrm{ng} / \mathrm{ml}$ NCS for $24 \mathrm{~h}$. (c) SW480 cells were depleted of the cellular RRM2 using siRNA mediated knockdowns. The cells were treated with 5-FU for 24 h. Samples were harvested and whole cell lysates were analyzed by immunoblotting using the indicated antibodies. $\beta$-actin/ Hsc70 staining served as a loading control. 


\subsection{Antagonizing HRR also results in persistent $\mathrm{YH2AX}$ in SW480 cells}

HRR is an essential component of DNA repair in cells, and it has been shown that targeting this machinery can cause radiosensitization. Based on our earlier observation that 5-FU reduces HRR, we next investigated if inhibition of HRR would give a similar phenotype as 5-FU, i.e. persistent $\mathrm{y}-\mathrm{H} 2 \mathrm{AX}$. This experiment could elucidate if the inhibition of HRR produces persistent $\mathrm{Y}-\mathrm{H} 2 \mathrm{AX}$, further incriminating 5FU as an agent that inhibits HRR.

To this end, we employed a newly discovered Rad51 inhibitor B02, to inhibit the HRR. Treatment with $10 \mathrm{mM} \mathrm{B02}$ alone was sufficient to cause accumulation of $\mathrm{y}$ $\mathrm{H} 2 \mathrm{AX}$ though this was accompanied by apoptosis, confirmed by the presence of cleaved PARP and cleaved caspase 3 (Figure 4.14). Upon inhibition of apoptosis with $20 \mu \mathrm{M}$ ZVAD-FMK, B02 did not show any significant $\mathrm{Y}-\mathrm{H} 2 \mathrm{AX}$ accumulation, thus confirming that $\mathrm{y}-\mathrm{H} 2 \mathrm{AX}$ accumulation seen with $\mathrm{B} 02$ was due to apoptosis. $\mathrm{B} 02$ in combination with NCS led to persistent $\mathrm{Y}-\mathrm{H} 2 \mathrm{AX}$ similar to $5-\mathrm{FU}$ in combination with NCS. This observation further affirms our hypothesis that 5 -FU affects the efficiency with which CRC cells perform the HRR.

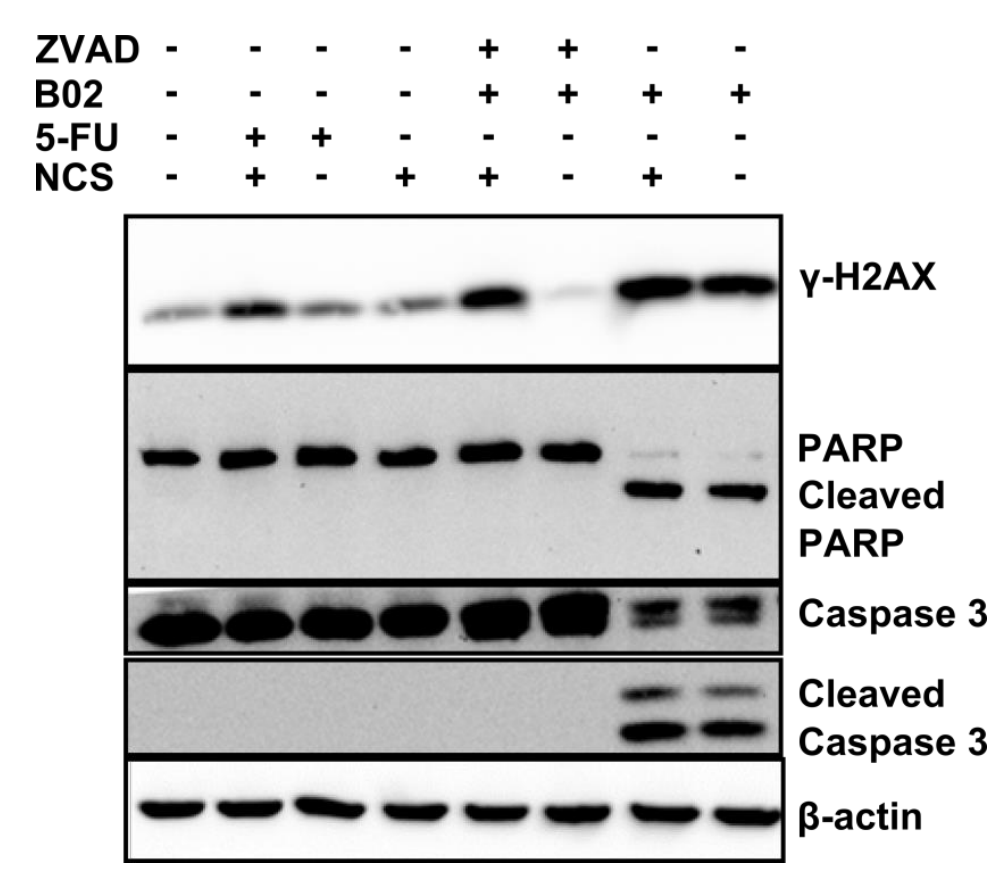

Figure 4.14 Inhibition of HRR by Rad51 inhibitor also causes persistent $\mathrm{Y}-\mathrm{H} 2 \mathrm{AX}$. 
SW480 cells were treated with $5 \mu \mathrm{M} 5$-FUIDMSOI $10 \mathrm{mM}$ B02 for $24 \mathrm{~h}$ followed by NCS and/or $20 \mu \mathrm{M}$ ZVAD for $24 \mathrm{~h}$. The samples were harvested and analyzed by immunoblotting using the indicated antibodies. Antibodies to $\mathrm{Y}-\mathrm{H} 2 \mathrm{AX}$ were used to quantify the extent of the DNA damage response, antibodies to cleaved caspase 3 and cleaved PARP were used to quantify the extent of apoptosis. $\beta$-actin staining served as a loading control.

\subsection{Investigating the role of mismatch repair system}

The role of MMR in the context of 5-FU has been extensively studied (Jiricny et al, 2006) and it has been speculated to act upstream of HRR (Mohindra et al., 2002) as its regulator. Acknowledging the role of MMR in 5-FU induced DNA damage, we studied the possible interaction between HRR and MMR in our treatments. Two of the important components of the MMR system are MLH1 and MSH2 (section 1.10). With this background, we wanted to know if MMR inhibition reduces the efficiency of $\mathrm{HRR}$. For this purpose we again used persistent $\mathrm{y}-\mathrm{H} 2 \mathrm{AX}$ as readout $(\mathrm{y}-\mathrm{H} 2 \mathrm{AX}$ observed $24 \mathrm{~h}$ post-NCS treatment) for DNA damage and effect on HRR.

To investigate the role of MMR as a regulator of HRR, we depleted SW480 cells of $\mathrm{MLH} 1$ and $\mathrm{MSH} 2$ and analyzed the samples using immunoblotting. Depletion of MLH1 and MSH2 in combination with NCS did not show any effect on the accumulation of $\mathrm{Y}-\mathrm{H} 2 \mathrm{AX}$ (Figure 4-16a \& 16b). Absence of apoptosis was confirmed from the lack of cleaved PARP, indicating that the $\mathrm{y}-\mathrm{H} 2 \mathrm{AX}$ levels were solely due to DNA damage and not due to apoptosis. However, 5-FU treatment in MLH1 and MSH2 depleted cells increased $\mathrm{y}-\mathrm{H} 2 \mathrm{AX}$ levels moderately but was not convincing to confirm synergistic effect. This was expected as MMR plays a critical role in identifying and repairing the damage induced by $5-\mathrm{FU}$. Therefore lack of $\mathrm{MSH} 2$ or MLH1 will render cells incapable of detecting and repairing the DNA damage induced by $5-\mathrm{FU}$ alone which may be a cause for increased $\mathrm{Y}-\mathrm{H} 2 \mathrm{AX}$ in cells. Interestingly, we also observed an increase in total Rad51 levels in response to both NCS and 5-FU but the differences could not be attributed to MLH1 depletion. This may indicate cells attempt to repair the damaged DNA, but because we do not see a corresponding reduction in $\mathrm{y}-\mathrm{H} 2 \mathrm{AX}$ levels it is hard to predict what this increased Rad51 levels mean. 
These results indicate that MMR may play only a minor role in HRR though depleting SW480 cells of the components of MMR slightly increased the DNA damaging activity of 5-FU. This therefore means that the presence or absence of MMR may not affect the HRR itself but may have a greater effect on the treatment with 5-FU.

(a)
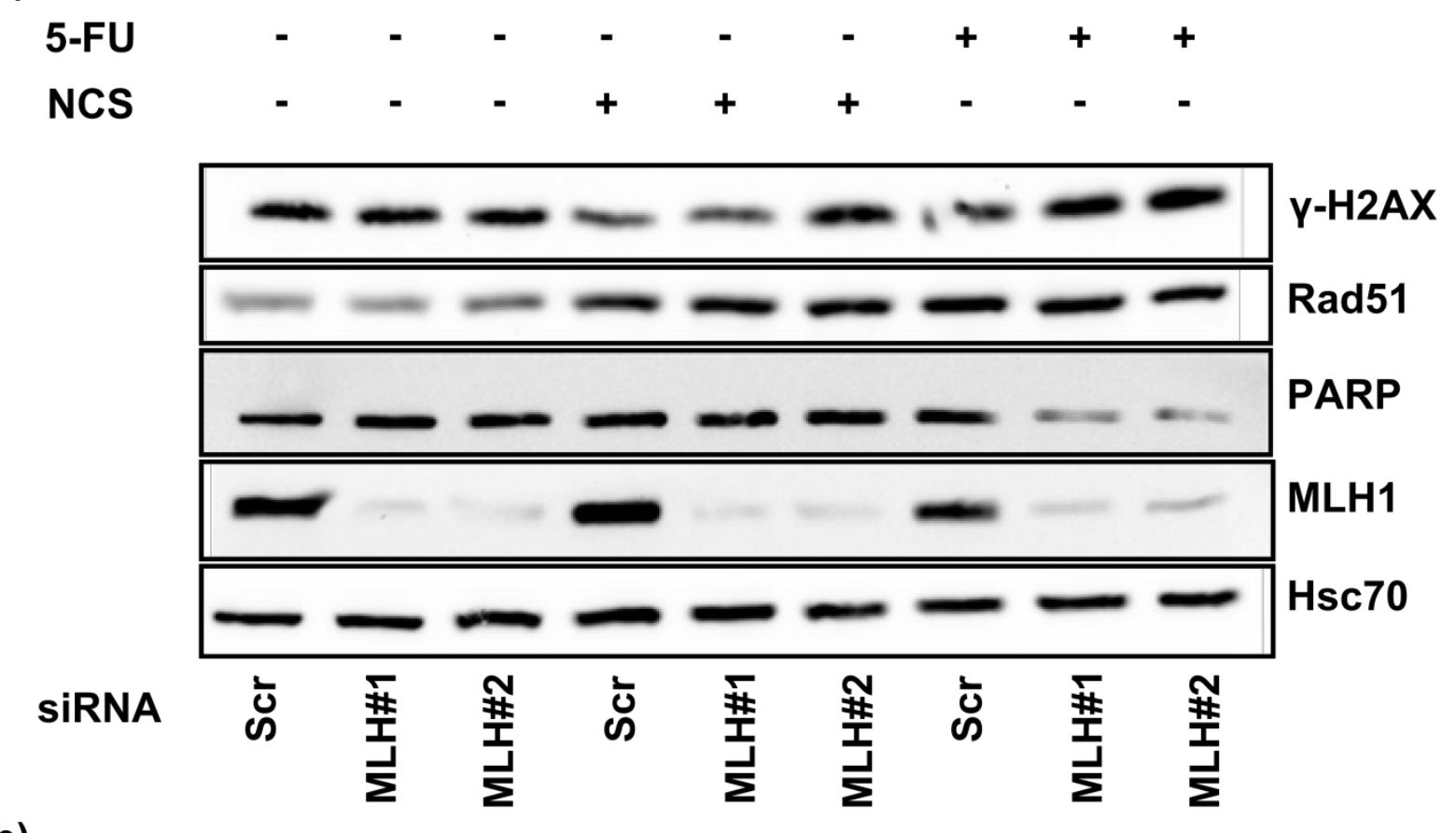

(b)

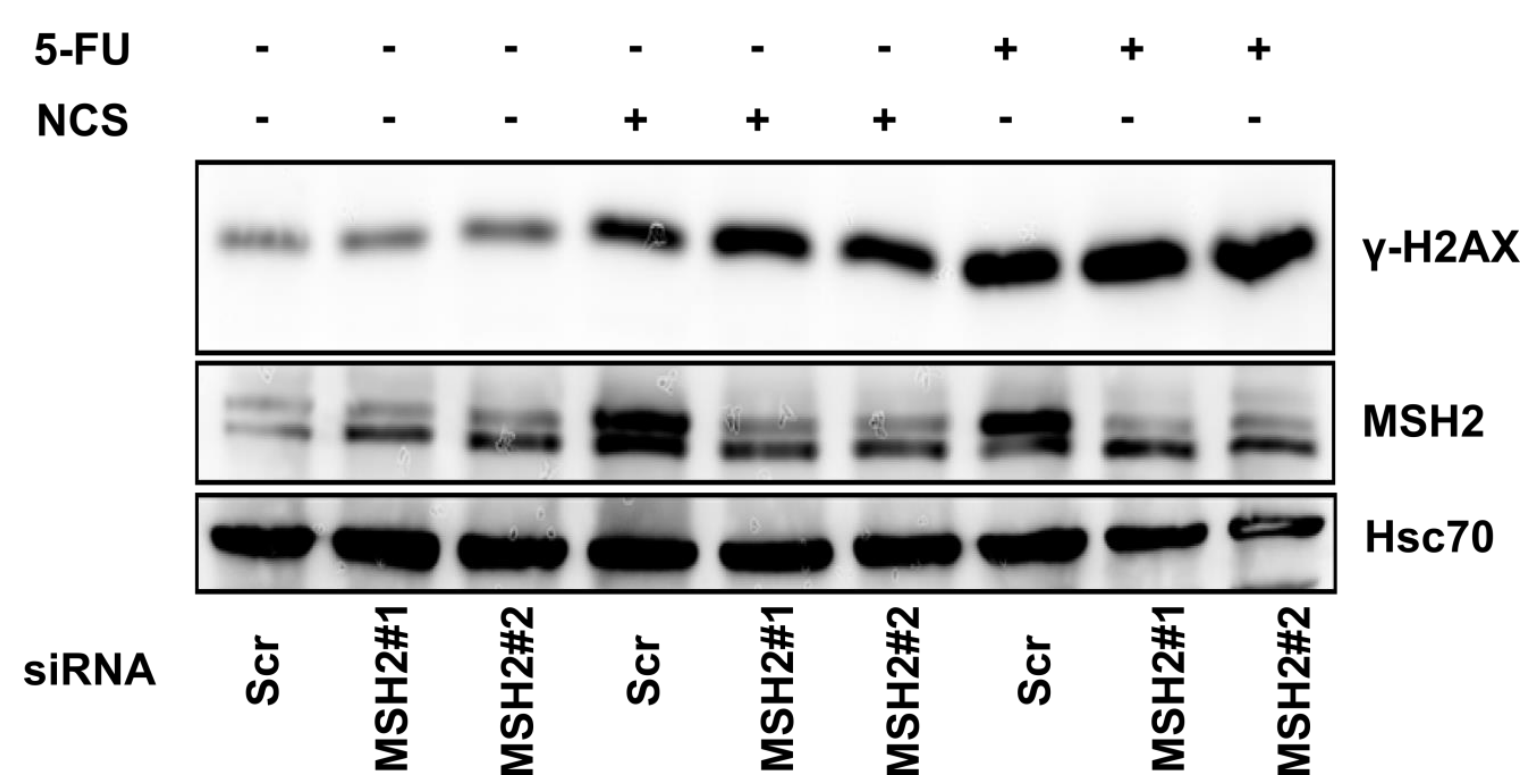

Figure 4.15 Inhibition of MMR does not synergize with NCS or 5-FU.

SW480 cells were depleted of (a) MLH1, (b) MSH2 for $16 \mathrm{~h}$ and treated with DMSO/5-FU for $24 \mathrm{~h}$ followed by NCS for $24 \mathrm{~h}$. Samples were harvested and whole cell lysates analyzed by immunoblotting. Antibodies to $\mathrm{y}-\mathrm{H} 2 \mathrm{AX}$ were used to quantify the extent of the DNA damage response, whereas $\mathrm{Hsc70}$ was detected as a loading control. 


\section{Discussion}

\subsection{Do nucleoside analogs induce $\mathrm{Y}-\mathrm{H} 2 \mathrm{AX}$ accumulation?}

Nucleoside analogs induce DNA damage by misincorporation into DNA. BER has been shown to recognize 5-FU induced DNA damage and during the repair, ssDNA is generated as an intermediate (Wyatt and Wilson, 2009). 5-FU induces both ssDNA and dsDNA breaks in SW620 cells (Matuo et al., 2009); however, higher 5FU concentrations were used $(15.4 \mu \mathrm{M}$ vs $5 \mu \mathrm{M})$. In this study, $\mathrm{y}-\mathrm{H} 2 \mathrm{AX}$ is observed $12 \mathrm{~h}$ after 5-FU treatment and coincides with apoptosis, which makes it difficult to identify the cause of $\mathrm{Y}-\mathrm{H} 2 \mathrm{AX}$ accumulation, but at lower concentrations of 5-FU (1 $\mu \mathrm{M}) \mathrm{Y}-\mathrm{H} 2 \mathrm{AX}$ is not observed. $5-\mathrm{FU}$ treatment for $24 \mathrm{~h}$ shows $\mathrm{Y}-\mathrm{H} 2 \mathrm{AX}$ accumulation in TE11 (Esophageal squamous cell carcinoma) cells but not in TE1 cells (Sakogawa et al., 2013). Similarly, 5-FU treatment causes y-H2AX accumulation in Ishikawa cells (endometeroid adenocarcinoma cell line) but not in HEC-1A and HEC1B, though high $\mathrm{y}-\mathrm{H} 2 \mathrm{AX}$ levels are attributed to $5-\mathrm{FU}$ induced apoptosis (Ikeda et al., 2000). Treatment with $15 \mu \mathrm{M} 5$-FU for $18 \mathrm{~h}$ causes increase in $\mathrm{Y}-\mathrm{H} 2 \mathrm{AX}$ levels in HCT 116 cells (Urick et al., 2011).

We also observe that 5-FU at lower concentrations (5 $\mu \mathrm{M})$ did not induce $\mathrm{y}-\mathrm{H} 2 \mathrm{AX}$ accumulation while at higher concentrations $(100 \mu \mathrm{M})$ there is a significant accumulation of $\mathrm{y}-\mathrm{H} 2 \mathrm{AX}$ but it is accompanied with apoptosis. Therefore, 5-FU induced $\mathrm{y}-\mathrm{H} 2 \mathrm{AX}$ accumulation appears to be both concentration and cell line dependent.

Gemcitabine, another nucleoside analog has been shown to induce $\mathrm{y}-\mathrm{H} 2 \mathrm{AX}$ in ML1 (Thyroid tumor cells) cells at very low concentrations $(10 \mathrm{nM})$ but at higher concentrations (100 nM) the $\mathrm{Y}-\mathrm{H} 2 \mathrm{AX}$ foci formation is quicker (foci formed in $2 \mathrm{~h}$ ). Interestingly, at both concentrations and at $24 \mathrm{~h}$ post gemcitabine treatment the number of $\mathrm{y}-\mathrm{H} 2 \mathrm{AX}$ positive foci remained the same. $\mathrm{Y}-\mathrm{H} 2 \mathrm{AX}$ foci are also induced in gemcitabine treated U2OS cells and Ara-C treated LoVo cells (Köpper et al., 2013). We also observe $\mathrm{y}-\mathrm{H} 2 \mathrm{AX}$ accumulation and foci formation in gemcitabine treated SW480 cells. However, the $\mathrm{Y}-\mathrm{H} 2 \mathrm{AX}$ intensities quantified in gemcitabine treated cells are concentration dependent, with higher concentrations causing more damage 
(Figure 4.11d). It therefore appears that gemcitabine induces the $\mathrm{Y}-\mathrm{H} 2 \mathrm{AX}$ foci in a variety of cell lines and at different concentrations although we observe that the extent of $\mathrm{y}-\mathrm{H} 2 \mathrm{AX}$ accumulation is dependent on the concentration at least in SW480 cells.

We observe gemcitabine induces DNA damage even at very low concentrations whereas 5-FU needs relatively higher concentration to induce DNA damage. At the same time, we observe synergism between 5-FU and NCS (Figure 4.1) whereas gemcitabine and NCS do not synergize (Figure $4.11 \mathrm{a}-\mathrm{d}$ ). The apparent difference in the observations with 5-FU and gemcitabine can be attributed to different mechanism of action of these two drugs. 5-FU misincorporation does not stop DNA polymerase from replicating DNA, while two adjacent gemcitabine molecules in DNA stall the DNA replication. Gemcitabine induced extensive DNA damage in SW480 cells indicate their sensitivity and the same also prevents the study of synergism with NCS. Both the drugs disrupt the nucleotide pools, though with different mechanisms, 5-FU inhibits TS and reduces the available dTMP pools but gemcitabine inhibits RR and therefore deprives the cells of all the deoxyribonucleotides and this difference may account for gemcitabine induced severe DNA damage at low concentrations. The lack of synergism in gemcitabine treated SW480 cells at various concentrations may explain its limited success in colorectal cancer therapy.

\subsection{Does 5-FU treatment activate DNA damage response?}

We observe that treatment with 5-FU caused an activation of Chk1, Chk2 and accumulation of $\mathrm{y}-\mathrm{H} 2 \mathrm{AX}$ indicating an activated DDR (Figure 4.1 and 4.7 ). It was shown that 5-FU treatment led to activation of Chk1 in HeLa and H1299 cells (Xiao et al., 2005) but not in HCT $116 \mathrm{p} 53^{+/+}$and HCT 116 p53 ${ }^{-/-}$cells. Surprisingly, 5-FU treatment does not induce the activation of Chk1, Chk2, ATM or Y-H2AX in HCT15 cells, a proven 5-FU resistant cell line (Adamson et al., 2005). It could be due to the difference in metabolism of $5-\mathrm{FU}$ in these cells. Nevertheless, it is clear that 5-FU induced activation of DDR is cell type specific and more importantly the components of the DDR getting activated are also cell type dependent. 
This is important because the same drug is eliciting different responses in different cells and this information can be used to decide the efficacy of combination therapy. The dependence of DDR activation on cell lines is of clinical use, as cells that do not activate DDR may show very little response to the inhibitors of DDR proteins. Currently, Chk1 and Chk2 inhibitors are in clinical trials and can be used in combination with 5-FU for CRC therapy. In order to improve the efficacy of these new age inhibitors with 5-FU, knowledge of DDR activation is important.

HCT 15 cells, which do not show DDR are also highly resistant to 5-FU; therefore patients having morphological features and expression pattern similar to HCT15 should be treated with other drugs. Interestingly, HCT 116 and HCT15 are MMR deficient cell lines, while the others including SW480 are MMR proficient, this testifies the importance of MMR in recognizing the DNA damage induced by 5-FU and activation of DDR. It has been reported that $\mathrm{hMSH} 2$ interacts with ATR providing a possible link between MMR and DDR (Wang and Qin, 2003).

Overall, the effectiveness of treatment with $5-\mathrm{FU}$ seems to be linked to the MMR status of cells. It can therefore be inferred that effectiveness of the treatment with 5FU depends on the MMR status of the cell line. Interestingly, $70-85 \%$ of the CRC cell lines are derived from CIN pathway and therefore our studies with 5-FU and NCS and synergisms between them may be applied to the majority of the cases. Our observations further consolidate the knowledge on the effect of 5-FU and its relation to MMR system. Therefore, cancers derived from MSI pathway may not respond very well to chemoradiotherapy and at the same time 5-FU induced radiosensitization may also not be seen in these cells.

\subsection{Is persistent $\mathrm{Y}-\mathrm{H} 2 \mathrm{AX}$ a mark for irreparable DNA damage?}

The $\mathrm{y}-\mathrm{H} 2 \mathrm{AX}$ foci remaining in the cells $24 \mathrm{~h}$ post NCS treatment are considered as persistent $\mathrm{Y}-\mathrm{H} 2 \mathrm{AX}$. Persistent $\mathrm{Y}-\mathrm{H} 2 \mathrm{AX}$ foci are believed to indicate irreparable DNA damage and have been described both in vitro (Banath et al., 2010) and in vivo (Ahmed et al., 2012). MNNG (methylnitronitrosoguanidine) treated $\mathrm{CHO}$ and V79 cells, and mitomycin $C$ treated corneal endothelial cells $C$, also show persistent $\gamma$ H2AX (Banáth et al., 2010). One reason for the persistence of $\mathrm{y}-\mathrm{H} 2 \mathrm{AX}$ foci could be 
that, extremely extensive DNA damage overwhelms the DNA repair machinery to such an extent that the rate of repair cannot keep up with activation of apoptotic mechanisms, leading to cell death. In support of this argument it was shown exposure to $\mathrm{\gamma}$-radiation of DNA repair deficient $\mathrm{CHO}$ cells leads to persistent $\mathrm{\gamma}$ $\mathrm{H} 2 \mathrm{AX}$, linking the deficient repair to the persistent $\mathrm{Y}-\mathrm{H} 2 \mathrm{AX}$ (Kato et al., 2008).

The other possibility for the persistence of $\mathrm{Y}-\mathrm{H} 2 \mathrm{AX}$ is the failure to dephosphorylate it upon completion of the repair. WIP1 (Wild type p53 induced phosphatase 1) phosphatase was shown to dephosphorylate $\mathrm{\gamma}-\mathrm{H} 2 \mathrm{AX}$ after DNA repair and depletion of WIP1 causes persistent Y-H2AX (Nguyen et al., 2010). SW480 cells or HeLa cells do not harbor any mutation in this gene and we observed that the m-RNA levels of WIP1 did not change after the treatment.

Oxidative stress was also shown to cause persistent $\mathrm{y}-\mathrm{H} 2 \mathrm{AX}$ though the molecular details for this are not known but a general hypothesis is that it could be a result of ROS mediated DNA damage (Tanaka et al., 2006). Neither 5-FU nor NCS have been reported to cause oxidative stress. We observe persistent $\mathrm{y}-\mathrm{H} 2 \mathrm{AX}$ in cells treated with 5-FU and NCS together, whereas the single treatments do not induce this persistence. As described above the SW480 and HeLa cells do not have any mutation in the WIP1; however, SW480 cells have a mutant p53 and HeLa cells do not express p53, but WIP1 expression was observed in a variety of p53 mutant cancer cell lines (Park et al., 2012).

Therefore the lack of WIP1 protein expression can be ruled out as a reason for the persistent $\mathrm{y}-\mathrm{H} 2 \mathrm{AX}$ observed in SW480 and the HeLa cells. The only remaining hypothesis to explain the persistent $\mathrm{Y}-\mathrm{H} 2 \mathrm{AX}$ in the 5-FU and NCS treated cells was inhibition of the repair pathways, and in accordance with this hypothesis we find that 5-FU reduces the HRR but not the NHEJ. Thus, we attribute suboptimal HRR efficiency as the molecular reason for the persistence of the $\mathrm{Y}-\mathrm{H} 2 \mathrm{AX}$ in $5-\mathrm{FU}$ pretreated cells combined with NCS. 


\subsection{Resistance to 5-FU and apoptosis}

HCT 116 have been reported to be very sensitive to 5-FU while SW620 and SW480 are resistant (Borralho et al., 2007). Recent classification of several CRC cell lines, based on the $\mathrm{Gl}_{50}$ values places SW480 $(6.36 \mu \mathrm{M})$ and SW620 $(17.23 \mu \mathrm{M})$ in the category of resistant cell lines. For comparison, this scale ranges from $0.03 \mu \mathrm{M}$ for HDC73 (indicating most inhibited) to $47.5 \mu \mathrm{M}$ for HT15 (indicating least inhibited) (Bracht et al., 2010). The IC 50 values for the SW480 and SW620 calculated were $17.5 \mu \mathrm{M}$ (Nita et al., 1998) and 15.3 $\mu \mathrm{M}$ (Mans et al., 1999) respectively. One study claims IC $\mathrm{C}_{50}$ for HT-29 as $19.3 \mu \mathrm{M}$ and SW480 as $17.5 \mu \mathrm{M}$ (Nita et al., 1998), whereas another study puts these values at $0.66 \mu \mathrm{M}$ for HT-29 and $2.75 \mu \mathrm{M}$ for SW480 (Violette et al., 2002b).

There are obvious differences in $\mathrm{IC}_{50}$ values in these reports, though overall, all the studies indicate that SW480 cells are intermediate- to- resistant for 5-FU. This implies that our studies are done in a background of resistant cell lines and can be extrapolated to other 5-FU resistant cell lines. This observation gains importance in the backdrop of the fact that 5-FU resistance in patients is a common phenomenon and a serious threat to disease free survival.

One of the reasons for these apparently contradictory studies on 5-FU resistance is the lack of complete understanding about the molecular mechanisms leading to resistance. Resistance towards 5-FU can be acquired by either evading apoptosis or overexpression of TS. Recently, attempts have been made to understand the molecular reasons behind 5-FU induced apoptosis. Contin B and Contin D, two 5-FU resistant cell lines derived from HCT 116 show marked reduction in apoptosis in response to 5-FU, though the 5-FU misincorporation in DNA is not reduced, indicating that 5-FU induced apoptosis and DNA damage are not coupled (Paolucci et al., 2006). We observe that 5-FU $(5 \mu \mathrm{M})$ treated SW480 cells do not show persistent $\mathrm{y}-\mathrm{H} 2 \mathrm{AX}$ or impaired cell proliferation and apoptosis (Figure 4.1 and 4.3 ). This again showcases that SW480 cells are resistant to 5-FU and the fact that apoptosis is not induced in these cells in response to $5-\mathrm{FU}$ indicates that $\mathrm{y}-\mathrm{H} 2 \mathrm{AX}$ accumulation is solely dependent on DDR. Furthermore, 5-FU sensitizes SW480 
cells to NCS but we do not observe immediate apoptosis confirmed by the absence of cleaved caspase 3 and cleaved PARP (Figure 4-15).

However, $100 \mu \mathrm{M}$ 5-FU induced apoptosis completely inhibits cell proliferation and leads to massive accumulation of $\mathrm{y}-\mathrm{H} 2 \mathrm{AX}$ (Figure 4.3 and 4.9). This signifies that apoptotic machinery is not inactivated in resistant cell and this tolerance can be overcome by sufficiently high doses of 5-FU.

It has also been reported that in $\mathrm{CRC}$ cell lines, chemosenstivity depends on $\mathrm{Bcl}-\mathrm{XL}$ to Bak ratio. Further, 5-FU causes 6 fold induction in the expression of Bax, and depleting cells of Fas reduces apoptosis (Borralho et al., 2007). An attempt to classify resistant CRC cell lines based on the expression of pro- and anti-apoptotic proteins has also not been very successful so far and SW480 cells did not show any correlation between pro and anti-apoptotic proteins (Violette et al., 2002a). Therefore, induction of apoptosis in response to 5-FU, though signifies cell death, apparently the correlation between pro- and anti-apoptotic proteins and resistance is not clear. Investigation of multiple pathways may hold the key to decipher 5-FU resistance in CRC cells and may also allow us to better target the resistance cells.

NCS concentrations above $20 \mathrm{nM}$ have been shown to severely impair cell proliferation in human cervical cancer cell lines (Bañuelos et al., 2003). Similarly, exposure of HCT 116, SW480, RKO and Colo 320 cells to $10 \mathrm{~Gy}$ radiation blocks cell proliferation and leads to cell death (van Engeland et al., 2011). We find that $100 \mathrm{ng} / \mathrm{ml} \mathrm{NCS}$, which correlates to $5 \mathrm{~Gy}$ of radiation, does not show any effect on the cell proliferation (Figure 4.3); however, combination of 5-FU and NCS severely impairs cell proliferation.

It is possible that the SW480 cell lines are more resistant to y-radiation and NCS compared to the cervical cancer cell lines. We did not try NCS concentrations equivalent to 10 Gy or more on SW480 cells, and therefore cannot agree or disagree with this report. However, our observation that 5-FU is lethal to HT-29 cells at a concentration of $5 \mu \mathrm{M}$ agrees with some studies (Lamberti et al., 2012) but is in contradiction with others, signifying variability in the expression landscape of the available intra- and inter-cancer cell lines. 
Gemcitabine is a radiosensitizer in pancreatic cancer, lung cancer, head and neck cancer and HT-29 cell lines though we did not see any synergistic effect of gemcitabine with NCS (Shewach and Lawrence, 1996a). Interestingly, gemcitabine alone was sufficient to induce extensive DNA damage that lead to apoptosis and this made it difficult to assign the source of $\mathrm{y}-\mathrm{H} 2 \mathrm{AX}$ accumulation. Inhibition of apoptosis also lead to similar $\mathrm{y}-\mathrm{H} 2 \mathrm{AX}$ accumulation indicating that gemcitabine induced DNA damage is responsible for $\mathrm{Y}-\mathrm{H} 2 \mathrm{AX}$ accumulation (Figure 4.11a and 4.11d).

However, there is some effect of the combination at a concentration of $10 \mathrm{nM}$ on cell proliferation but this is not significant enough to be classified as synergistic effect (Figure $4.11 \mathrm{~b}$ and $4.11 \mathrm{c}$ ). Surprisingly, no synergistic effect was observed in terms of $\mathrm{Y}-\mathrm{H} 2 \mathrm{AX}$ accumulation at $10 \mathrm{nM}$ gemcitabine concentration (Figure 4.11d). Therefore, the initial lag in cell proliferation at low concentrations is overcome by the SW480 cells. The fact that synergism between gemcitabine and NCS is not observed even at a concentration of $5 \mathrm{nM}$ indicates that gemcitabine may not produce encouraging results in CRC therapy and in line with our observations, gemcitabine based clinical trials have shown modest benefits to CRC patients. The difference in the response to gemcitabine can be attributed to different cell lines in ours and the indicated study.

\subsection{Does inhibition of double strand break repair sensitize cells to NCS/radiation?}

Many compounds have been described that affect DSB repair processes like 17AAG, an HSP90 inhibitor inhibits HRR (Kobayashi et al., 2005) and reduces the total Rad51 levels to radiosensitize HT-29 and EOC (ovarian cancer) (Choi et al., 2014). Similarly, persistent $\mathrm{y}-\mathrm{H} 2 \mathrm{AX}$ and reduction of DNA repair occurs in 17DMAG treated MiaPaCa cells (Dote et al., 2006). Rad51 foci formation was reportedly affected in gemcitabine treated V79 cells, however this report concludes that gemcitabine affects only large foci formation and not all foci (Floris et al., 2003). Moreover, DRGFP assay performed in gemcitabine treated MiaPaCa cells does not show reduction of HRR (Morgan et al., 2010). 
It has been reported that Chk1 phosphorylates Thr309 of Rad51 which facilitates its recruitment to the chromatin (Sorensen et al., 2005). Furthermore, AZD7762, a Chk1inhibitor prevents Rad51 foci formation and leads to persistent $\mathrm{y}-\mathrm{H} 2 \mathrm{AX}$ in MiaPaCa-2 cells (Morgan et al., 2010) . In light of the information that Chk1 inhibition reduces the HRR, it can be conceived that Chk1 inhibition would radiosensitze 5-FU resistant cells, but as stated earlier it is important to verify the activation of DDR proteins in resistant cell lines before moving ahead with targeting the DDR proteins.

Hypersensitivity of BRCA2 deficient cell line, Capan-1 has been attributed to impaired Rad51 foci formation and BRCA1 defective breast cancer cells were found to be very sensitive to PARP inhibitors (McCabe et al., 2005; Rottenberg et al., 2008). We observe that 5-FU inhibits HRR (Figure 4.4) and HRR deficient cells were shown to be hypersensitive to PARP inhibitors. PARP inhibitors are being investigated for the treatment of triple negative breast tumors harboring BRCA1/2 mutations. Encouraging response rates were observed in phase I clinical trials of Olaparib and Paclitaxel (mitotic inhibitor), similarly, use of Olaparib in triple negative breast cancers, as a single agent has also yielded positive results.

We, therefore, propose that combination of 5-FU and PARP inhibitors might be very effective in CRC therapy. However, in ovarian cancer cells, PARP inhibitors synergized with 5-FdUrD and not with 5-FU and similar results were obtained in esophegal cancer cell lines TE11 (Huehls et al., 2011; Sakogawa et al., 2013). 5FdUrD is a metabolite of 5-FU and it can be thought that metabolism of 5-FU may be different in these cancer cells. The fact that a metabolite of 5-FU synergizes with PARP inhibitors further strengthens our observations of 5-FU induced HRR inhibition and our proposal on the use of PARP inhibitors with 5-FU in CRC therapy.

\subsection{Why TS inhibition does not sensitize cells to NCS and why do 5-FU and RTX synergize in CRC cells?}

It has been shown that TS expression is inversely related to $5-\mathrm{FU}$ and methotrexate response rates in patients (Cascinu et al., 1999). Interestingly, latter studies show that TS expression in primary tumors is higher compared to metastatic tumors and 
that there is no correlation between TS expression and 5-FU response (Aschele et al., 2000). Other studies; however, show that only TS expression is sufficient to predict 5-FU action (van Triest et al., 1999).

Transient knockdown of TS reduces cell proliferation in HeLa cells and it therefore becomes apparent that the levels of TS is an important marker for deciding the action of 5-FU (Ferguson et al., 1999). We do not find any significant change in the total TS expression in tumors compared to the mucosa of patients (Figure 4.8). Surprisingly, TS expression remains unaffected in tumors and a variety of CRC cell lines (Amatori et al., 2006). It also supports other observations that expression of TS cannot be used to predict the response rates to chemotherapeutics (Aschele et al., 2000)

We employed pharmacological and siRNA mediated depletion of TS in our studies, For instance, shRNA depletion of TS induces radiosensitization in HCT116 and HT29 cells but siRNA mediated depletion of TS does not (Flanagan et al., 2012). It is difficult to explain this difference, though different methods of depletion may play a role. Our studies are in accordance with the study indicated above.

RTX induced pharmacological TS inhibition increases $\mathrm{Y}-\mathrm{H} 2 \mathrm{AX}$ and RPA foci in HT29 and HeLa cells (Yang et al., 2008). RTX and y-radiation synergize in clinical treatment and are used in neoadjuvant therapy. RTX fared better with y-radiation than 5-FU in HT-29 and Scc 25 (head and neck cancer) cells, in reducing cell proliferation (Teicher et al., 1998). Surprisingly, TS depletion or pharmacological inhibition with RTX does not synergize with NCS in SW480 cells (Figure 4.9a and 4.9c). Most likely, this is due to the variability in cellular resistance to 5 -FU between ours and reported studies. This also explains as to why even at several (7nM - 700 $\mu \mathrm{M}) \mathrm{RTX}$ concentrations we did not see any synergism in SW480 cells.

As stated earlier, one of the reason for 5-FU resistance is overexpression of TS, though we did not compare the expression levels of TS in different cell lines, it is conceivable that SW480 cells on account of being 5-FU resistant overexpress TS thus limiting the effect of RTX. Interestingly, our study also indicates that inhibition of TS alone may not sensitize the CRC cells. The fact that 5-FU sensitizes SW480 cells 
to NCS and TS does not, can be used to speculate that, other activities of 5-FU which include DNA and RNA damage are crucial to radiosensitization, though we do not have any direct proof for it.

5-FU and RTX in combination show synergistic effect in HCT-8 cells; this is surprising since both the drugs inhibit the same enzyme (Longo et al., 1998). One possible reason for this synergism is the different binding sites on TS, for RTX and 5-FU. Such a situation where the absence of the protein targeted by the drugs potentiates their efficacy is referred to as complementary lethality (Rytelewski et al., 2013). It has been shown that, TS depletion along with 5-FUdR treatment causes complementary lethality (Rytelewski et al., 2013). We also have similar observations with 5-FU and TS knockdown (Figure 4-9b) in terms of $\mathrm{y}-\mathrm{H} 2 \mathrm{AX}$ accumulation but there was no significant increase in pChk2 levels.

Taken together our results indicate that TS depletion by siRNA does not synergize with NCS while pharmacological inhibition shows additive effect with NCS but not synergistic. The observation that 5-FU synergizes with RTX is surprising, but it may be used in clinics to treat patients. So far RTX has been used as a substitute to 5-FU but our studies and similar other studies indicate that the use of 5-FU and RTX together may improve the efficacy of the regimen.

\subsection{Can gemcitabine be used as an alternative to 5-FU in CRC patients?}

Gemcitabine was reported to have modest effect on the response rates in CRC patients, though it reduced the locoregional recurrence in patients with advanced CRC in combination with $y$-radiation (Allal et al., 2005; Salgado et al., 2013). In combination with capecitabine (oral 5-FU drug) it does not improve the response rates (Salgado et al., 2013).

In our studies we did not see any synergism between gemcitabine and NCS which raises a significant question on the use of gemcitabine in CRC therapy. As stated earlier, it only has a modest effect on the outcome but interestingly no molecular reason has been implicated for the poor response to gemcitabine in CRC patients. 
Gemcitabine has been shown to induce apoptosis in HCT $116 \mathrm{p} 53^{+/+}$and U2OS cells while no apoptosis is seen in HCT 116 p5 $3^{-1-}$ and SaOS cells (Hill et al., 2013). This indicates that gemcitabine induces p53 dependent apoptosis. Furthermore, PUMA levels increase in response to gemcitabine, thus confirming the involvement of p53 mediated apoptosis.

SW480 cells harbor a mutant p53 and do not transcribe PUMA (Yu et al., 2001). Surprisingly, we observed apoptosis in SW480 cells and therefore this raises an interesting question of why do the SW480 cells undergo apoptosis in response to gemcitabine? Recently, it has been reported in HCT 116 and SW480 cells, that selenite induced stress leads to ROS mediated apoptosis in which FOXO3a and Bim play critical roles (Luo et al., 2008). Gemcitabine also induces ROS in MiaPaCa and Colo357 (Arora et al., 2013). This indicates that apoptosis seen in SW480 cells can be due to gemcitabine induced ROS generation leading to activation of FOXO3a. Though we observed increased apoptosis in SW480 cells, we do not see synergism with NCS (Figure 4.11a and 4.11d).

Similarly, we do not see any synergism in cell growth inhibition between gemcitabine and NCS (Figure 4.11c). Interestingly, even in the absence of apoptosis gemcitabine did not synergize with NCS. Our findings suggest that gemcitabine cannot synergize with NCS in CRC cell lines; however, the mode of apoptosis induction by gemcitabine in p53 mutant CRC cell lines needs further studies.

\subsection{Why MK2 does not rescue 5-FU treated cells?}

It has been reported that MK2 is needed for preventing apoptosis in p53 deficient cells for instance MK2 also mediates radioresistance in Panc1, MiaPaCa2 and BxPC3 cell lines by phosphorylating ATDC (Reinhardt et al., 2007; Wang et al., 2014).This indicates that cells depleted of MK2 should be more sensitive to NCS but we do not observe any effect of MK2 knockdown on NCS treatment either on cell proliferation or $\mathrm{y}-\mathrm{H} 2 \mathrm{AX}$ accumulation (Figure 4.10a-d) this could be due to differing cell lines between our and the quoted study. 
MK2 has also been reported to increase resistance to cisplatin in p53- deficient tumors indicating that the resistance to cisplatin is independent of p53 status (Morandell et al., 2013) and MK2 in combination with camptothecin does not show any effect on long term cell survival (Zhang et al., 2009).

p38/MK2/AATF pathway is the repressor of p53 dependent apoptosis and this indicates that inhibition of p38 pathway might be a viable option for CRC therapy. However, it is also known that curcumin dependent increase in ROS levels facilitate apoptosis and has been shown in colo205 cells. Studies indicate that MK2 increases the ROS level which could argue that it might facilitate apoptosis, though this was not stated in the studies (Kobayashi et al., 2012).

It has been shown that MK2 depletion attenuates DDR and decreases $\mathrm{y}-\mathrm{H} 2 \mathrm{AX}$ in response to gemcitabine induced DNA damage (Köpper et al., 2013). Also, MK2 knock down effectively rescues these cells and improves their proliferation. However, we did not see any effect of MK2 depletion or pharmacological inhibition on cell proliferation or reduction in $\mathrm{Y}-\mathrm{H} 2 \mathrm{AX}$. This variation is most likely due to cellular variability and ensuing stress response.

Further, as discussed earlier, differing mechanisms of 5-FU and gemcitabine action might also contribute to this observation. Gemcitabine addition in DNA produces lesions that cannot be read by DNA polymerase leading to DNA fork stalls. It has been speculated that MK2 depletion allows the recruitment of translesion polymerases that overlook the lesions and continue the DNA replication. In the case of 5-FU, such DNA lesions are not formed and so far the translesion polymerases have not been implicated in overcoming 5-FU induced replication fork stalls. As predicted, MK2 may play an important part in translesion DNA synthesis and therefore may rescue the gemcitabine treated cells. 5-FU treated cells on the other hand may not employ translesion synthesis and therefore depletion of MK2 may not rescue these cells. Therefore, it becomes evident that the involvement of MK2 strongly depends on cell type and drug being used. 


\subsection{Summary and future perspectives}

Protecting the integrity of information in DNA is a big challenge for cells exposed to various chemical and physical agents. Nucleoside analogs represent one of many different chemotherapeutics that induce DNA damage and are the mainstay in treatment of a variety of cancers like 5-FU in CRC, gemcitabine in pancreatic cancer. They have been used in the clinics for a long time, however many questions regarding the action of the nucleoside analogs remain unanswered. One of the frequently asked questions is how to improve the efficacy of the nucleoside analogs? With poor response rates in the clinics necessitate this study. Nucleoside analogs are known to radiosensitize tumor cells but the mechanisms underlying this effect are poorly understood. Similarly, the resistance of tumors to chemotherapeutics is a well-known phenomenon in cancer treatment. The current study aims at understanding the molecular mechanisms behind 5-FU induced radiosensitization and finding novel pathways to selectively target cancer cells.

Our study indicates that 5-FU pretreatment in combination with NCS results in persistent $\mathrm{y}-\mathrm{H} 2 \mathrm{AX}$ in $\mathrm{CRC}$ cell lines, which is a result of reduced DNA repair. We further prove that, 5-FU inhibits HRR while unaffecting the NHEJ and this could explain the molecular reason behind the 5-FU induced radiosensitization. 5-FU inhibits TS and disrupts the nucleotide pools; we therefore reasoned that the reduction in HRR could be a consequence of TS inhibition.

We next performed ribonucleotide supplementation and found that the disruption of nucleotide pools was responsible for the persistent $\mathrm{Y}-\mathrm{H} 2 \mathrm{AX}$. We then employed B02, an inhibitor of Rad51, to show that HRR inhibition leads to persistent $\mathrm{Y}-\mathrm{H} 2 \mathrm{AX}$ similar to 5 -FU. Considering the fact that 5-FU resistance is frequently seen in clinics, our results provide the basis for targeting HRR to overcome the 5-FU resistance. As discussed earlier, breast tumors with defective HRR are hypersensitive to $\mathrm{Y}$ radiation, our study corroborates with this observation that, inhibition of HRR can be used as a therapeutic strategy to radiosensitize cells. It is also observed that HRR deficient breast tumors respond to PARP inhibitors, and we show that 5-FU inhibits HRR, this alludes to the fact that PARP inhibitors may be used in combination with 
5-FU or may be introduced in 5-FU based regimens to improve the overall response rates in patients.

5-FU resistance is a common clinical curse that dampens the treatment outcome, our study indicates that use of HRR inhibitors in such cases may re-sensitize the cells to radiation therapy. Unfortunately, only a few specific HRR inhibitors are available and they have a very high $\mathrm{IC}_{50}$ value, making them unfit for clinical use. There is a need for more intensive research to identify specific HRR inhibitors with low IC50 values, which can be translated to clinically useful drugs.

Interestingly, depletion of TS or use of a TS inhibitor raltitrexed, did not synergize with NCS arguing that 5-FU induced radiosenstization does not depend on the TS inhibition alone. TS depletion did not exhibit synergism with NCS in inducing DNA damage, although combined treatment with 5-FU showed complementary lethality. This argues for the use of RTX with 5-FU and not as a substitute of 5-FU.

Furthermore, we investigated the possible use of gemcitabine in CRC treatment and find that gemcitabine does not synergize with NCS to induce DNA damage in CRC cell lines. Moreover, 5-FU synergizes with NCS to reduce the cell proliferation while gemcitabine does not, indicating that gemcitabine is not a good alternative to 5-FU in CRC therapy.

RRM2 inhibition also does not show synergism with NCS, indicating that depletion or inhibition of RR may not be beneficial in CRC therapy. Similar observations have been made in clinical trials that indicate that, gemcitabine only modestly improves the response rates in patients, our study also indicates that single treatment with gemcitabine is able to produce almost the same amount of damage as in combination with NCS. However, it does indicate that RR is a key enzyme that may be targeted to achieve the desired cell death but it may not synergize with NCS or $\mathrm{y}$ radiation. Identifying appropriate concentrations of RR specific inhibitors like HU may further improve the response rates. 


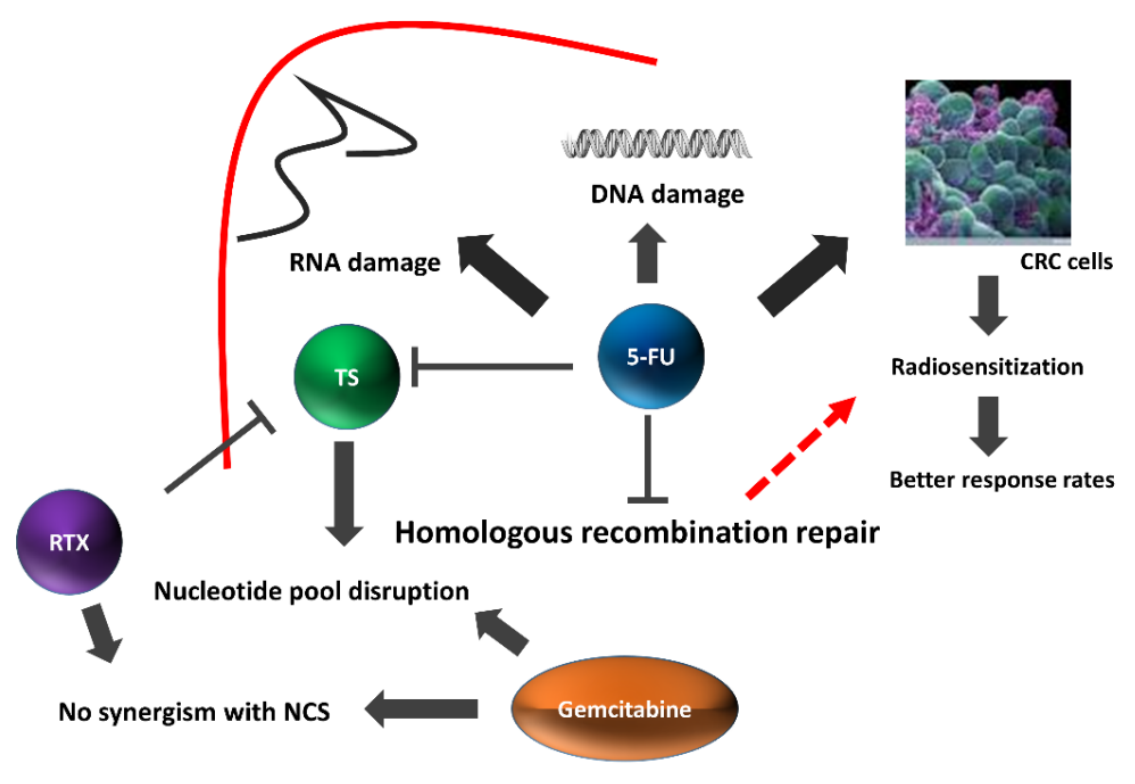

Figure 5.1 A model for 5-FU induced HRR inhibition.

Combined effect of 5-FU on DNA, RNA damage and TS inhibition leads to reduced HRR and radiosensitization. RTX mediated TS inhibition alone does not synergize with NCS, similarly, gemcitabine induced DNA damage and nucleotide pool disruption also does not synergize with NCS.

MK2 is reported to reduce the $\mathrm{Y}-\mathrm{H} 2 \mathrm{AX}$ levels in gemcitabine treated U2OS cells, we therefore investigated the role of MK2 in 5-FU induced damage in SW480 cells and found that MK2 does not reduce the $\mathrm{Y}-\mathrm{H} 2 \mathrm{AX}$ levels or rescue the 5-FU and NCS treated cells. Interestingly, MK2 inhibitors have been shown to reduce the tumor size in combination with cisplatin. Our study indicates that using 5-FU in combination with MK2 inhibitors may not be beneficial to patients.

MMR is a key component in identifying and repairing 5-FU induced DNA damage, and as described earlier, mutations in this pathway are associated with predisposition to CRC. Interestingly, this pathway has been speculated to be involved in HRR but its role in HRR is not clear. In order to elucidate its role in radiosensitization, we depleted cells of $\mathrm{MSH} 2$ and $\mathrm{MLH} 1$. We find that depletion of MMR components does not sensitize cells to NCS or 5-FU. This elucidates that though MMR participates in HRR, during strand invasion but its loss does not significantly hamper the process. It also suggests that in clinics the MMR status may not correlate with response to radiation therapy. 
Finally, we propose a model, wherein 5-FU induced HRR inhibition can be attributed to depletion of nucleotide pools along with DNA and RNA damage. We believe that the reduction in HRR is responsible for the radiosensitzation and persistent $\mathrm{y}-\mathrm{H} 2 \mathrm{AX}$ which then causes cell death via apoptosis. Gemcitabine also disrupts the nucleotide pools and induces DNA damage but did not sensitize cells to NCS. RTX inhibits TS, but even RTX did not synergize with NCS. Taken together the radiosensitization effect of 5-FU can be attributed to reduced HRR efficiency of cells as a result of 5FU induced DNA damage along with TS inhibition and RNA damage (Figure 5.1). 


\section{References}

Adamson, A. W., Beardsley, D. I., Kim, W. J., Gao, Y., Baskaran, R., and Brown, K. D. (2005). Methylator-induced, mismatch repair-dependent $\mathrm{G} 2$ arrest is activated through Chk1 and Chk2. Molecular biology of the cell 16, 1513-1526.

Ahmed, E. A., Agay, D., Schrock, G., Drouet, M., Meineke, V., and Scherthan, H. (2012). Persistent DNA damage after high dose in vivo gamma exposure of minipig skin. PloS one 7 , e39521.

Allal, A. S., Bieri, S., Gervaz, P., Soravia, C., Bernier, J., Gertsch, P., Morel, P., and Roth, A. D. (2005). Preoperative concomitant hyperfractionated radiotherapy and gemcitabine for locally advanced rectal cancers: a phase I-II trial. Cancer J 11, 133-139.

Alter, P., Herzum, M., Soufi, M., Schaefer, J. R., and Maisch, B. (2006). Cardiotoxicity of 5fluorouracil. Cardiovascular \& hematological agents in medicinal chemistry 4, 1-5.

Amatori, F., Di Paolo, A., Del Tacca, M., Fontanini, G., Vannozzi, F., Boldrini, L., Bocci, G., Lastella, M., and Danesi, R. (2006). Thymidylate synthase, dihydropyrimidine dehydrogenase and thymidine phosphorylase expression in colorectal cancer and normal mucosa in patients. Pharmacogenetics and genomics 16, 809-816.

Arora, S., Bhardwaj, A., Singh, S., Srivastava, S. K., McClellan, S., Nirodi, C. S., Piazza, G. A., Grizzle, W. E., Owen, L. B., and Singh, A. P. (2013). An undesired effect of chemotherapy: gemcitabine promotes pancreatic cancer cell invasiveness through reactive oxygen speciesdependent, nuclear factor kappaB- and hypoxia-inducible factor 1alpha-mediated upregulation of CXCR4. The Journal of biological chemistry 288, 21197-21207.

Aschele, C., Debernardis, D., Tunesi, G., Maley, F., and Sobrero, A. (2000). Thymidylate synthase protein expression in primary colorectal cancer compared with the corresponding distant metastases and relationship with the clinical response to 5-fluorouracil. Clinical cancer research : an official journal of the American Association for Cancer Research 6, 4797-4802.

Bakkenist, C. J., and Kastan, M. B. (2003). DNA damage activates ATM through intermolecular autophosphorylation and dimer dissociation. Nature 421, 499-506.

Banath, J. P., Klokov, D., MacPhail, S. H., Banuelos, C. A., and Olive, P. L. (2010). Residual gammaH2AX foci as an indication of lethal DNA lesions. BMC cancer 10, 4.

Banáth, J. P., Klokov, D., MacPhail, S. H., Banuelos, C. A., and Olive, P. L. (2010). Residual gammaH2AX foci as an indication of lethal DNA lesions. BMC cancer 10, 4.

Bañuelos, A., Reyes, E., Ocadiz, R., Alvarez, E., Moreno, M., Monroy, A., and Gariglio, P. (2003). Neocarzinostatin induces an effective p53-dependent response in human papillomavirus-positive cervical cancer cells. The Journal of pharmacology and experimental therapeutics 306, 671-680.

Bardin, A. J., and Amon, A. (2001). Men and sin: what's the difference? Nature reviews Molecular cell biology 2, 815-826.

Borralho, P. M., Moreira da Silva, I. B., Aranha, M. M., Albuquerque, C., Nobre Leitao, C., Steer, C. J., and Rodrigues, C. M. (2007). Inhibition of Fas expression by RNAi modulates 5fluorouracil-induced apoptosis in HCT116 cells expressing wild-type p53. Biochimica et biophysica acta $1772,40-47$. 
Bracht, K., Nicholls, A. M., Liu, Y., and Bodmer, W. F. (2010). 5-Fluorouracil response in a large panel of colorectal cancer cell lines is associated with mismatch repair deficiency. British journal of cancer 103, 340-346.

Bugreev, D. V., Mazina, O. M., and Mazin, A. V. (2006). Rad54 protein promotes branch migration of Holliday junctions. Nature 442, 590-593.

Bunz, F. (1998). Requirement for p53 and p21 to Sustain G2 Arrest After DNA Damage. Science 282.

Burma, S., Chen, B. P., and Chen, D. J. (2006). Role of non-homologous end joining (NHEJ) in maintaining genomic integrity. DNA repair 5, 1042-1048.

Calnan, B. J., Szychowski, S., Chan, F. K., Cado, D., and Winoto, A. (1995). A role for the orphan steroid receptor Nur77 in apoptosis accompanying antigen-induced negative selection. Immunity 3, 273-282.

Carreras, C. W., and Santi, D. V. (1995). The catalytic mechanism and structure of thymidylate synthase. Annual review of biochemistry 64, 721-762.

Carson, D. A., Seto, S., Wasson, D. B., and Carrera, C. J. (1986). DNA strand breaks, NAD metabolism, and programmed cell death. Exp Cell Res 164, 273-281.

Carson, D. A., Wasson, D. B., Esparza, L. M., Carrera, C. J., Kipps, T. J., and Cottam, H. B. (1992). Oral antilymphocyte activity and induction of apoptosis by 2-chloro-2'-arabinofluoro-2'-deoxyadenosine. Proceedings of the National Academy of Sciences of the United States of America 89, 2970-2974.

Cascinu, S., Aschele, C., Barni, S., Debernardis, D., Baldo, C., Tunesi, G., Catalano, V., Staccioli, M. P., Brenna, A., Muretto, P., and Catalano, G. (1999). Thymidylate synthase protein expression in advanced colon cancer: correlation with the site of metastasis and the clinical response to leucovorin-modulated bolus 5-fluorouracil. Clinical cancer research : an official journal of the American Association for Cancer Research 5, 1996-1999.

Chapman, J. R., Taylor, M. R., and Boulton, S. J. (2012). Playing the end game: DNA doublestrand break repair pathway choice. Molecular cell 47, 497-510.

Choi, Y. E., Battelli, C., Watson, J., Liu, J., Curtis, J., Morse, A. N., Matulonis, U. A., Chowdhury, D., and Konstantinopoulos, P. A. (2014). Sublethal concentrations of 17-AAG suppress homologous recombination DNA repair and enhance sensitivity to carboplatin and olaparib in HR proficient ovarian cancer cells. Oncotarget 5, 2678-2687.

Ciccia, A., and Elledge, S. J. (2010). The DNA damage response: making it safe to play with knives. Molecular cell 40, 179-204.

Coqueret, O. (2003). New roles for p21 and p27 cell-cycle inhibitors: a function for each cell compartment? Trends in cell biology 13, 65-70.

Davis, A. J., and Chen, D. J. (2013). DNA double strand break repair via non-homologous end-joining. Translational cancer research 2, 130-143.

Derynck, R., Akhurst, R. J., and Balmain, A. (2001). TGF-beta signaling in tumor suppression and cancer progression. Nat Genet 29, 117-129.

Dong, Y., Guha, S., Sun, X., Cao, M., Wang, X., and Zou, S. (2012). Nutraceutical interventions for promoting healthy aging in invertebrate models. Oxidative medicine and cellular longevity 2012, 718491.

Dote, H., Burgan, W. E., Camphausen, K., and Tofilon, P. J. (2006). Inhibition of hsp90 compromises the DNA damage response to radiation. Cancer research 66, 9211-9220. 
Dupre, A., Boyer-Chatenet, L., and Gautier, J. (2006). Two-step activation of ATM by DNA and the Mre11-Rad50-Nbs1 complex. Nat Struct Mol Biol 13, 451-457.

Esashi, F., Christ, N., Gannon, J., Liu, Y., Hunt, T., Jasin, M., and West, S. C. (2005). CDKdependent phosphorylation of BRCA2 as a regulatory mechanism for recombinational repair. Nature 434, 598-604.

Falck, J., Mailand, N., Syljuasen, R. G., Bartek, J., and Lukas, J. (2001). The ATM-Chk2-Cdc25A checkpoint pathway guards against radioresistant DNA synthesis. Nature 410, 842-847.

Feijoo, C., Hall-Jackson, C., Wu, R., Jenkins, D., Leitch, J., Gilbert, D. M., and Smythe, C. (2001). Activation of mammalian Chk1 during DNA replication arrest: a role for Chk1 in the intra-S phase checkpoint monitoring replication origin firing. The Journal of cell biology 154, 913-923.

Ferguson, P. J., Collins, O., Dean, N. M., DeMoor, J., Li, C. S., Vincent, M. D., and Koropatnick, J. (1999). Antisense down-regulation of thymidylate synthase to suppress growth and enhance cytotoxicity of 5-FUdR, 5-FU and Tomudex in HeLa cells. British journal of pharmacology 127, 1777-1786.

Flanagan, S. A., Cooper, K. S., Mannava, S., Nikiforov, M. A., and Shewach, D. S. (2012). Short hairpin RNA suppression of thymidylate synthase produces DNA mismatches and results in excellent radiosensitization. International journal of radiation oncology, biology, physics 84 , 20.

Fleming, F. J., Pahlman, L., and Monson, J. R. (2011). Neoadjuvant therapy in rectal cancer. Diseases of the colon and rectum 54, 901-912.

Floris, M. W., John, W. G. v. P., Jan, G. M., Malgorzata, Z. Z., Harry, J. M. G., and Harm, H. K. (2003). Selective targeting of homologous DNA recombination repair by gemcitabine. International Journal of Radiation Oncology*Biology*Physics 57.

Fodde, R. (2002). The APC gene in colorectal cancer. Eur J Cancer 38, 867-871.

Ghoshal, K., and Jacob, S. T. (1994). Specific inhibition of pre-ribosomal RNA processing in extracts from the lymphosarcoma cells treated with 5-fluorouracil. Cancer research 54, 632636.

Goldberg, I. H. (1991). Mechanism of neocarzinostatin action: role of DNA microstructure in determination of chemistry of bistranded oxidative damage. Accounts of chemical research. Gross, L. (2007). Paradox resolved? The strange case of the radiation-resistant bacteria. PLoS biology 5, e108.

Grove, K. L., and Cheng, Y. C. (1996). Uptake and metabolism of the new anticancer compound beta-L-(-)-dioxolane-cytidine in human prostate carcinoma DU-145 cells. Cancer research 56, 4187-4191.

Guha, M. (2012). Cyclin-dependent kinase inhibitors move into Phase III. Nature reviews Drug discovery 11, 892-894.

Guo, M., House, M. G., Suzuki, H., Ye, Y., Brock, M. V., Lu, F., Liu, Z., Rustgi, A. K., and Herman, J. G. (2007). Epigenetic silencing of CDX2 is a feature of squamous esophageal cancer. International journal of cancer Journal international du cancer 121, 1219-1226.

Heidelberger, C., Chaudhuri, N. K., Danneberg, P., Mooren, D., Griesbach, L., Duschinsky, R., Schnitzer, R. J., Pleven, E., and Scheiner, J. (1957). Fluorinated pyrimidines, a new class of tumour-inhibitory compounds. Nature 179, 663-666. 
Hertel, L. W., Boder, G. B., Kroin, J. S., Rinzel, S. M., Poore, G. A., Todd, G. C., and Grindey, G. B. (1990). Evaluation of the antitumor activity of gemcitabine (2',2'-difluoro-2'deoxycytidine). Cancer research 50, 4417-4422.

Heyer, W.-D. D., Ehmsen, K. T., and Liu, J. (2010). Regulation of homologous recombination in eukaryotes. Annual review of genetics 44, 113-139.

Hill, R., Rabb, M., Madureira, P. A., Clements, D., Gujar, S. A., Waisman, D. M., Giacomantonio, C. A., and Lee, P. W. (2013). Gemcitabine-mediated tumour regression and p53-dependent gene expression: implications for colon and pancreatic cancer therapy. Cell death \& disease 4, e791.

Honda, M., Okuno, Y., Hengel, S. R., Martín-López, J. V., Cook, C. P., Amunugama, R., Soukup, R. J., Subramanyam, S., Fishel, R., and Spies, M. (2014). Mismatch repair protein hMSH2-hMSH6 recognizes mismatches and forms sliding clamps within a D-loop recombination intermediate. Proceedings of the National Academy of Sciences of the United States of America 111, 25.

Huehls, A. M., Wagner, J. M., Huntoon, C. J., Geng, L., Erlichman, C., Patel, A. G., Kaufmann, S. H., and Karnitz, L. M. (2011). Poly(ADP-Ribose) polymerase inhibition synergizes with 5fluorodeoxyuridine but not 5-fluorouracil in ovarian cancer cells. Cancer research 71, 49444954.

Ikeda, K., Saitoh, S., Kobayashi, M., Suzuki, Y., Suzuki, F., Tsubota, A., Arase, Y., Chayama, K., Murashima, N., and Kumada, H. (2000). Hepatic vascular side effects of styrene maleic acid neocarzinostatin in the treatment of hepatocellular carcinoma. Journal of gastroenterology 35, 353-360.

Jasin, M. (2002). Homologous repair of DNA damage and tumorigenesis: the BRCA connection. Oncogene 21, 8981-8993.

Jemal, A., Bray, F., Center, M. M., Ferlay, J., Ward, E., and Forman, D. (2011). Global cancer statistics. CA: a cancer journal for clinicians 61, 69-90.

Jiricny, J. (2006). The multifaceted mismatch-repair system. Nature reviews Molecular cell biology 7, 335-346.

Johnson, R. A., Wang, X., Ma, X. L., Huong, S. M., and Huang, E. S. (2001). Human cytomegalovirus up-regulates the phosphatidylinositol 3-kinase (PI3-K) pathway: inhibition of PI3-K activity inhibits viral replication and virus-induced signaling. Journal of virology 75 , 6022-6032.

Kaiyawet, N., Rungrotmongkol, T., and Hannongbua, S. (2013). Effect of halogen substitutions on dUMP to stability of thymidylate synthase/dUMP/mTHF ternary complex using molecular dynamics simulation. Journal of chemical information and modeling 53, 1315-1323.

Kantarjian, H., Faderl, S., Garcia-Manero, G., Luger, S., Venugopal, P., Maness, L., Wetzler, M., Coutre, S., Stock, W., Claxton, D., et al. (2012). Oral sapacitabine for the treatment of acute myeloid leukaemia in elderly patients: a randomised phase 2 study. The lancet oncology 13, 1096-1104.

Kappen, L. S., Napier, M. A., and Goldberg, I. H. (1980). Roles of chromophore and apoprotein in neocarzinostatin action. Proceedings of the National Academy of Sciences of the United States of America 77, 1970-1974.

Kato, T. A., Okayasu, R., and Bedford, J. S. (2008). Comparison of the induction and disappearance of DNA double strand breaks and gamma-H2AX foci after irradiation of 
chromosomes in G1-phase or in condensed metaphase cells. Mutation research 639, 108112.

Kelly, R. J., Thomas, A., Rajan, A., Chun, G., Lopez-Chavez, A., Szabo, E., Spencer, S., Carter, C. A., Guha, U., Khozin, S., et al. (2013). A phase I/II study of sepantronium bromide (YM155, survivin suppressor) with paclitaxel and carboplatin in patients with advanced non-small-cell lung cancer. Annals of oncology : official journal of the European Society for Medical Oncology / ESMO 24, 2601-2606.

Kikuchi, K., Taniguchi, Y., Hatanaka, A., Sonoda, E., Hochegger, H., Adachi, N., Matsuzaki, Y., Koyama, H., van Gent, D. C., Jasin, M., and Takeda, S. (2005). Fen-1 facilitates homologous recombination by removing divergent sequences at DNA break ends. Molecular and cellular biology 25, 6948-6955.

Kinner, A., Wu, W., Staudt, C., and Iliakis, G. (2008). Gamma-H2AX in recognition and signaling of DNA double-strand breaks in the context of chromatin. Nucleic acids research 36, 5678-5694.

Kobayashi, S., Nantz, R., Kitamura, T., Higashikubo, R., and Horikoshi, N. (2005). Combined inhibition of extracellular signal-regulated kinases and HSP9O sensitizes human colon carcinoma cells to ionizing radiation. Oncogene 24, 3011-3019.

Köpper, F., Bierwirth, C., Schön, M., Kunze, M., Elvers, I., Kranz, D., Saini, P., Menon, M. B., Walter, D., Sørensen, C. S., et al. (2013). Damage-induced DNA replication stalling relies on MAPK-activated protein kinase 2 activity. Proceedings of the National Academy of Sciences of the United States of America 110, 16856-16861.

Kroemer, G., Galluzzi, L., Vandenabeele, P., Abrams, J., Alnemri, E. S., Baehrecke, E. H., Blagosklonny, M. V., El-Deiry, W. S., Golstein, P., Green, D. R., et al. (2009). Classification of cell death: recommendations of the Nomenclature Committee on Cell Death 2009. Cell death and differentiation 16, 3-11.

Kuo, L. J., and Yang, L. X. (2008). Gamma-H2AX - a novel biomarker for DNA double-strand breaks. In Vivo 22, 305-309.

Lamberti, M., Porto, S., Marra, M., Zappavigna, S., Grimaldi, A., Feola, D., Pesce, D., Naviglio, S., Spina, A., Sannolo, N., and Caraglia, M. (2012). 5-Fluorouracil induces apoptosis in rat cardiocytes through intracellular oxidative stress. Journal of experimental \& clinical cancer research : CR 31, 60.

Lieber, M. R. (2010). The mechanism of double-strand DNA break repair by the nonhomologous DNA end-joining pathway. Annual review of biochemistry 79, 181-211.

Liu, J., Meng, X., and Shen, Z. (2002). Association of human RAD52 protein with transcription factors. Biochemical and biophysical research communications 297, 1191-1196.

Lokich, J., Chaffey, J., and Neptune, W. (1989). Concomitant 5-fluorouracil infusion and highdose radiation for stage III non-small cell lung cancer. Cancer 64, 1021-1025.

Longley, D. B., Harkin, D. P., and Johnston, P. G. (2003). 5-fluorouracil: mechanisms of action and clinical strategies. Nature reviews Cancer 3, 330-338.

Longo, G. S., Izzo, J., Chang, Y. M., Tong, W. P., Zielinski, Z., Gorlick, R., Chou, T. C., and Bertino, J. R. (1998). Pretreatment of colon carcinoma cells with Tomudex enhances 5fluorouracil cytotoxicity. Clinical cancer research : an official journal of the American Association for Cancer Research 4, 469-473. 
Lukas, J., Lukas, C., and Bartek, J. (2011). More than just a focus: The chromatin response to DNA damage and its role in genome integrity maintenance. Nature cell biology 13, 11611169.

Luo, Y., Walla, M., and Wyatt, M. D. (2008). Uracil incorporation into genomic DNA does not predict toxicity caused by chemotherapeutic inhibition of thymidylate synthase. DNA repair 7, 162-169.

Maloisel, L., Fabre, F., and Gangloff, S. (2008). DNA polymerase delta is preferentially recruited during homologous recombination to promote heteroduplex DNA extension. Molecular and cellular biology 28, 1373-1382.

Malumbres, M., and Barbacid, M. (2005). Mammalian cyclin-dependent kinases. Trends in biochemical sciences 30, 630-641.

Mans, D. R., Grivicich, I., Peters, G. J., and Schwartsmann, G. (1999). Sequence-dependent growth inhibition and DNA damage formation by the irinotecan-5-fluorouracil combination in human colon carcinoma cell lines. Eur J Cancer 35, 1851-1861.

Markman, B., Javier Ramos, F., Capdevila, J., and Tabernero, J. (2010). EGFR and KRAS in colorectal cancer. Advances in clinical chemistry 51, 71-119.

Masson, J. Y., Tarsounas, M. C., Stasiak, A. Z., Stasiak, A., Shah, R., Mcllwraith, M. J., Benson, F. E., and West, S. C. (2001). Identification and purification of two distinct complexes containing the five RAD51 paralogs. Genes Dev 15, 3296-3307.

Matuo, R., Sousa, F. G., Escargueil, A. E., Grivicich, I., Garcia-Santos, D., Chies, J. A., Saffi, J., Larsen, A. K., and Henriques, J. A. (2009). 5-Fluorouracil and its active metabolite FdUMP cause DNA damage in human SW620 colon adenocarcinoma cell line. Journal of applied toxicology : JAT 29, 308-316.

Mazin, A. V., Mazina, O. M., Bugreev, D. V., and Rossi, M. J. (2010). Rad54, the motor of homologous recombination. DNA repair 9, 286-302.

McCabe, N., Lord, C. J., Tutt, A. N., Martin, N. M., Smith, G. C., and Ashworth, A. (2005). BRCA2-deficient CAPAN-1 cells are extremely sensitive to the inhibition of Poly (ADP-Ribose) polymerase: an issue of potency. Cancer Biol Ther 4, 934-936.

Mohindra, A., Hays, L. E., Phillips, E. N., Preston, B. D., Helleday, T., and Meuth, M. (2002). Defects in homologous recombination repair in mismatch-repair-deficient tumour cell lines. Human molecular genetics 11, 2189-2200.

Molinari, F., and Frattini, M. (2013). Functions and Regulation of the PTEN Gene in Colorectal Cancer. Frontiers in oncology 3, 326.

Morandell, S., Reinhardt, H. C., Cannell, I. G., Kim, J. S., Ruf, D. M., Mitra, T., Couvillon, A. D., Jacks, T., and Yaffe, M. B. (2013). A reversible gene-targeting strategy identifies synthetic lethal interactions between MK2 and p53 in the DNA damage response in vivo. Cell reports 5, 868-877.

Morgan, M. A., Parsels, L. A., Zhao, L., Parsels, J. D., Davis, M. A., Hassan, M. C., Arumugarajah, S., Hylander-Gans, L., Morosini, D., Simeone, D. M., et al. (2010). Mechanism of radiosensitization by the Chk1/2 inhibitor AZD7762 involves abrogation of the G2 checkpoint and inhibition of homologous recombinational DNA repair. Cancer research 70, $4972-4981$.

Najdi, R., Holcombe, R. F., and Waterman, M. L. (2011). Wnt signaling and colon carcinogenesis: beyond APC. Journal of carcinogenesis 10, 5 . 
Nakada, S., Yonamine, R. M., and Matsuo, K. (2012). RNF8 regulates assembly of RAD51 at DNA double-strand breaks in the absence of BRCA1 and 53BP1. Cancer research 72, 49744983.

Nakanoko, T., Saeki, H., Morita, M., Nakashima, Y., Ando, K., Oki, E., Ohga, T., Kakeji, Y., Toh, Y., and Maehara, Y. (2013). Erratum to: Rad51 Expression Is a Useful Predictive Factor for the Efficacy of Neoadjuvant Chemoradiotherapy in Squamous Cell Carcinoma of the Esophagus. Annals of surgical oncology.

Nguyen, T. A., Slattery, S. D., Moon, S. H., Darlington, Y. F., Lu, X., and Donehower, L. A. (2010). The oncogenic phosphatase WIP1 negatively regulates nucleotide excision repair. DNA repair 9, 813-823.

Nita, M. E., Nagawa, H., Tominaga, O., Tsuno, N., Fujii, S., Sasaki, S., Fu, C. G., Takenoue, T., Tsuruo, T., and Muto, T. (1998). 5-Fluorouracil induces apoptosis in human colon cancer cell lines with modulation of Bcl-2 family proteins. British journal of cancer 78, 986-992.

Norbury, C. J., and Zhivotovsky, B. (2004). DNA damage-induced apoptosis. Oncogene 23, 2797-2808.

Osolodkin, D. I., Kozlovskaya, L. I., Dueva, E. V., Dotsenko, V. V., Rogova, Y. V., Frolov, K. A., Krivokolysko, S. G., Romanova, E. G., Morozov, A. S., Karganova, G. G., et al. (2013). Inhibitors of tick-borne flavivirus reproduction from structure-based virtual screening. ACS medicinal chemistry letters 4, 869-874.

Ou, L. S., Goleva, E., Hall, C., and Leung, D. Y. (2004). T regulatory cells in atopic dermatitis and subversion of their activity by superantigens. The Journal of allergy and clinical immunology 113, 756-763.

Paolucci, S., Bragoni, M., Coiro, P., De Angelis, D., Fusco, F. R., Morelli, D., Venturiero, V., and Pratesi, L. (2006). Is sex a prognostic factor in stroke rehabilitation? A matched comparison. Stroke; a journal of cerebral circulation 37, 2989-2994.

Park, J. Y., Song, J. Y., Kim, H. M., Han, H. S., Seol, H. S., Jang, S. J., and Choi, J. (2012). p53Independent expression of wild-type p53-induced phosphatase 1 (Wip1) in methylmethane sulfonate-treated cancer cell lines and human tumors. The international journal of biochemistry \& cell biology 44, 896-904.

Park, M. J., Kim, S. H., Lee, S. J., Jang, K. M., and Rhim, H. (2011). Locally advanced rectal cancer: added value of diffusion-weighted MR imaging for predicting tumor clearance of the mesorectal fascia after neoadjuvant chemotherapy and radiation therapy. Radiology 260, 771-780.

Pena-Diaz, J., Bregenhorn, S., Ghodgaonkar, M., Follonier, C., Artola-Boran, M., Castor, D., Lopes, M., Sartori, A. A., and Jiricny, J. (2012). Noncanonical mismatch repair as a source of genomic instability in human cells. Molecular cell 47, 669-680.

Pena-Diaz, J., and Jiricny, J. (2012). Mammalian mismatch repair: error-free or error-prone? Trends in biochemical sciences 37, 206-214.

Penkner, A., Portik-Dobos, Z., Tang, L., Schnabel, R., Novatchkova, M., Jantsch, V., and Loidl, J. (2007). A conserved function for a Caenorhabditis elegans Com1/Sae2/CtIP protein homolog in meiotic recombination. The EMBO journal 26, 5071-5082.

Pereira, S., Fernandes, P. A., and Ramos, M. J. (2004). Mechanism for ribonucleotide reductase inactivation by the anticancer drug gemcitabine. Journal of computational chemistry 25, 1286-1294. 
Randerath, K., Tseng, W. C., Harris, J. S., and Lu, L. J. (1983). Specific effects of 5fluoropyrimidines and 5-azapyrimidines on modification of the 5 position of pyrimidines, in particular the synthesis of 5-methyluracil and 5-methylcytosine in nucleic acids. Recent results in cancer research Fortschritte der Krebsforschung Progres dans les recherches sur le cancer 84, 283-297.

Reinhardt, S., Ewald, A., and Hellwig, F. (2007). The anatomy of the stigma and style from Cyclamen persicum (Mill.) cv. "pure white" and its relation to pollination success. Plant Biol (Stuttg) 9, 158-162.

Resende, R. R., Torres, H. A., Yuahasi, K. K., P, M., and H, U. (2007). Delivery systems for in vivo use of nucleic Acid drugs. Drug target insights 2, 183-196.

Rogakou, E. P., Pilch, D. R., Orr, A. H., Ivanova, V. S., and Bonner, W. M. (1998). DNA doublestranded breaks induce histone $H 2 A X$ phosphorylation on serine 139 . The Journal of biological chemistry 273, 5858-5868.

Rottenberg, S., Jaspers, J. E., Kersbergen, A., van der Burg, E., Nygren, A. O., Zander, S. A., Derksen, P. W., de Bruin, M., Zevenhoven, J., Lau, A., et al. (2008). High sensitivity of BRCA1deficient mammary tumors to the PARP inhibitor AZD2281 alone and in combination with platinum drugs. Proceedings of the National Academy of Sciences of the United States of America 105, 17079-17084.

Rustgi, A. K. (2007). The genetics of hereditary colon cancer. Genes Dev 21, 2525-2538.

Rytelewski, M., Ferguson, P. J., Maleki Vareki, S., Figueredo, R., Vincent, M., and Koropatnick, J. (2013). Inhibition of BRCA2 and Thymidylate Synthase Creates Multidrug Sensitive Tumor Cells via the Induction of Combined "Complementary Lethality". Molecular therapy Nucleic acids 2, e78.

Saito, S., Goodarzi, A. A., Higashimoto, Y., Noda, Y., Lees-Miller, S. P., Appella, E., and Anderson, C. W. (2002). ATM mediates phosphorylation at multiple p53 sites, including Ser(46), in response to ionizing radiation. The Journal of biological chemistry $277,12491-$ 12494.

Sakogawa, K., Aoki, Y., Misumi, K., Hamai, Y., Emi, M., Hihara, J., Shi, L., Kono, K., Horikoshi, Y., Sun, J., et al. (2013). Involvement of homologous recombination in the synergism between cisplatin and poly (ADP-ribose) polymerase inhibition. Cancer science 104, 15931599.

Salgado, M., Reboredo, M., Mendez, J. C., Quintero, G., Pellon, M. L., Romero, C., Jorge, M., Montes, A. F., Valladares-Ayerbes, M., Ramos, M., et al. (2013). Gemcitabine and capecitabine as third- or later-line therapy for refractory advanced colorectal cancer: a retrospective study. Anticancer Res 33, 4089-4096.

Sampath, D., Shi, Z., and Plunkett, W. (2002). Inhibition of cyclin-dependent kinase 2 by the Chk1-Cdc25A pathway during the S-phase checkpoint activated by fludarabine: dysregulation by 7-hydroxystaurosporine. Molecular pharmacology 62, 680-688.

Sauer, R., Becker, H., Hohenberger, W., Rodel, C., Wittekind, C., Fietkau, R., Martus, P., Tschmelitsch, J., Hager, E., Hess, C. F., et al. (2004). Preoperative versus postoperative chemoradiotherapy for rectal cancer. The New England journal of medicine 351, 1731-1740. Schoenmakers, E. F., Huysmans, C., and Van de Ven, W. J. (1999). Allelic knockout of novel splice variants of human recombination repair gene RAD51B in $\mathrm{t}(12 ; 14)$ uterine leiomyomas. Cancer research 59, 19-23. 
Sebesta, M., Burkovics, P., Juhasz, S., Zhang, S., Szabo, J. E., Lee, M. Y., Haracska, L., and Krejci, L. (2013). Role of PCNA and TLS polymerases in D-loop extension during homologous recombination in humans. DNA repair 12, 691-698.

Shewach, D. S., and Lawrence, T. S. (1996a). Gemcitabine and radiosensitization in human tumor cells. Investigational new drugs 14, 257-263.

Shewach, D. S., and Lawrence, T. S. (1996b). Radiosensitization of human solid tumor cell lines with gemcitabine. Seminars in oncology 23, 65-71.

Shi, Z., Azuma, A., Sampath, D., Li, Y. X., Huang, P., and Plunkett, W. (2001). S-Phase arrest by nucleoside analogues and abrogation of survival without cell cycle progression by 7 hydroxystaurosporine. Cancer research 61, 1065-1072.

Simsek, D., Brunet, E., Wong, S. Y., Katyal, S., Gao, Y., McKinnon, P. J., Lou, J., Zhang, L., Li, J., Rebar, E. J., et al. (2011). DNA ligase III promotes alternative nonhomologous end-joining during chromosomal translocation formation. PLoS genetics 7, e1002080.

Sorensen, C. S., Hansen, L. T., Dziegielewski, J., Syljuasen, R. G., Lundin, C., Bartek, J., and Helleday, T. (2005). The cell-cycle checkpoint kinase Chk1 is required for mammalian homologous recombination repair. Nature cell biology 7, 195-201.

Stevens, C., Smith, L., and La Thangue, N. B. (2003). Chk2 activates E2F-1 in response to DNA damage. Nature cell biology 5, 401-409.

Stucki, M., Clapperton, J. A., Mohammad, D., Yaffe, M. B., Smerdon, S. J., and Jackson, S. P. (2005). MDC1 directly binds phosphorylated histone H2AX to regulate cellular responses to DNA double-strand breaks. Cell 123, 1213-1226.

Summers, K. C., Shen, F., Sierra Potchanant, E. A., Phipps, E. A., Hickey, R. J., and Malkas, L. H. (2011). Phosphorylation: the molecular switch of double-strand break repair. International journal of proteomics 2011, 373816.

Tanaka, Y., Kurbanov, F., Mano, S., Orito, E., Vargas, V., Esteban, J. I., Yuen, M. F., Lai, C. L., Kramvis, A., Kew, M. C., et al. (2006). Molecular tracing of the global hepatitis C virus epidemic predicts regional patterns of hepatocellular carcinoma mortality. Gastroenterology 130, 703-714.

Teicher, B. A., Ara, G., Chen, Y. N., Recht, A., and Coleman, C. N. (1998). Interaction of tomudex with radiation in vitro and in vivo. International journal of oncology 13, 437-442.

Touroutoglou, N., and Pazdur, R. (1996). Thymidylate synthase inhibitors. Clinical cancer research : an official journal of the American Association for Cancer Research 2, 227-243.

Townsend, A. J., and Cheng, Y. C. (1987). Sequence-specific effects of ara-5-aza-CTP and araCTP on DNA synthesis by purified human DNA polymerases in vitro: visualization of chain elongation on a defined template. Molecular pharmacology 32, 330-339.

Urick, M. E., Chung, E. J., Shield, W. P., 3rd, Gerber, N., White, A., Sowers, A., Thetford, A., Camphausen, K., Mitchell, J., and Citrin, D. E. (2011). Enhancement of 5-fluorouracil-induced in vitro and in vivo radiosensitization with MEK inhibition. Clinical cancer research : an official journal of the American Association for Cancer Research 17, 5038-5047.

Valentini, A. M., Pirrelli, M., Renna, L., Armentano, R., and Caruso, M. L. (2003). P53 and beta-catenin in colorectal cancer progression. Current pharmaceutical design 9, 1932-1936. van Engeland, M., Derks, S., Smits, K. M., Meijer, G. A., and Herman, J. G. (2011). Colorectal cancer epigenetics: complex simplicity. Journal of clinical oncology : official journal of the American Society of Clinical Oncology 29, 1382-1391. 
van Triest, B., Pinedo, H. M., van Hensbergen, Y., Smid, K., Telleman, F., Schoenmakers, P. S., van der Wilt, C. L., van Laar, J. A., Noordhuis, P., Jansen, G., and Peters, G. J. (1999). Thymidylate synthase level as the main predictive parameter for sensitivity to 5 -fluorouracil, but not for folate-based thymidylate synthase inhibitors, in 13 nonselected colon cancer cell lines. Clinical cancer research : an official journal of the American Association for Cancer Research 5, 643-654.

Vesely, J., Havlicek, L., Strnad, M., Blow, J. J., Donella-Deana, A., Pinna, L., Letham, D. S., Kato, J., Detivaud, L., Leclerc, S., and et al. (1994). Inhibition of cyclin-dependent kinases by purine analogues. European journal of biochemistry / FEBS 224, 771-786.

Violette, S., Poulain, L., Dussaulx, E., Pepin, D., Faussat, A.-M. M., Chambaz, J., Lacorte, J.-M. M., Staedel, C., and Lesuffleur, T. (2002a). Resistance of colon cancer cells to long-term 5fluorouracil exposure is correlated to the relative level of $\mathrm{Bcl}-2$ and $\mathrm{Bcl}-\mathrm{X}(\mathrm{L})$ in addition to Bax and p53 status. International journal of cancer Journal international du cancer 98, 498504.

Violette, S., Poulain, L., Dussaulx, E., Pepin, D., Faussat, A. M., Chambaz, J., Lacorte, J. M., Staedel, C., and Lesuffleur, T. (2002b). Resistance of colon cancer cells to long-term 5fluorouracil exposure is correlated to the relative level of $\mathrm{Bcl}-2$ and $\mathrm{Bcl}-\mathrm{X}(\mathrm{L})$ in addition to Bax and p53 status. International journal of cancer Journal international du cancer 98, 498504.

Vogelstein, B., Lane, D., and Levine, A. J. (2000). Surfing the p53 network. Nature 408, 307310.

Wang, L., Yang, H., Palmbos, P. L., Ney, G., Detzler, T. A., Coleman, D., Leflein, J., Davis, M., Zhang, M., Tang, W., et al. (2014). ATDC/TRIM29 phosphorylation by ATM/MAPKAP kinase 2 mediates radioresistance in pancreatic cancer cells. Cancer research 74, 1778-1788.

Wang, Y., and Qin, J. (2003). MSH2 and ATR form a signaling module and regulate two branches of the damage response to DNA methylation. Proceedings of the National Academy of Sciences of the United States of America 100, 15387-15392.

Wong, A. K., Ormonde, P. A., Pero, R., Chen, Y., Lian, L., Salada, G., Berry, S., Lawrence, Q., Dayananth, P., Ha, P., et al. (1998). Characterization of a carboxy-terminal BRCA1 interacting protein. Oncogene 17, 2279-2285.

Worthley, D. L., and Leggett, B. A. (2010). Colorectal cancer: molecular features and clinical opportunities. The Clinical biochemist Reviews / Australian Association of Clinical Biochemists 31, 31-38.

Wyatt, M. D., and Wilson, D. M. (2009). Participation of DNA repair in the response to 5fluorouracil. Cellular and molecular life sciences: CMLS 66, 788-799.

Xiao, Z., Xue, J., Sowin, T. J., Rosenberg, S. H., and Zhang, H. (2005). A novel mechanism of checkpoint abrogation conferred by Chk1 downregulation. Oncogene 24, 1403-1411.

Yang, Z., Waldman, A. S., and Wyatt, M. D. (2008). DNA damage and homologous recombination signaling induced by thymidylate deprivation. Biochemical pharmacology 76, 987-996.

Yin, Y., Seifert, A., Chua, J. S., Maure, J. F., Golebiowski, F., and Hay, R. T. (2012). SUMOtargeted ubiquitin E3 ligase RNF4 is required for the response of human cells to DNA damage. Genes Dev 26, 1196-1208.

Yu, J., Zhang, L., Hwang, P. M., Kinzler, K. W., and Vogelstein, B. (2001). PUMA induces the rapid apoptosis of colorectal cancer cells. Molecular cell 7, 673-682. 
Yu, X., and Chen, J. (2004). DNA damage-induced cell cycle checkpoint control requires CtIP, a phosphorylation-dependent binding partner of BRCA1 C-terminal domains. Molecular and cellular biology 24, 9478-9486.

Zhang, Y.-W. W., Brognard, J., Coughlin, C., You, Z., Dolled-Filhart, M., Aslanian, A., Manning, G., Abraham, R. T., and Hunter, T. (2009). The $F$ box protein Fbx6 regulates Chk1 stability and cellular sensitivity to replication stress. Molecular cell 35, 442-453. 


\section{Appendix}

\subsection{Plasmid maps of DRGFP, pCBASCE I.}
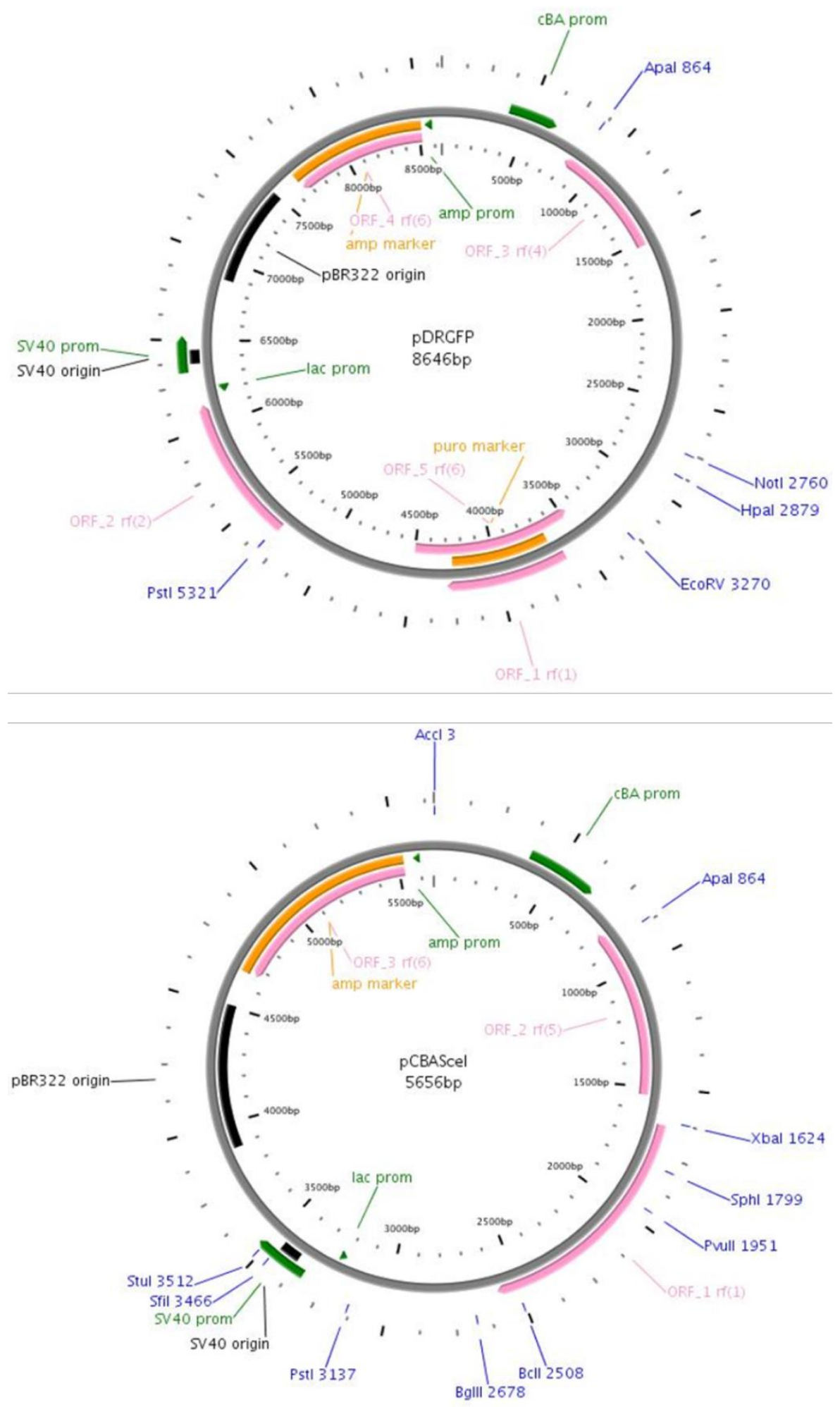


\subsection{Compounds screened for synergistic activity with 5-FU}

Naturally secreted chemical compounds from soil microbes were tested for their synergistic activity with 5-FU. After the initial screen 10 compounds that modulated $\mathrm{Y}-\mathrm{H} 2 \mathrm{AX}$ were chosen for validation. (a) Compounds that increased $\mathrm{y}-\mathrm{H} 2 \mathrm{AX}$ levels (b) compounds that reduced $\mathrm{y}-\mathrm{H} 2 \mathrm{AX}$ levels.

(a)
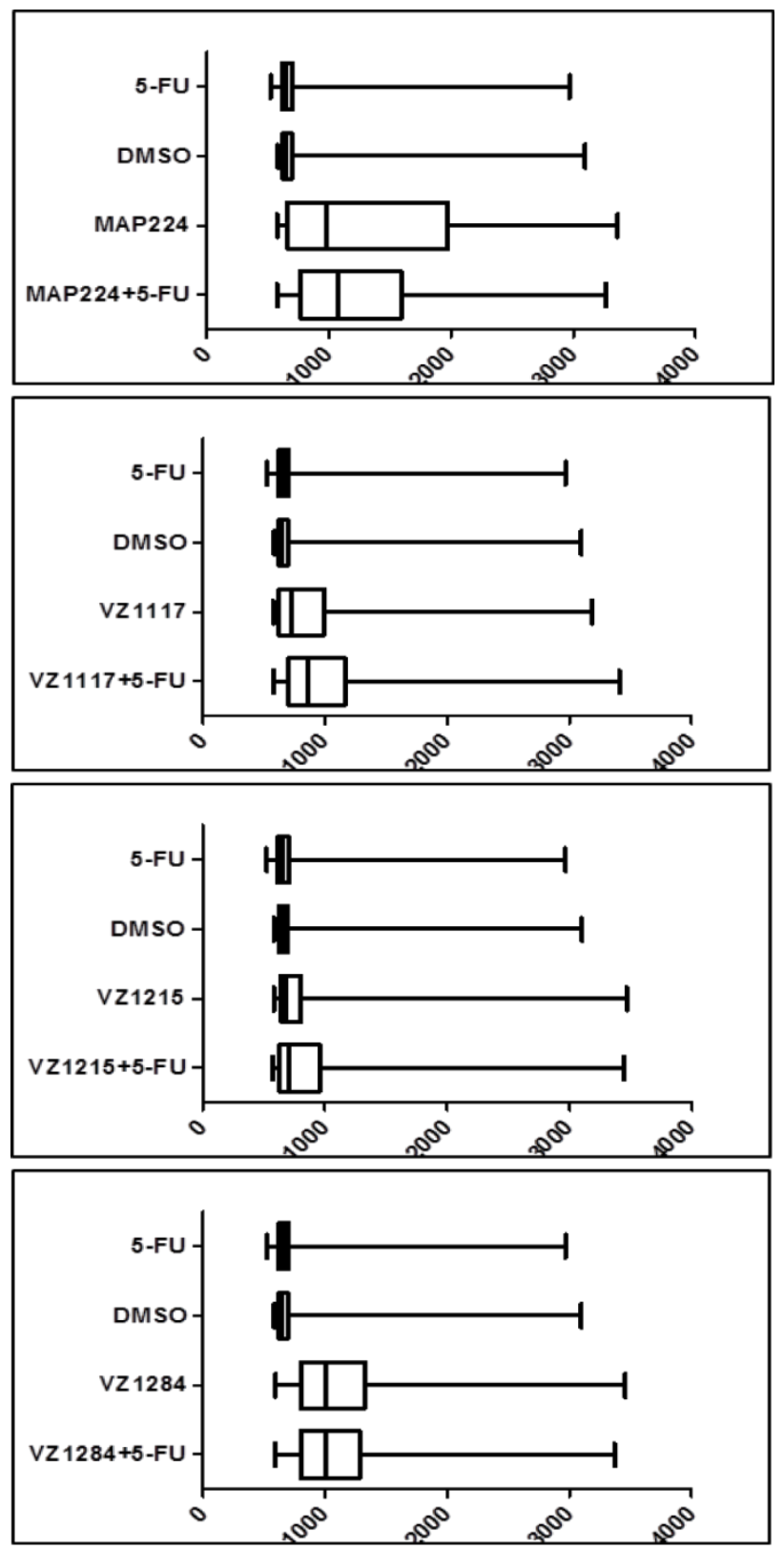

V-H2AX intensitiy 
(b)
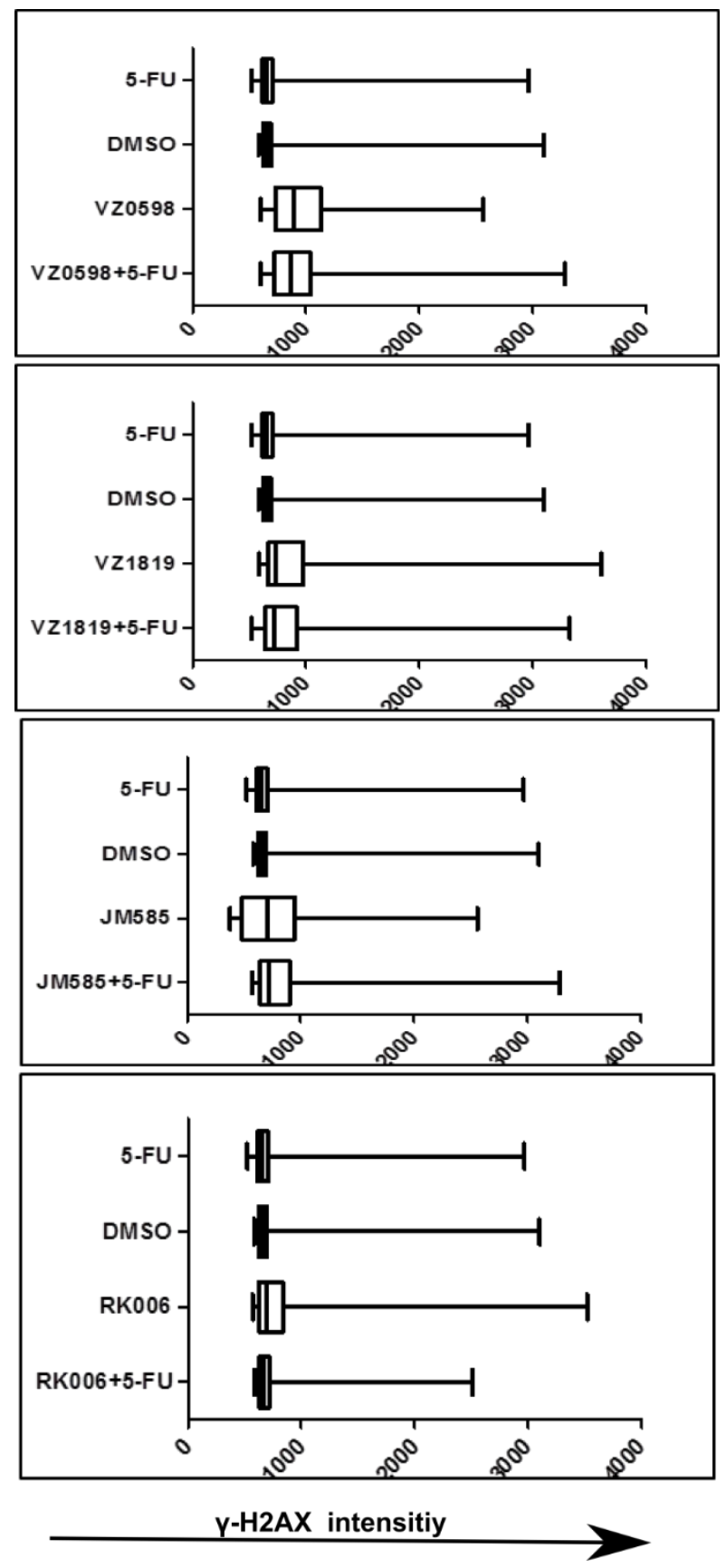


\section{Curriculum Vitae}

\section{Upadhyayula Sai Srinivas}

Apartment 279, Philip Reis straße 9, Goettingen, 37075, u.saisrinivas@gmail.com

\section{Education}

University of Göttingen, Germany 2009-2011

Masters in Molecular Biology, IMPRS Molecular Biology

Thesis " NIPP1 and Wip1 two regulators of protein phosphorylation and their impact on DNA damage response"

University of Hyderabad, India

2007-2009

M.Sc Biochemistry

Passed with Distinction

Osmania University, India

B.Sc (Biochemistry, Microbiology, Chemistry)

Passed with Distinction

All India Senior School Certificate Examination

2004

Passed with Distinction

All India Secondary School Certificate Examination

2002

Passed with distinction

\section{Teaching experience}

Supervised 3 lab rotation students, supervised tutorials for IMPRS Molecular Biology students, supervised advanced PCR courses for PhD students from GGNB and IMPRS Molecular Biology students. 